O planejamento e a execução da transferência da política do Tratamento Diretamente Observado da Tuberculose no município de Porto Alegre - RS

RIBEIRÃO PRETO

2015 


\title{
O planejamento e a execução da transferência da política do Tratamento Diretamente Observado da Tuberculose no município de Porto Alegre - RS
}

\author{
Tese apresentada à Escola de Enfermagem de \\ Ribeirão Preto da Universidade de São Paulo, para \\ obtenção do título de Doutora em Ciências, \\ Programa de Pós-Graduação Enfermagem em \\ Saúde Pública.
}

Linha de pesquisa: Práticas, saberes e políticas de saúde

Orientador: Pedro Fredemir Palha

\section{RIBEIRÃO PRETO}


Autorizo a reprodução e divulgação total ou parcial deste trabalho, por qualquer meio convencional ou eletrônico, para fins de estudo e pesquisa, desde que citada a fonte.

Peruhype, Rarianne Carvalho

O planejamento e a execução da transferência da política do Tratamento

Diretamente Observado da Tuberculose no município de Porto Alegre - RS. Ribeirão Preto, 2015.

180 p. : il. ; $30 \mathrm{~cm}$

Tese de Doutorado, apresentada à Escola de Enfermagem de Ribeirão Preto/USP. Área de concentração: Enfermagem Saúde Pública.

Orientador: Pedro Fredemir Palha

1. Tuberculose. 2. Planejamento em Saúde. 3.Políticas Públicas. 
PERUHYPE, Rarianne Carvalho

O planejamento e a execução da transferência da política do Tratamento Diretamente Observado da Tuberculose no município de Porto Alegre - RS

Tese apresentada à Escola de Enfermagem de Ribeirão Preto da Universidade de São Paulo, para obtenção do título de Doutor em Ciências, Programa de Pós-Graduação Enfermagem Saúde Pública.

Aprovado em

Comissão Julgadora

Prof. Dr.

Instituição:

Prof. Dr.

Instituição:

Prof. Dr.

Instituição:

Prof. Dr.

Instituição: 


\title{
DEDICATÓRIA
}

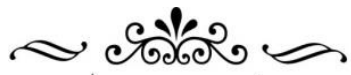

À minha mãe, pela incansável luta, ao meu pai, pelo carinho e apoio, e a Matheus, compantheiro dileto de todas as horas 


\section{AGRADECIMENTOS}

Nenhuma atividade no bem é insignificante... As mais altas árvores são oriundas de minúsculas sementes.

Chico Xavier

\section{Agradeço:}

A Deus, razão do meu existir e sem o qual nada teria sido possível.

Aos meus pais, Maria Natal e Lélis Newton, por terem trilhado este caminho comigo de forma amorosa e dedicada.

Ao Matheus, pelo amor, paciência e auxílio constante.

Aos meus irmãos, Renanderson e Renner, pela amizade incondicional.

À minha pequena grande avó Terezinha, a quem tanto amo e admiro, pelos incentivos diários e orações fervorosas. Aos meus avós Milton, Lélis e Neusa (in memorian) por sempre acreditarem no meu potencial.

Às minhas tias Nazareth, Neuma e Juliana, pelo apoio e carinho.

À Lurdinha, pela escuta amiga e conselhos edificantes.

Em especial, ao professor Dr. Pedro Fredemir Palha, pelos ensinamentos, pela oportunidade, amizade e confiança destinadas a minha pessoa nestes anos de aprendizado.

Aos professores Dra. Solange Mittman e Dra. Filomena Elaine Paiva Assolini, por descortinarem com maestria os horizontes ilimitados da Análise do Discurso Pêcheuxtiana, Dr. Antônio Ruffino-Neto, Dra. Lenilde Duarte de Sá e Dra. Fiona Bath-Hextall, pelas contribuições ímpares neste trabalho.

Ao Jonas Bodini Alonso e à professora Dra. Cláudia Benedita dos Santos, pelas assessorias estatísticas.

Aos colegas do Grupo de Estudos Qualitativos em Saúde (GEQualiS), por juntos edificarmos o conhecimento. 


\section{RESUMO}

PERUHYPE, R. C. O planejamento e a execução da transferência da política do Tratamento Diretamente Observado da Tuberculose no município de Porto Alegre - RS. 2015. 180 f. Tese (Doutorado) - Escola de Enfermagem de Ribeirão Preto, Universidade de São Paulo, Ribeirão Preto, 2015.

Ainda hoje são grandes os desafios envolvidos no controle da tuberculose (TB), doença sabidamente negligenciada e que há muito atinge a humanidade. $O$ presente estudo tem como objetivo analisar o planejamento e a execução da transferência da política do Tratamento Diretamente Observado (TDO) no município de Porto Alegre. A capital gaúcha tem ocupado as primeiras colocações no ranking das capitais brasileiras com maior incidência da TB nas últimas décadas, configurando-se um cenário preocupante no que diz respeito à doença. Como método de pesquisa, optou-se pelo modelo misto de abordagens. $\mathrm{Na}$ abordagem quantitativa, aplicou-se um questionário validado autodirigido para os profissionais de saúde, dentre médicos, enfermeiros, auxiliares e técnicos de enfermagem, envolvidos com o TDO e pertencentes às Unidades de Saúde Comunitária do Grupo Hospitalar Conceição. Por meio deste questionário foram analisadas três dimensões relacionadas ao processo de transferência de uma política pública: Informação, Conhecimento e Inovação. Beta regressão e técnica descritiva foram utilizadas para a análise estatística. $\mathrm{Na}$ abordagem qualitativa, utilizaram-se roteiros constituídos por questões semidirigidas na realização de entrevistas com os coordenadores e gestores dos níveis municipal e estadual, vinculados ao programa de controle da tuberculose, bem como com o secretário municipal de saúde de Porto Alegre. A Análise do Discurso (AD) de linha francesa foi utilizada como referencial analíticometodológico. No total, foram entrevistados 109 profissionais de saúde, a maioria pertencente ao sexo feminino $(77,06 \%)$ e à categoria médica $(37,61 \%)$. A média geral dos escores padronizados obtidos pelas respostas dos participantes foi de 72,7\% para a dimensão "Informação", 77,8\% para o "Conhecimento" e 67,7\% para a "Inovação". Traços de resistência dos profissionais e alguns gestores/coordenadores no trato com a política, a descrença e a falta de motivação, a fragmentação da rede, a carência de recursos institucionais, estruturais e financeiros para lidar com a demanda e o controle da doença e a incipiência da atividade de planejamento foram alguns resultados obtidos a partir das entrevistas. Frente às necessidades de reformulações, espera-se que os achados dessa pesquisa possam constituir-se em subsídios teóricos para possíveis melhorias e avanços locais, no que tange não apenas ao planejamento e à transferência do TDO, mas ao controle da TB como um todo.

PALAVRAS-CHAVE: Tuberculose; Planejamento em Saúde; Políticas Públicas. 


\begin{abstract}
PERUHYPE, R. C. The planning and transfer of the Directly Observed Treatment of Tuberculosis policy in the municipality of Porto Alegre - RS. 2015, 180 f. PhD Thesis - Nursing School of Ribeirão Preto, University of São Paulo, Ribeirão Preto, 2015.

Even today there are countless challenges involved in the eradication and control of tuberculosis, a neglected disease that concerns greatly the humanity. This study aims to evaluate the planning and execution of the transfer regarding the policy named Directly Observed Treatment (DOT) of tuberculosis in the city of Porto Alegre, the capital of Rio Grande do Sul state, in Brazil. As known, this municipality has occupied the first positions in the ranking of the Brazilian capitals with the highest TB incidence rates in recent decades, which turns it into a very worrying scenario. A mixed-model approach (with quantitative and qualitative contents) was used for the research. With respect to the quantitative approach, it was applied a validated selfadministered questionnaire for all the healthcare professionals among physicians, nurses, nursing assistants and technicians working with DOT and belonging to the Community Health Units from the Grupo Hospitalar Conceição. Three dimensions related to the transfer of a public policy, which are Information, Knowledge and Innovation, were analyzed through this questionnaire. Beta regression and descriptive technique were used for the statistical analysis. In the qualitative approach, there were interviews conducted with the Municipal Health Secretary of Porto Alegre and with the coordinators/managers of the tuberculosis control program in the local and state levels. The interpretation and analysis of the interviews were based on the Discourse Analysis and its French approach. A total of 109 health professionals were interviewed, most of them female $(77.06 \%)$ and physicians $(37.61 \%)$. The overall average of the standardized scores for the dimensions was $72.7 \%$ (Information), 77.8\% (Knowledge) and 67.7\% (Innovation). The resistance of some health professionals and coordinators/managers in dealing with the policy, their disbelief and lack of motivation in working with it, the network fragmentation and the lack of institutional, structural and financial resources to cope with the demand and the disease control and the still incipient planning activity were some results obtained from the interviews. Thus, faced with the need for reformulation, it is expected that the findings in this research may be considered theoretical inputs for possible improvements and local advances with respect to the TB policy, planning and the transfer of DOT.
\end{abstract}

KEYWORDS: Tuberculosis; Health Planning; Public Policies. 


\section{RESÚMEN}

PERUHYPE, R. C. La planificación y transferencia de la política de Tratamiento Acortado Estrictamente Supervisado de la Tuberculosis en la ciudad de Porto Alegre - RS. 2015, 180 f. Tese (Doctorado) - Escuela de Enfermería de Ribeirão Preto, Universidad de São Paulo, Ribeirão Preto, 2015.

Hoy en día hay un sinnúmero de desafíos involucrados en el control de la tuberculosis, una enfermedad desatendida y que preocupa enormemente a la humanidad. El presente estudio tiene como objetivo analizar la planificación y ejecución de la transferencia de la política de Tratamiento Acortado Estrictamente Supervisado (TAES) en la ciudad de Porto Alegre, la capital del estado de Rio Grande do Sul, Brasil. Este municipio ha alcanzado los primeros lugares en el ranking de las capitales brasileñas con las mayores tasas de incidencia de tuberculosis en las últimas décadas, una situación que ha generado gran preocupación. Como método de investigación optamos por el modelo mixto (enfoque cuantitativo y cualitativo). En el enfoque cuantitativo se aplicó un cuestionario validado autodirigido para profesionales de la salud, entre médicos, enfermeras, auxiliares de enfermería y técnicos, que trabajan con el TAES y que pertenecen a las unidades de salud comunitaria del Grupo Hospitalar Conceição. En este cuestionario fueran analizadas tres dimensiones, relacionadas con el proceso de transferencia de una política pública, a saber la Información, el Conocimiento y la Innovación. Regresión beta y técnica descriptiva fueran utilizadas para el análisis estadístico. En el enfoque cualitativo, se realizaron entrevistas (script de preguntas semiestructuradas) con el secretario municipal de salud de Porto Alegre e con los coordinadores y directores de los niveles municipales y estatales, vinculados al programa de control de la tuberculosis. Se utilizó el Análisis del Discurso de la línea Francesa como marco analítico y metodológico de las entrevistas. Un total de 109 profesionales de la salud fueron entrevistados, la mayoría pertenecientes al sexo femenino $(77,06 \%)$ y la categoría médica $(37,61 \%)$. El promedio general de los puntajes estandarizados fue de 72,7\% (Información), 77,8\% (Conocimiento) y 67,7\% (Innovación). La resistencia, la incredulidad y la falta de motivación de algunos profesionales y gestores/coordinadores en el trato con la política, la fragmentación de la red, la falta de recursos institucionales, estructurales y financieros para hacer frente al control de la enfermedad y la incipiente actividad de planificación fueron algunos de los resultados obtenidos de las entrevistas. Por lo tanto, dada la necesidad de reformulaciones, se espera que los resultados de esta investigación puedan ser considerados aportaciones teóricas para posibles mejoras locales con respecto a la política de control de la tuberculosis, la planificación y la transferencia de la política del Tratamiento Acortado Estrictamente Supervisado.

PALABRAS CLAVE: Tuberculosis; Planificación de la salud; Políticas públicas. 


\section{LISTA DE FIGURAS}

Figura 1- Modelo de Análise para a Transferência da Política da Saúde 44

Figura 2 - Representação do Triângulo do Governo proposto por Carlos Matus .....50

Figura 3 - Representação do sujeito no nó borromeano. 54

Figura 4 - Box-plot da distribuição dos escores padronizados das respostas dos participantes segundo a dimensão Informação. 124

Figura 5 - Box-plot da distribuição dos escores padronizados das respostas dosparticipantes segundo a dimensão Conhecimento.

Figura 6 - Box-plot da distribuição dos escores padronizados das respostas dos participantes segundo a dimensão Inovação

Figura 7 - Box-plot da distribuição dos escores padronizados das respostas dos participantes na dimensão Informação e segundo a categoria profissional

Figura 8 - Box-plot da distribuição dos escores padronizados das respostas dos participantes na dimensão Conhecimento e segundo a categoria profissional.

Figura 9 - Box-plot da distribuição dos escores padronizados das respostas dos participantes na dimensão Inovação e segundo a categoria profissional.

Figura 10 - Distribuição geral dos escores padronizados segundo as respostas dos participantes

Figura 11 - Representação dos resíduos do modelo, da distância de Cook e da matriz de influência (matriz $\mathrm{H}$ ) 
Figura 12 - Representação dos resíduos do modelo, da distância de Cook e da matriz de influência (matriz H) após novo ajuste ....................................................132 


\section{LISTA DE GRÁFICOS}

Gráfico 1 - Distribuição dos escores padronizados por categoria profissional para o domínio Informação

Gráfico 2 - Distribuição dos escores padronizados por categoria profissional para o domínio Conhecimento.

Gráfico 3 - Distribuição dos escores padronizados por categoria profissional para o domínio Inovação 


\section{LISTA DE QUADROS}

Quadro 1 - Características e principais resultados dos estudos selecionados. Tratamento Diretamente Observado versus Tratamento Auto- administrado

Quadro 2 - Estratégia de Busca do Embase .28

Quadro 3 - Intervenção educativa em DOTS/TDO versus ausência de intervenção educativa 30 


\section{LISTA DE TABELAS}

Tabela 1 - Representação das médias e dos escores padronizados das respostas dos participantes por item do instrumento ATP- IINFOC-TB.

Tabela 2 - Teste de Normalidade dos escores padronizados do modelo 129

Tabela 3 - Estimativa dos parâmetros do modelo de regressão Beta 130

Tabela 4 - Estimativa dos parâmetros do modelo de regressão Beta após a exclusão dos valores aberrantes ou outliers

Tabela 5 - Estimativa dos parâmetros do modelo de regressão Beta (Heterocedástico).

Tabela 6 - Estimativa dos parâmetros do modelo de regressão Beta (Heterocedástico) após exclusão dos valores aberrantes ou outliers

Tabela 7 - Valores preditos para o modelo em relação à média e ao desvio padrão segundo os domínios e as categorias profissionais 


\section{LISTA DE ABREVIATURAS E SIGLAS}

AB: Atenção Básica

AD: Análise de Discurso

Aids: Síndrome da Imunodeficiência Adquirida

APS: Atenção Primária à Saúde

ATP- IINFOC-TB: Avaliação da Transferência de Políticas - Inovação, Informação e Conhecimento em Tuberculose

BRICS: Grupamento econômico composto por Brasil, Rússia, Índia, China e África do Sul

CENTRAL: Cochrane Central Register of Controlled Trials

CEP: Comitê de Ética da Pesquisa

CGVS: Coordenadoria Geral de Vigilância em Saúde

CNES: Cadastro Nacional de Estabelecimentos de Saúde

CNPq: Conselho Nacional de Desenvolvimento Científico e Tecnológico

CPPS: Centro Pan-Americano de Planejamento em Saúde

CRTB: Centro de Referência em Tuberculose

CRTB NHNI: Noroeste-Humaitá-Navegante-Ilhas

CRTB LENO: Leste-Nordeste

CRTB GCC: Glória-Cruzeiro-Cristal

CRTB PLP: Partenon-Lomba do Pinheiro

DAB: Departamento de Atenção Básica

DOTS: Directly Observed Treatment Short-Course

DOT: Directly Observed Treatment 
EC: Emenda Constitucional

ENSP: Escola Nacional de Saúde Pública

ESFs: Estratégias de Saúde da Família

FD: Formação Discursiva

FI: Formação Ideológica

GD: Gerências Distritais

GHC: Grupo Hospitalar Conceição

G6: Grupamento econômico composto por Estados Unidos, Japão, Alemanha, Reino Unido, França e Itália

HBCs: High TB Burden Countries

HIV: Vírus da Imunodeficiência Humana

IBGE: Instituto Brasileiro de Geografia e Estatística

JBI: Joanna Briggs Institute

KT: Knowledge Translation

MAPP: Método Altadir de Planificação Popular

MeSH: Medical Subject Headings (termos médicos)

OMS: Organização Mundial de Saúde

OPAS: Organização Pan-Americana da Saúde

PACS: Programa de Agentes Comunitários de Saúde

PCT: Programa de Controle da Tuberculose

PES: Planejamento Estratégico Situacional

PNAB: Política Nacional de Atenção Básica

PNCT: Plano Nacional de Controle da Tuberculose 
PRPG - USP: Pró-Reitoria de Pós-Graduação da Universidade de São Paulo

PSF: Programa Saúde da Família

RS: Rio Grande do Sul

SD: Sequência Discursiva

SMS: Secretaria Municipal de Saúde

SINAN: Sistema de Informação de Agravos de Notificação

SUS: Sistema Único de Saúde

TAA: Tratamento Auto-administrado

TB: Tuberculose

TCLE: Termo de Consentimento Livre e Esclarecido

TDO: Tratamento Diretamente Observado

UBS: Unidade Básica de Saúde

UFBA: Universidade Federal da Bahia

UNICEF: United Nations Children's Fund (Fundo das Nações Unidas para a Infância)

USP: Universidade de São Paulo

ZOPP: Ziel-Orientierte Projekt Planung (Planejamento de Projetos Orientado por Objetivos). 


\section{SUMÁRIO}

1. APRESENTAÇÃO ….......................................................................20

2. INTRODUÇÃO

2.1 TUBERCULOSE: EPIDEMIOLOGIA E O TRATAMENTO DIRETAMENTE OBSERVADO (TDO).

2.2 INFORMAÇÃO, CONHECIMENTO E INOVAÇÃO: DIMENSÕES QUE PERPASSAM

O PROCESSO DE TRANSFERÊNCIA DE UMA POLÍTICA PÚBLICA ........................... 32

2.3 QUESTÃO NORTEADORA E PRESSUPOSTO DE INVESTIGAÇÃO ........................ 36

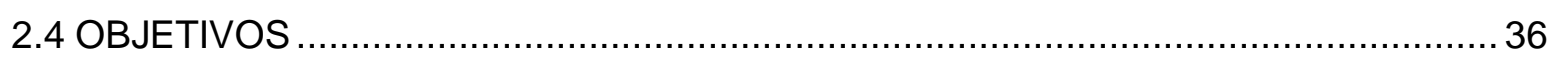

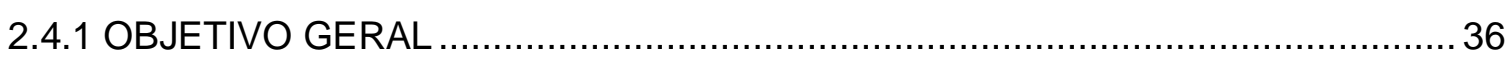

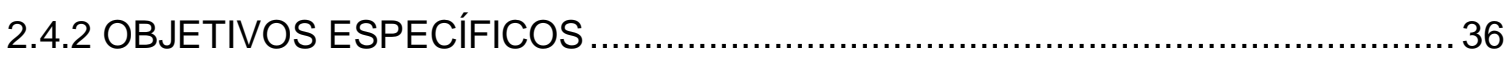

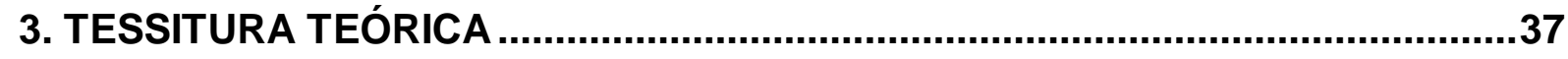

3.1 TRANSFERÊNCIA DE POLÍTICA PÚBLICA: O PROCESSO E SUAS

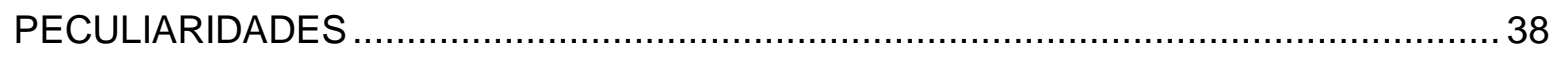

3.2 NOS DOMÍNIOS DO PLANEJAMENTO ........................................................... 45

3.3 MICHEL PÊCHEUX E A ANÁLISE DO DISCURSO: NOS ENTREMEIOS DO

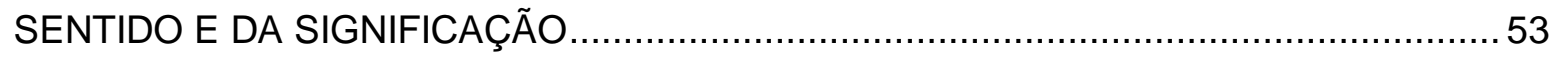

3.3.1 PRIMEIRA FASE DA ANÁLISE DO DISCURSO FRANCESA …........................ 55

3.3.2 SEGUNDA FASE DA ANÁLISE DO DISCURSO FRANCESA ............................. 56

3.3.3 TERCEIRA FASE DA ANÁLISE DO DISCURSO FRANCESA ..........................63

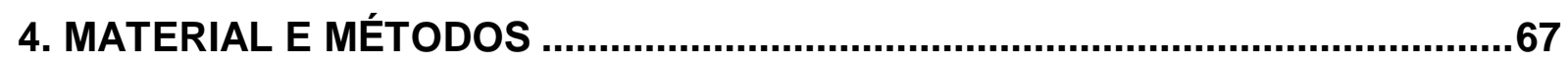

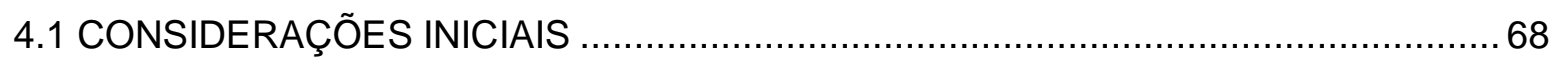

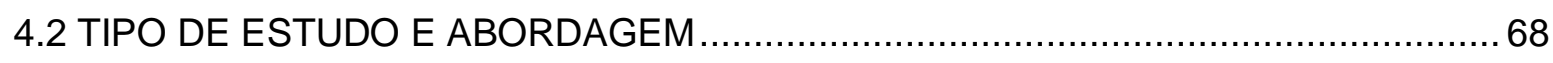

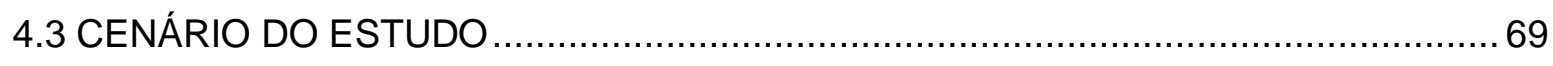

4.3.1 CARACTERIZAÇÃO DO LOCAL DE ESTUDO …...................................... 70

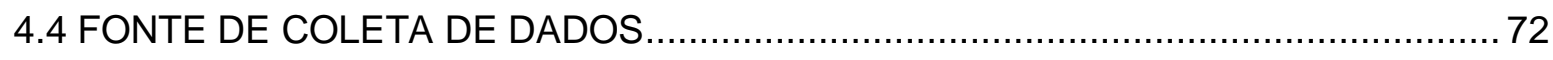

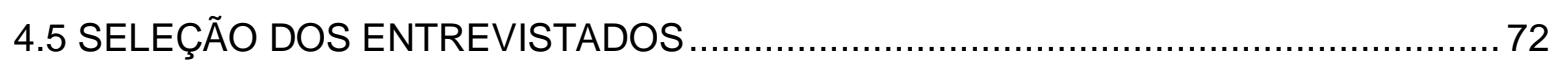

4.5.1 SUJEITOS DA PESQUISA E CRITÉRIO DE INCLUSÃO ............................... 73

4.5.2 INSTRUMENTOS DE COLETA DE DADOS ................................................ 73

4.5.3 PRODUÇÃO DO MATERIAL DE ANÁLISE ................................................. 76

4.6 DISPOSITIVOS E PROCEDIMENTOS DE ANÁLISE ......................................... 77

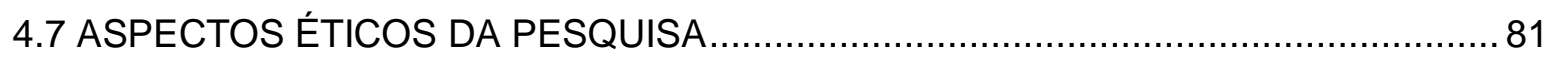

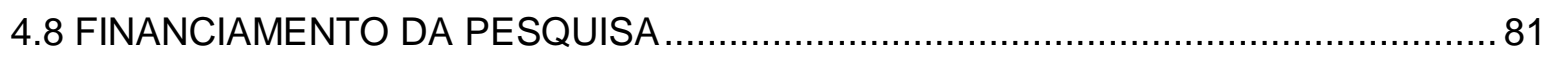




\section{RESULTADOS E DISCUSSÃO}

5.1 DO CONTEXTO IMEDIATO AO CONTEXTO SÓCIO-HISTÓRICO DO DISCURSO DA TUBERCULOSE

5.2 A TRANSFERÊNCIA DA POLÍTICA DO TDO: SEUS ELEMENTOS NA MALHA DA

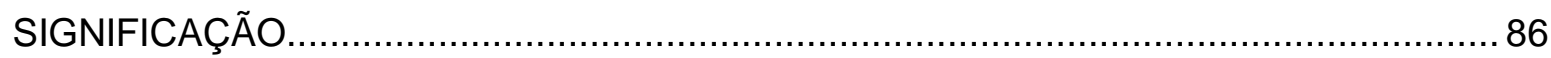

5.2.1 MOTIVAÇÃO E TIPOLOGIA: COERCITIVA OU VOLUNTÁRIA ............................ 86

5.2.2 CONTEXTO SÓCIO-HISTÓRICO, POLÍTICO E CULTURAL ……………….......95

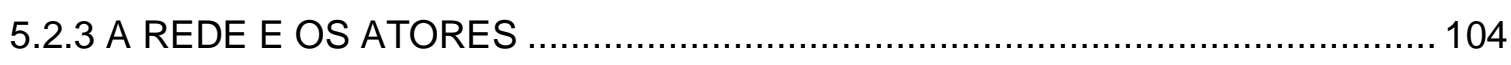

5.3 NO CAMINHO DO PLANEJAMENTO E NO PLANEJAMENTO DO CAMINHO .......112 5.4 DO DISCURSO AOS NÚMEROS: RESULTADOS PROVENIENTES DA APLICAÇÃO DO INSTRUMENTO ATP-IINFOC-TB AOS PROFISSIONAIS DE SAÚDE 122 5.5 ENTRE NÚMEROS E PALAVRAS, DADOS E FATOS: POSSÍVEIS

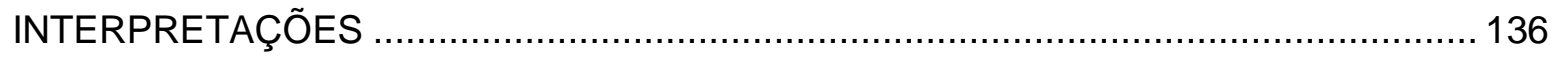
5.6 IMPLICAÇÕES DA PESQUISA PARA A PRÁTICA EM ENFERMAGEM ................140

6. CONSIDERAÇÕES FINAIS 143

\section{REFERÊNCIAS BIBLIOGRÁFICAS}

8. ANEXOS 159

ANEXO A - INSTRUMENTO DA PESQUISA - ATP- IINFOC-TB 160

ANEXO B - TERMO DE CONSENTIMENTO LIVRE E ESCLARECIDO - GRUPO HOSPITALAR CONCEIÇÃO 163

ANEXO C - TERMO DE CONSENTIMENTO LIVRE E ESCLARECIDO - SECRETARIA MUNICIPAL DE SAÚDE DE PORTO ALEGRE 165

ANEXO D - ROTEIRO DE ENTREVITA - SECRETÁRIO MUNICIPAL/ESTADUAL DE SAÚDE. 166

ANEXO E - ROTEIRO DE ENTREVISTA - COORDENADORES DA ATENÇÃO À TUBERCULOSE . 168

ANEXO F - ROTEIRO DE ENTREVISTA - PLANEJAMENTO. 170

ANEXO G - PARECER CONSUBSTANCIADO - PREFEITURA MUNICIPAL DE PORTO ALEGRE

ANEXO H - PARECER CONSUBSTANCIADO - GRUPO HOSPITALAR CONCEIÇÃO 172 ANEXO I - PARECER CONSUBSTANCIADO - ESCOLA DE ENFERMAGEM DE RIBEIRÃO PRETO/ USP

ANEXO J - TERMO DE CIÊNCIA - GRUPO HOSPITALAR CONCEIÇÃO 177

ANEXO K - TERMO DE CIÊNCIA - PREFEITURA MUNICIPAL DE PORTO ALEGRE.. 178 ANEXO L - TERMO DE CIÊNCIA - CENTRO ESTADUAL DE VIGILÂNCIA EM SAÚDE DO RIO GRANDE DO SUL 
Transferência de políticas públicas ainda é um assunto pouco explorado nas produções acadêmicas brasileiras. Por outro lado, a tuberculose (TB) constitui-se em problema tanto antigo quanto atual e parece não sair de evidência. Justamente por tratar-se de doença curável, acreditamos que todo esforço na qualificação de processos que culminem em sua erradicação e controle acaba sendo de grande valia. Dessa forma, ao pesquisar um tema relativamente recente vinculando-o a outro não tão novo assim, contudo ainda problemático, buscamos não apenas expandir o corpo de evidências científicas sobre o assunto, mas também contribuir para a melhoria da assistência e dos serviços de saúde.

Partimos do princípio de que a execução da transferência de uma política pública deve ser precedida de uma etapa de planejamento, em que se anteveem o caminho, as metas, os recursos e as estratégias necessárias, dentre outros fatores, quando da operacionalização da transferência. Assim, são mobilizados elementos envolvidos em dois processos tão complexos quanto complementares.

Neste percurso investigativo, buscamos inicialmente abordar o contexto epidemiológico da TB, com destaque para o cenário da pesquisa, Porto Alegre, assim como o advento, objetivo e importância do Tratamento Diretamente Observado (TDO) no controle da doença. Ressaltamos também as dimensões "Informação", "Conhecimento" e "Inovação", na qualidade de objetos inerentes à transferência de uma política pública e enquanto subsídios teóricos fundantes do questionário aplicado aos profissionais de saúde. Em seguida, apresentamos as premissas e os objetivos da pesquisa que se vinculam ao entendimento do planejamento e execução da transferência da política do TDO na capital gaúcha.

$\mathrm{Na}$ "tessitura teórica", discorremos sobre elementos envolvidos no processo de transferência e as principais correntes de planejamento na América Latina, com ênfase ao arcabouço operacional elaborado por Bissell, Lee e Freeman, e ao Planejamento Estratégico Situacional de Carlos Matus, ambos adotados como referenciais teóricos das análises do presente estudo. Destacamos ainda a abordagem da Análise do Discurso (AD) de Linha Francesa, seus principais conceitos e pressupostos, tidos como fundamentais na interpretação e significação dos discursos dos coordenadores/gestores dos programas de controle da TB e do secretário municipal de saúde de Porto Alegre. 
Em "material e métodos", abordamos as técnicas estatísticas empregadas na elaboração e análise do questionário, bem como a mobilização dos conceitos e procedimentos da AD para a interpretação dos discursos obtidos com as entrevistas. Já na seção "resultados e discussão", abrimos precedentes para a apresentação, análises e ponderações acerca dos resultados obtidos, tanto por meio da pesquisa qualitativa, quanto pela quantitativa. Neste espaço, buscamos uma interlocução entre palavras e números, fatos e dados, com o intuito de se alcançar uma maior completude da pesquisa realizada.

Por fim, as "considerações finais" deste trabalho investigativo, que, embora revestido de um efeito "fim", nada mais é do que a possibilidade de novas investidas e recomeços. 
2. INTRODUÇÃO 


\subsection{TUBERCULOSE: EPIDEMIOLOGIA E O TRATAMENTO DIRETAMENTE OBSERVADO (TDO)}

Embora seja conhecida e enfrentada há séculos, a tuberculose (TB) ainda constitui-se em grande problema de saúde pública mundial. Estima-se que, no ano de 2012, 8.6 milhões de pessoas tenham sido infectadas pela doença, ainda que curável, e 1.3 milhões tenham morrido em sua decorrência (WORLD HEALTH ORGANIZATION, 2013).

Sua incidência varia substancialmente de continente para continente, de país para país, podendo alcançar, por exemplo, taxas de 1000 casos ou mais para cada 100.000 habitantes na África do Sul e na Suazilândia (África Austral), até menos de 10 casos por 100.000 habitantes em muitos locais da Europa Ocidental, nas Américas, Japão, Nova Zelândia e Austrália (WORLD HEALTH ORGANIZATION, 2013).

Dessa forma, a Organização Mundial de Saúde (OMS) elencou os 22 países responsáveis por $80 \%$ dos casos de tuberculose no mundo, reconhecidos como "22 High TB Burden Countries (HBCs)" (WORLD HEALTH ORGANIZATION, 2013). Dentre os listados encontram-se China, Índia, África do Sul, Rússia e Brasil, países considerados emergentes e participantes do agrupamento econômico denominado "BRICS", cujo crescimento econômico e influência mundial vêm se tornando indiscutivelmente representativos: calcula-se que, nos próximos 50 anos, o BRICS possivelmente assumirá a posição de principal força econômica global, hoje ocupada pelo grupo composto por Estados Unidos, Japão, Alemanha, Reino Unido, França e Itália (o G6) (VIEIRA; VERÍSSIMO, 2009).

Contraditoriamente ao crescimento econômico experimentado pelo BRICS, destaca-se o agravamento da tuberculose em seus domínios territoriais. Índia, China e África do Sul, por exemplo, encabeçam a lista dos cinco países com o maior número de casos incidentes em 2012: 2.0 a 2.4 milhões, 0.9 a 1.1 milhões e 0.4 a 0.6 milhões, respectivamente (WORLD HEALTH ORGANIZATION, 2013).

Não menos alarmante encontra-se a problemática da TB no Brasil. Embora a taxa nacional de incidência tenha reduzido de 42,8 casos/100.000 habitantes em 
2001 para 36,0 casos/100.000 habitantes em 2011, é possível destacar a gravidade do quadro epidemiológico da tuberculose por meio dos elevados indicadores da doença registrados no mesmo ano em muitas regiões e municípios brasileiros. É o caso dos Estados do Amazonas (62,6 casos/100.000 habitantes), do Rio de Janeiro (57,6 casos/100.000 habitantes) e do Rio Grande do Sul $(46,1$ casos $/ 100.000$ habitantes) (SECRETARIA DE VIGILÂNCIA EM SAÚDE, 2012).

O Rio Grande do Sul (RS), mais precisamente sua capital, Porto Alegre, constitui o cenário desta pesquisa. A capital gaúcha destaca-se no contexto brasileiro pelo seu posicionamento entre as líderes no "ranking" das capitais com maior incidência da tuberculose, atingindo por vezes proporções assustadoras e alarmantes em relação à disseminação da doença.

A taxa de incidência em Porto Alegre para todas as formas de TB manteve-se majoritariamente acima de 100 casos/100.000 habitantes na última década, chegando a 121,27 casos/100.000 habitantes em 2009, e 110,26 casos/100.000 habitantes em 2011 (NÚCLEO DAS CRÔNICAS/EVDT/CGVS/SMS/POA, 2012), níveis considerados de alto risco epidemiológico, conforme categorização de Clancy, (1991). Outro motivo de preocupação no município refere-se ao aumento da taxa de abandono (15,7\% para 28,6\%, de 2002 a 2011) e à diminuição da taxa de cura das coortes de tratamento (68,6\% para 57,4\%, considerando-se o mesmo período) (SECRETARIA MUNICIPAL DE SAÚDE DE PORTO ALEGRE, 2012).

Frente à gravidade do problema e na tentativa de controlar a disseminação da TB, o Ministério da Saúde lançou, em 1998, o Plano Nacional de Controle da Tuberculose (PNCT), em substituição ao então vigente Plano Emergencial. Dentre as principais inovações do PNCT destaca-se a instituição do Tratamento Supervisionado ou Tratamento Diretamente Observado, um dos preceitos enfatizados na estratégia Directly Observed Treatment Short-Course (DOTS) (RUFFINO-NETTO, 2001) criada pela OMS a partir de uma estratégia internacional predecessora implementada em 1994 (WORLD HEALTH ORGANIZATION, 2006).

O TDO é um dos cinco elementos componentes do DOTS, juntamente com a ênfase ao compromisso governamental em relação à $T B$, à detecção de casos por meio de bacteriologia de qualidade, à busca de um sistema regular e eficaz de abastecimento, gestão e suprimento de medicamentos e, por fim, a ênfase ao 
desenvolvimento de um sistema eficiente de monitoramento, avaliação e impacto da doença. Uma vez instituído internacionalmente, o DOTS passou a ocupar posição central numa segunda estratégia de combate à tuberculose também elaborada pela OMS e denominada "Stop TB Strategy", cujo principal objetivo é o de reduzir "dramaticamente" os casos de tuberculose até 2015, com metas de eliminação da doença até 2050 (WORLD HEALTH ORGANIZATION, 2006).

Com relação à definição conceitual, o TDO pode ser compreendido como o acompanhamento da ingestão dos medicamentos pelos pacientes diariamente, ou seja, de $2^{\underline{a}}$ a $6^{\text {a }}$ feira na fase de ataque e no mínimo três vezes por semana na fase de manutenção, sendo que esse acompanhamento pode ser realizado por profissionais de saúde (preferencialmente) ou por qualquer outra pessoa, desde que seja capacitada e esteja sob supervisão profissional (MINISTÉRIO DA SAÚDE, 2011). Acredita-se que o uso correto dos medicamentos de combate à Tuberculose viabilize um percentual de cura de $90 \%$ dos casos da doença (STOP TB PARTNESHIP, 2011-2015). Nesse sentido, o TDO torna-se fundamental ao assegurar a ingestão medicamentosa pelo paciente, favorecer o apoio e adesão ao tratamento, aumentar as chances de cura e diminuir a probabilidade de eventual resistência medicamentosa.

Para efeito de investigação sobre a eficácia do TDO comparada à do Tratamento Auto-administrado (TAA), realizamos uma revisão da literatura, em maio de 2014, nas bases de dados do Lilacs, CINAHL, Cochrane Central Register of Controlled Trials (CENTRAL) e Ovid Medline, direcionada aos estudos publicados nos últimos 10 anos (2003 - 2013). Utilizamos, para o referido propósito, os descritores controlados do Medical Subject Headings (MeSH) "Tuberculosis" e "Directly Observed Therapy" e as palavras-chave "DOT" (TDO em inglês) e "Supervised Treatment", isolados ou combinados pelo operador booleano "and". Tanto os descritores quanto as palavras-chave foram traduzidas para o português e espanhol para atenderem às especificidades do LILACS.

Consideramos os estudos experimentais e observacionais que investigaram os resultados do tratamento (cura, morte, resistência medicamentosa, outros) da tuberculose quando da utilização do TDO versus o TAA. Excluímos os estudos qualitativos, teses e dissertações, bem como as revisões sistemáticas, resumos e 
publicações de conferências/congressos, boletins epidemiológicos e revistas não científicas. A busca foi restrita aos idiomas inglês, português e espanhol. No total foram obtidos 808 estudos, dos quais apenas 4 satisfizeram aos critérios de inclusão, sendo que não foi possível ter acesso a um deles. As principais características dos demais artigos e seus resultados podem ser visualizados no Quadro 1.

\begin{tabular}{|c|c|c|c|c|c|}
\hline Referência & $\begin{array}{l}\text { Design } \\
\text { metodológico }\end{array}$ & $\begin{array}{c}\text { № de } \\
\text { participantes }\end{array}$ & $\begin{array}{l}\text { Cenário da } \\
\text { Pesquisa }\end{array}$ & TDO & TAA \\
\hline $\begin{array}{c}\text { Jasmer et al. } \\
(2004)\end{array}$ & $\begin{array}{c}\text { Coorte } \\
\text { Observacional }\end{array}$ & $\begin{array}{c}372 \text { (TDO: } \\
\text { 149; TAA:223) }\end{array}$ & $\begin{array}{c}\text { São } \\
\text { Francisco } \\
\text { (Tuberculosis } \\
\text { Control } \\
\text { Section } \\
\text { of the } \\
\text { Department } \\
\text { of Public } \\
\text { Health) }\end{array}$ & $\begin{array}{c}\text { - Cura: 97,8\%; } \\
\text { - Morte por TB: } \\
0 \% ; \\
\text { - Resistência } \\
\text { Medicamentosa: } \\
0 \% ;\end{array}$ & $\begin{array}{c}\text { - Cura: 88,6\% } \\
\text { - Morte por TB: } \\
\text { 5,5\%; } \\
\text { - Resistência } \\
\text { Medicamentos } \\
\text { a: 0,9\%; }\end{array}$ \\
\hline $\begin{array}{l}\text { Vieira; } \\
\text { Ribeiro } \\
\text { (2011) }\end{array}$ & $\begin{array}{l}\text { Coorte } \\
\text { histórica }\end{array}$ & $\begin{array}{c}360 \text { (TDO: } \\
\text { 187; TAA:173) }\end{array}$ & $\begin{array}{l}\text { Carapicuíba/ } \\
\text { SP (Plano de } \\
\text { Controle da } \\
\text { Tuberculose) }\end{array}$ & $\begin{array}{c}\text { - Probabilidade } \\
\text { de alta por cura: } \\
\text { 91,61\%; } \\
\text { - Adesão (TB } \\
\text { bacilífera): } \\
\text { 90,75\%; }\end{array}$ & $\begin{array}{c}\text { - Probabilidade } \\
\text { de alta por } \\
\text { cura: } 85,52 \% \\
\text { - Adesão (TB } \\
\text { bacilífera): } \\
\text { 87,38\%; }\end{array}$ \\
\hline $\begin{array}{l}\text { Charokopos } \\
\text { et al. (2013) }\end{array}$ & $\begin{array}{c}\text { Estudo } \\
\text { observacional }\end{array}$ & $\begin{array}{c}54 \text { (TDO:13; } \\
\text { TAA:41) }\end{array}$ & $\begin{array}{c}\text { Grécia } \\
\text { (Prefecture } \\
\text { of Ilia) }\end{array}$ & $\begin{array}{c}\text { M-DOT (TDO } \\
\text { modificado); } \\
\text { - Taxa de } \\
\text { sucesso do } \\
\text { tratamento: } \\
\text { 84,6\%; } \\
\text { - Morte:7,7\%; } \\
\text { Cura: } 69,2 \%\end{array}$ & - \\
\hline
\end{tabular}

Quadro 1 - Características e principais resultados dos estudos selecionados. Tratamento Diretamente Observado versus Tratamento Auto-administrado

Notamos, em pelo menos dois dos três estudos - Jasmer et al. (2004) e Vieira e Ribeiro (2011) -, que a prática do TDO culminou em taxas de cura e de adesão superiores àquelas obtidas com o TAA. Outros indicadores, como o percentual de mortes e de resistência medicamentosa, foram também melhores quando se optou 
por realizar o tratamento supervisionado. Não objetivamos generalizar os achados por meio desses estudos, contudo, eles ajudam a reconhecer a importância do TDO no controle da tuberculose.

Em outra ocasião, realizamos uma revisão sistemática da literatura com 0 objetivo de investigar a efetividade de intervenções educativas e treinamentos utilizados para ampliar o conhecimento dos profissionais de saúde sobre a estratégia geral DOTS ou o TDO, um de seus componentes. Nessa oportunidade, consideramos ambas as políticas como já implementadas nos serviços, e a intervenção se daria no sentido de aumentar tal conhecimento. Consideramos ainda a taxa de detecção de casos de TB como resultado primário a ser investigado e as taxas de cura, abandono de tratamento, sucesso do tratamento, mortalidade, dentre outras, como resultados secundários.

As bases de dados pesquisadas e os períodos temporais correspondentes foram os seguintes: Ovid Medline (de 1946 a março de 2014), Ovid Embase (de 1980 a março de 2014), CINAHL e Lilacs (até março de 2014) e Cochrane Central Register of Controlled Trials (CENTRAL - edição 1 de 12; janeiro de 2014). A busca foi realizada em julho de 2013 e atualizada em março de 2014. Apenas os estudos experimentais e quase-experimentais, publicados em inglês, português e espanhol, foram incluídos na revisão.

Palavras-chave como "Tuberculosis", "TB", "DOTS”, Directly Observed Treatment Short-Course", "DOT", "Education”, "Educational Intervention”, "Observed Therapy", "Standardized Treatment", "Supervised Treatment" and "Training" foram utilizadas no Lilacs e no Cochrane, de forma individual ou combinadas, e traduzidas para o português e espanhol conforme necessidade. Um exemplo da busca realizada no Embase, e replicadas de forma similar, no Medline e CINAHL, pode ser visualizada no Quadro 2 que se segue.

\begin{tabular}{|l|l|}
\hline \# Searches \\
\hline 1 \\
$\begin{array}{l}\text { exp latent tuberculosis/ or exp tuberculosis control/ or exp extrapulmonary tuberculosis/ or exp } \\
\text { postprimary tuberculosis/ or exp tuberculosis rapid test/ or exp primary tuberculosis/or exp }\end{array}$ \\
$\begin{array}{l}\text { abdominal tuberculosis/ or exp miliary tuberculosis/ or exp urogenital tuberculosis/ or exp ocular } \\
\text { tuberculosis/ or exp extensively drug resistant tuberculosis/ or exp central nervous system } \\
\text { tuberculosis/ or exp kidney tuberculosis/ or exp lung tuberculosis/ or exp multidrug resistant } \\
\text { tuberculosis/ or exp tuberculosis/ or exp Mycobacterium tuberculosis/or exp intestine tuberculosis/ }\end{array}$ \\
\hline
\end{tabular}




\begin{tabular}{|l|l|}
\hline & $\begin{array}{l}\text { or exp congenital tuberculosis/ or Tuberculosis.mp. or exp laryngeal tuberculosis/ or exp skin } \\
\text { tuberculosis/ or exp drug resistant tuberculosis/ }\end{array}$ \\
\hline 2 & TB.mp. \\
\hline 3 & 1 or 2 \\
\hline 4 & $\begin{array}{l}\text { exp medical education/ or exp education program/ or exp education/ or exp patient education/ or } \\
\text { educational intervention.mp. or exp health education/ }\end{array}$ \\
\hline 5 & DOT.mp. \\
\hline 6 & Observed therapy of Tuberculosis.mp. \\
\hline 7 & Directly observed therapy.mp. or directly observed therapy/ \\
\hline 8 & Supervised therapy.mp. \\
\hline 9 & Supervised treatment.mp. \\
\hline 10 & $\begin{array}{l}\text { Standardi?ed treatment.mp. [mp=title, abstract, original title, name of substance word, subject } \\
\text { heading word, keyword heading word, protocol supplementary concept word, rare disease } \\
\text { supplementary concept word, unique identifier] }\end{array}$ \\
\hline 11 & DOTS.mp. or exp short course therapy/ \\
\hline 12 & Directly observed treatment short course.mp. \\
\hline 13 & 5 or 6 or 7 or 8 or 9 or 10 or 11 or 12 \\
\hline 14 & 3 and 4 and 13 \\
\hline 15 & limit 14 to yr="1997 -Current" \\
\hline
\end{tabular}

\section{Quadro 2 - Estratégia de Busca do Embase}

Esse estudo contou com a elaboração prévia de um protocolo de pesquisa devidamente aprovado e publicado pelo Instituto Joanna Briggs - JBI (PERUHYPE et al., 2014) e pode ser acessado na íntegra na biblioteca on-line dessa instituição. No total foram obtidos 1615 estudos, dos quais apenas 2 satisfizeram aos critérios de inclusão, sendo ambos desenvolvidos no continente africano. Devido aos vários tipos de intervenções educativas encontradas (treinamentos, descentralização do tratamento, consultorias, opção de escolha pelo paciente do responsável pelo TDO, supervisão reforçada nas unidades de saúde, sessões educativas sobre o tema ministradas por profissionais para a população, dentre outras) não foi possível realizar uma meta-análise, e os dados foram apresentados de forma descritiva.

Ambos os estudos apresentaram, para o grupo da intervenção, um aumento nas taxas de detecção da TB, de cura e do sucesso do tratamento, bem como uma redução das taxas de abandono, quando comparados ao grupo controle, conforme se observa no Quadro seguinte. 


\begin{tabular}{|c|c|c|c|c|}
\hline Referência & $\begin{array}{l}\text { Número de } \\
\text { Participantes }\end{array}$ & Resultados & $\begin{array}{c}\text { Grupo de } \\
\text { Intervenção }\end{array}$ & $\begin{array}{l}\text { Grupo } \\
\text { Controle }\end{array}$ \\
\hline Thiam, S. et al. (2007) & $\begin{array}{l}\text {-1522 pacientes: } \\
\text { - } 778 \text { do grupo } \\
\text { de intervenção; } \\
\text { - } 744 \text { do grupo } \\
\text { controle. }\end{array}$ & $\begin{array}{c}\text {-Taxa de detecção } \\
\text { (<60 cases/100. } \\
000 \text { hab.) } \\
\text {-Taxa de detecção } \\
\text { ( } \geq 60 \text { cases } / 100 . \\
000 \text { hab.) } \\
\text { - Cura } \\
\text { - Morte } \\
\text { - Abandono } \\
\text {-Sucesso do } \\
\text { tratamento } \\
\text { - Finalização do } \\
\text { tratamento }\end{array}$ & $\begin{array}{c}84(37-182) \\
\\
90(25-186) \\
\\
\\
83.4 \% \\
1.5 \% \\
5.5 \% \\
87.7 \% \\
4.3 \%\end{array}$ & $\begin{array}{c}36(21-128) \\
\\
121(41- \\
239) \\
\\
69.9 \% \\
3.4 \% \\
16.8 \% \\
75.7 \% \\
5.8 \%\end{array}$ \\
\hline $\begin{array}{l}\text { Datiko, D. G; Lindtjorn, B } \\
(2009)\end{array}$ & $\begin{array}{l}\text {-318 pacientes: } \\
\text { - } 230 \text { do grupo } \\
\text { de intervenção; } \\
\text { - } 88 \text { do grupo } \\
\text { controle. }\end{array}$ & $\begin{array}{c}\text {-Taxa de detecção } \\
\text { - Cura } \\
\text { - Morte } \\
\text { - Abandono } \\
\text { - Finalização do } \\
\text { tratamento }\end{array}$ & $\begin{array}{c}122,2 \% \\
74.8 \%(172) \\
3.5 \%(8) \\
6.5 \%(15) \\
14.3 \%(33)\end{array}$ & $\begin{array}{c}69,4 \% \\
68.2 \%(60) \\
2.3 \%(2) \\
10.2 \%(9) \\
15.9 \%(14)\end{array}$ \\
\hline
\end{tabular}

Quadro 3 - Intervenção educativa em DOTS/TDO versus ausência de intervenção educativa

Novamente, não pretendemos generalizar os achados dessa revisão, tendo em vista o número reduzido de estudos encontrados. Contudo, chamamos a atenção para a importância do DOTS e do TDO no combate à tuberculose e para o papel central da qualificação dos recursos humanos na operacionalização das políticas.

Frente ao exposto, quando se analisam os números do TDO no município de Porto Alegre, deparamos com uma taxa irrisória e uma baixíssima cobertura populacional. Dos $100 \%$ de casos de todas as formas de TB no ano de 2009 , somente $9,70 \%$ foram indicados para TDO e apenas $5,94 \%$ destes foram realizados. Situação ainda mais grave foi observada no ano de 2011, em que se obteve um percentual de apenas $6,76 \%$ de TDO realizado, de um total de 16,09\% indicado. Em 2012, o TDO realizado estava em $4,87 \%$ de $21,31 \%$ indicado, de acordo com dados atualizados em 26 de novembro de 2012 (Núcleo das Crônicas/EVDT/CGVS/SMS/POA, 2012). 
Para Bueno et al. (2006), alguns fatores dificultam a viabilização do DOTS e do Tratamento Supervisionado em Porto Alegre, tais como: a cultura dos gestores, que relutam em adotar e incorporar novas estratégias que não a do acompanhamento auto-administrado; forte centralização da rede laboratorial e de saúde; descentralização paulatina dos serviços de saúde com uma baixa cobertura de Estratégias de Saúde da Família/Agentes Comunitários de Saúde (ESFs/PACS) e o descrédito atribuído ao Tratamento Supervisionado pelos profissionais de saúde, que não o classificam como prioritário para uma população que desfruta de elevado padrão de vida e pode arcar financeiramente com a prestação de serviços de cuidadores.

Com base na relevância do TDO para o controle da tuberculose e mediante o grave quadro epidemiológico de Porto Alegre, propomos neste trabalho a investigação do planejamento e do processo de transferência da política do Tratamento Diretamente Observado da tuberculose entre as diferentes instâncias de governo, seus coordenadores, gestores e os profissionais (médicos, enfermeiros, técnicos e auxiliares de enfermagem) de algumas instituições de saúde do município, mais especificamente das 12 Unidades de Saúde Comunitária do Grupo Hospitalar Conceição (GHC).

Por transferência de política, entende-se o processo em que "[...] 0 conhecimento sobre políticas, medidas administrativas, instituições etc. num tempo e/ou lugar é usado no desenvolvimento de políticas, medidas administrativas e instituições em outro tempo e/ou lugar" (DOLOWITZ; MARSH, 1996, p.344, tradução nossa). Ele pode se dar sob a forma voluntária - a política é naturalmente aceita e inserida no contexto de trabalho dos indivíduos, que, insatisfeitos com o status quo, buscam soluções para os problemas - ou coercitiva, em que uma instituição governamental ou supranacional força outro governo a adotar uma política (DOLOWITZ; MARSH, 1996; 1998).

Dentre outros elementos que influenciam o processo de transferência de uma política pública, encontraremos: o contexto político, econômico, social, cultural, a disponibilidade de recursos financeiros, humanos, materiais e técnicos, a escolha do modelo, do estilo e dos canais de comunicação, tendo em vista que os diferentes atores envolvidos no processo possuem formas diversificadas de processar os 
dados recebidos (informação), validá-los em conhecimento e inovar suas ações (BISSELL; LEE; FREEMAN, 2011).

A essas três dimensões (Informação, Conhecimento, Inovação), daremos especial atenção por se constituírem em importante elemento de análise do presente estudo.

\subsection{INFORMAÇÃO, CONHECIMENTO E INOVAÇÃO: DIMENSÕES QUE PERPASSAM O PROCESSO DE TRANSFERÊNCIA DE UMA POLÍTICA PÚBLICA}

Informação pode ser compreendida como "[...] dados coletados, organizados e ordenados aos quais são atribuídos significados e contexto" (PRUSAK e McGEE, 1994, p.24). Na transferência de políticas públicas, é sempre relevante observar o quanto de informação obtida poderá e deverá estar envolvida nesse processo. Decisões de como utilizá-la podem influenciar as interações com o sistema político e cultural preexistentes, assim como determinar o grau de facilidade de sua abordagem no processo de formulação de políticas (DOLOWITZ, 2003). A qualidade e a natureza da informação também devem ser verificadas (TURGEON et al., 2008).

Com relação aos fluxos de informação, estes podem ser caracterizados como internos (dividido em primeiro e segundo nível), nos quais a informação é selecionada, armazenada, classificada e assimilada pelo indivíduo, e extremos, quando o receptor processa e significa a mensagem do interlocutor, transformando-a em conhecimento (BARRETO, 2001).

O conhecimento, por sua vez, é "[...] socialmente moldado, possuindo não apenas uma dimensão temporal/histórica, mas também espacial/territorial" (ALBAGLI; MACIEL, 2004, p.10). A sua utilização é um tema bastante enfatizado pelas teorias do aprendizado e considerado como conceito pilar da sociedade do conhecimento. Ainda hoje, são grandes os desafios nessa área, e modificações tornam-se necessárias, tal qual a mudança da concepção de aprendizagem como a edificação do conhecimento pelos indivíduos para uma em que a aprendizagem e o conhecimento sejam frutos do compartilhamento entre os indivíduos (CARR; 
CLARKE, 2010). A formação do conhecimento só pode ser entendida quando levamos em consideração as especificidades das relações no interior das instituições em seus mais diferentes níveis (nacional, regional, local), suas características e demais fatores que contribuem para as formas diferenciadas de seu apoderamento e da prática inovativa (LEMOS, 1999).

Ao remetermo-nos à aplicação prática do conhecimento, discorremos sobre um campo de domínio que pode ser abordado enquanto "Knowledge Translation" (KT). A definição conceitual do termo pode ser compreendida como "[...] a troca, síntese e aplicação eticamente sólida de conhecimento, dentro de um complexo sistema de interações [...]" (CANADIAN INSTITUTES OF HEALTH RESEARCH, 2004, p.4, tradução nossa). O objetivo principal da KT encontra-se em trabalhar a lacuna existente entre a síntese do conhecimento e sua implementação pelos principais atores (stakeholders) numa instituição, com vistas à qualificação do sistema de saúde e dos seus resultados (GRAHAM et al., 2006).

A qualificação do sistema e dos resultados pode estar diretamente vinculada às formas pelas quais esse conhecimento é empregado, bem como às estratégias inovadoras que são desenvolvidas e implementadas a partir dele no ambiente de trabalho. Frente às várias definições de inovação, torna-se útil enfatizar que o nosso estudo mobilizará dois enfoques diferentes do termo inovação. O primeiro deles atrela a inovação à esfera das melhorias produzidas pelos profissionais de saúde em suas unidades de serviço, ou seja, na perspectiva da inovação na prestação de serviços e na organização, que pode ser definida como

[...] um novo conjunto de comportamentos, rotinas, e formas de trabalho que são direcionadas a melhorar os resultados de saúde, a eficiência administrativa, a relação custo-efetividade, ou a experiência dos usuários e que são implementadas por ações planejadas e coordenadas (GREENHALGH et al., 2004, p.582, tradução nossa).

Nesse contexto, a inovação decorre da iniciativa coletiva dos diferentes atores na busca de modificações e aperfeiçoamento do seu contexto social, sendo caracterizada como um processo dinâmico em constante transformação (FARAH, 2008a). Para Albagli e Maciel (2004), as dinâmicas cognitiva, informacional, 
inovativa e socioespacial são indissociáveis, e a utilização de informações e do conhecimento e a produção de inovações podem ser caracterizados como processos socioculturais, vinculados a um espaço e a sua própria criação.

Lemos (1999), reforça que a difusão/transferência/distribuição do conhecimento ocorre de maneira desigual entre países, regiões, instituições, e, por isso, são importantes investimentos para a expansão do estoque de informação e conhecimento, bem como para a capacitação de recursos humanos que trabalhem com o processo inovativo.

O outro enfoque da inovação relaciona-se à compreensão desta enquanto um programa, uma proposta inovadora, uma tecnologia que é transferida de um cenário/instituição para outro/a. Esses dois tipos de inovação que aqui distinguimos podem ser classificadas como inovação incremental e radical, respectivamente. A de caráter incremental refere-se à "[...] introdução de qualquer tipo de melhoria em um produto, processo ou organização da produção dentro de uma empresa, sem alteração na estrutura industrial" (FREEMAN, 1988 apud LEMOS, 1999, p.124) ${ }^{1}$. Já a radical é compreendida como "[...] o desenvolvimento e a introdução de um novo produto, processo ou forma de organização da produção inteiramente nova. Esse tipo de inovação pode representar uma ruptura estrutural com o padrão tecnológico anterior [...]" (LEMOS, 1999, p.124).

Portanto, abordaremos a inovação ora em referência à otimização da prática proposta pelos profissionais de saúde no serviço (Inovação incremental), ora enquanto um programa inovador, uma tecnologia, uma política (TDO) a ser transferido(a) (Inovação radical). Merhy et al. (1997) propõe uma estratificação de três categorias de tecnologia na área da saúde: a Dura (representada pelo objeto concreto, equipamentos, o maquinário, normas), a Leve-Dura (o saber constituído e estruturado de disciplinas da saúde, como a Clínica, a Epidemiologia, etc.), e a Leve (o processo das relações, da produção de vínculo, do acolhimento, da gestão no direcionamento do trabalho, outros).

Acreditamos que o nosso objeto de estudo incorpora elementos tanto da tecnologia Leve-Dura, considerando o TDO enquanto uma política elaborada na

\footnotetext{
${ }^{1}$ FREEMAN, C. "Introduction". In: DOSI, G. et alii (orgs.). Technical change and economic theory. Londres: Pinter Publishers, 1988.
} 
congruência dos saberes de várias áreas da saúde, quanto da tecnologia Leve, tendo em vista que o processo de sua transferência envolve relações entre gestores, coordenadores e profissionais de saúde que se refletem na interface profissional de saúde - usuário.

Na transferência de uma política pública (programa inovador), torna-se vital elucidar fatores que podem influir diretamente na magnitude da disseminação e da adoção da inovação. Alguns deles podem ser caracterizados da seguinte maneira: a capacidade de resposta ao problema e a eficácia do programa inovador; a potencialidade da inovação em responder a problemas comuns às diversas localidades (aumenta a chance de disseminação); a convergência da proposta inovadora e a agenda governamental local, os entraves institucionais e estruturais (incentivos políticos, financeiros, as características do quadro institucional local, a capacidade administrativa e de recursos, o legado de políticas prévias e a ideologia) (FARAH, 2008a).

O conhecimento desses fatores torna-se indispensável à nossa proposta de análise da transferência da política do Tratamento Diretamente Observado da tuberculose em Porto Alegre, enquanto elementos basilares ao entendimento do cenário político-institucional local.

Cientes de que informação, conhecimento e inovação são três dimensões intrinsecamente imbricadas que perpassam o processo de transferência de uma política pública, antecipamos que elas foram tomadas como objetos teóricos fundantes do questionário aplicado aos profissionais de saúde das unidades pesquisadas no GHC, como veremos adiante na seção "Material e Métodos”.

Ressalvamos ainda que a incipiência do tema "transferência de políticas públicas" no meio acadêmico brasileiro (FARAH, 2008b) torna este estudo uma oportunidade de ampliação das evidências científicas no assunto, bem como um possível instrumento de auxílio no planejamento, reformulação e reestruturação dos serviços locais de controle à TB em Porto Alegre. 


\subsection{QUESTÃO NORTEADORA E PRESSUPOSTO DE INVESTIGAÇÃO}

O presente trabalho foi desenvolvido com base nas seguintes questões norteadoras:

Como tem se desenvolvido o processo de planejamento e a execução da transferência da política do TDO entre coordenadores e gestores das diferentes instâncias de governo (estadual, municipal) e profissionais de saúde do município de Porto Alegre? A política vem sendo transferida de forma coercitiva ou voluntária?

Parte-se da premissa de que houve planejamento para a transferência da política do TDO e de que esta tende a ser transferida mais sob a tipologia voluntária do que coercitiva.

\subsection{OBJETIVOS}

\subsubsection{Objetivo Geral}

Analisar o processo de planejamento e de transferência da política do Tratamento Diretamente Observado (TDO) para o controle da Tuberculose em Porto Alegre, RS.

\subsubsection{Objetivos Específicos}

1. Analisar a discursividade dos gestores sobre o planejamento e a transferência da política do TDO;

2. Investigar a tipologia da transferência da política (coercitiva ou voluntária);

3. Analisar a transferência da política do TDO segundo as dimensões informação, conhecimento e inovação. 
3. TESSITURA TEÓRICA 
Em nossa via investigativa, apoiamo-nos em postulados conceituais referentes às temáticas da transferência da política e do planejamento (considerados elementos centrais deste trabalho), bem como da Análise de Discurso (AD) de Linha Francesa, mais especificamente a vertente Pecheuxtiana, tomada como referencial analítico-metodológico da pesquisa qualitativa.

\subsection{TRANSFERÊNCIA DE POLÍTICA PÚBLICA: O PROCESSO E SUAS PECULIARIDADES}

Conforme dito anteriormente, embora incipiente nos trabalhos acadêmicos brasileiros, pode-se dizer que o tema transferência de políticas públicas ('policy transfer', também reconhecido enquanto 'lesson drawing', ou seja, lição, instrução a ser aprendida) tem sido estudado desde antes de 1940 (DOLOWITZ E MARSH, 1996). Afinal, trata-se de um conceito simples que provavelmente surgiu há muitos anos, desde a época dos homens da caverna, em que um percebeu como o outro era mais efetivo na caça e resolveu copiar suas técnicas (DOLOWITZ, 2003). Segundo Akkari (2006), mesmo que em franca expansão na literatura anglófona, não se pode observar uma nítida distinção terminológica e na nomenclatura referente aos termos "transferência de política", "difusão", "lição a ser aprendida", "aprender" e "tomar emprestado".

Para James e Lodge (2003), é difícil distinguir os conceitos de "policy transfer" e "lesson drawing", inclusive de outras formas de elaboração de política (policymaking). Já Evans e Davies (1999) enfatizam que a convergência de políticas (policy convergence), a difusão de políticas (policy diffusion), o aprendizado da política (policy learning) e a lição a ser aprendida (lesson drawing) são todos ramos do processo de transferência de uma política (policy transfer), ainda que dotados de algumas distinções.

Não entraremos no mérito das diferenciações de cada vertente deste guardachuva; antes, focaremos no processo de transferência de política como um todo. Dessa forma, com o intuito de facilitar a abordagem do tema, procuramos discorrer sobre alguns de seus principais elementos conceituais, contextualizados inicialmente 
em referência ao quê, quem, onde, quando e o porquê do engajamento na transferência de uma política pública, como se segue.

Políticas (seus objetivos, conteúdo, estrutura), instrumentos de política, técnicas administrativas, instituições, ideologias, ideias, atitudes, conceitos e lições negativas são alguns elementos que podem ser transferidos, de uma forma voluntária ou coercitiva (direta - pelo uso da força -; ou indireta - por dependência interfuncional ou influência de fatores externos), como visto anteriormente. Os mais diversos atores podem engajar-se no processo de transferência, tais como: os representantes eleitos; os partidos políticos; as instituições burocráticas e funcionários públicos; os grupos de pressão; os empreendedores de políticas e especialistas; as instituições supranacionais, dentre outros (DOLOWITZ; MARSH, 1996).

A transferência de uma política pública pode ocorrer dentro do próprio país, entre unidades subnacionais, em nível regional, estadual, local, e de um país para outro, sendo necessário haver uma similitude das condições ideológicas e de recursos entre estes últimos (DOLOWITZ; MARSH 1996; 1998). Não se pode, contudo, deixar de considerar as dificuldades e limitações que podem permear esse processo em todas as instâncias, como por exemplo, a depender da complexidade de um programa (quanto mais complexo, mais difícil de transferi-lo), das restrições impostas por políticas passadas, das limitações estruturais e institucionais, bem como dos recursos políticos, burocráticos e econômicos (DOLOWITZ; MARSH, 1996). O estímulo à mudança, as circunstâncias que demandam a mudança, o potencial de apoio e/ou resistência da instituição beneficiária da inovação são outros fatores que influenciam diretamente o processo (PAGE, 2000).

Por outro lado, podemos obter resultados diversos no processo de transferência de uma política. Correlacionando-os ao tipo de mudança que produzem, teríamos: as mudanças de primeira ordem (referentes aos ajustes contextuais, do cenário e do status quo), as de segunda ordem (vinculadas às redefinições e modificações dos próprios instrumentos políticos para o alcance das metas) e as de terceira ordem (redefinições dos objetivos que orientam a política numa determinada área) (EVANS, 2010). 
Quanto à época para realizar a transferência de políticas, a oportunidade pode depender do ciclo político dos governantes, com eleições de novos membros, ou ainda da disponibilidade de recursos humanos qualificados para desempenhar tal atividade (STONE, 1999). Deve-se compreender que muitas políticas desenvolvemse com o tempo e que a própria decisão de quando extrair lições pode ter uma influência crítica nas lições aprendidas. O tempo não é constante, os obstáculos não são permanentes e podem ser convertidos em variáveis no percurso (DOLOWITZ, 1996).

Quanto às razões pelas quais os indivíduos envolvem-se com transferência de política, estas podem variar, seja na perspectiva de se obter um subsídio, uma justificativa para decisões tomadas, ou para o uso de um determinado modelo externo, ou ainda pela busca de soluções na resolução de problemas/disfuncionalidade da política (DOLOWITZ, 2003).

Com relação aos graus, ou tipos de transferência de políticas/lições, podemse observar cinco formas distintas: cópia (utiliza o programa de um país/lugar na íntegra, sem modificação); emulação (rejeição da cópia detalhada do programa, mas aceita que alguns de seus aspectos ou de outro programa em particular podem ser a/o melhor alternativa/padrão para o contexto próprio); hibridização e síntese (tomadas numa abordagem coletiva, referem-se à combinação de elementos de programas de dois ou mais países, com o objetivo de atendimento da demanda do 'imitador'); e inspiração (o programa serve enquanto influência, inspiração para expansão de ideias e reflexão sobre as possibilidades locais) (ROSE, 1991²; $1993^{3}$; WALTMAN, $1980^{4}$ apud DOLOWITZ; MARSH, 1996, p.351).

Quando pensarmos sobre o processo de análise da transferência de uma política, torna-se de grande valia pautar-nos na perspectiva elucidada por Evans e Davies (1999, p.363, tradução nossa):

\footnotetext{
${ }^{2}$ ROSE, R. What is lesson drawing? Journal of Public Policy,11, p.3-30, 1991.

${ }^{3}$ ROSE, R. Lesson-drawing in Public Policy: a guide to learning across time and space. Chatham House Publishers, 1993. $176 \mathrm{p}$.

${ }^{4}$ WALTMAN, J. L. Copying other Nations' Policies: Two American Case Studies. Cambrigde MA, Schenkman Pub. Co, 1980. 126 p.
} 
[...] análise da transferência de uma política não se constitui numa teoria explicativa, mas pode ser vista como um modelo analógico no sentido de que ele se baseia em sugestões de similitudes substanciais entre duas entidades. Por exemplo, na comparação de uma organização a uma máquina ou um organismo. Ele também pode ser visto como um conceito do nível Meso, que pode fornecer uma ligação entre o nível Micro, que trata dos interesses e dos níveis de governo em relação a determinadas decisões políticas, e o nível Macro de análise, que se preocupa com questões mais amplas sobre a distribuição de poder dentro da sociedade contemporânea.

Como se pode observar, a transferência de política não se reduz a um processo meramente conceitual e descritivo, podendo ser vista, dentre outras formas, enquanto modelo de interposição, elo entre os mais diversos níveis de gestão. Ressalta-se, nesse sentido, que a gestão pública em saúde pode ser escalonada em três níveis principais, sendo eles o da Macrogestão (envolve a intervenção do Estado na gestão, no financiamento, na saúde, nas atividades de formulação de políticas), a Mesogestão (referente às ações de condução e direcionamento de uma organização, pode abarcar os centros clínicos-hospitalares, bem como outras instituições de saúde) e a Microgestão (a responsabilidade maior é assinalada aos profissionais; remete à coordenação do processo de trabalho no interior de uma instituição) (SOUZA, 2009; GARCIA, 2001).

De acordo com Evans e Davies (1999), a avaliação do nível Meso tem se tornado uma ferramenta crucial no desenvolvimento de análises integrativas. Tal nível é considerado, na Grã-Bretanha, como sendo o mais apropriado e fértil para a análise da elaboração de políticas (policy making), já que as teorias do nível Macro tendem a ser muito abstratas e destinam pouca atenção aos processos de mediação, enquanto no nível Micro elas tendem a ignorar o impacto de fatores estruturais mais amplos e globais nas decisões locais. O nível Meso, por sua vez, requer dos pesquisadores um olhar simultâneo para as questões de ambos os níveis, Macro e Micro, sem perder de vista o caráter integrativo da análise.

Neste estudo, focaremos a análise do processo de transferência da política do TDO em conformidade com o Nível Meso de gestão, na ótica dos coordenadores e gestores dos Programas de Controle da Tuberculose, bem como em alguns aspectos do nível Micro, estes relacionados não apenas ao processo de transferência do TDO (na qualidade de uma política inovadora) para os profissionais 
de saúde, mas em referência aos possíveis elementos de reformulação de seus processos de trabalho em seus respectivos loci funcionais.

Antes de apresentarmos o modelo operacional para a análise da transferência da política no qual basearemos este trabalho, abriremos espaço para uma breve consideração sobre o tema na área da saúde.

Entende-se política de saúde enquanto ação (ou sua falta) de instituições e organizações - por exemplo, o Estado - com vistas à gestão, regulação de bens e serviços, distribuição, intervenção em questões relacionadas ao ambiente, à saúde humana (individual e coletiva) e seus determinantes. Envolve elementos relativos tanto ao poder em saúde (Politics), quanto aos relacionados à elaboração e definição de diretrizes, programas e planos na área (Policy). (PAIM; TEIXEIRA, 2006).

Transferência, por sua vez, pode ser entendida no sentido de movimento considerável de algo relacionado à política (Policy, neste caso) de um lugar para o outro, não simplesmente tomada como mera difusão de conhecimento interinstitucional. Precisa ainda levar-se em consideração a dimensão espacial, além da temporal (BISSELL; LEE; FREEMAN, 2011).

Também nos domínios da saúde, a transferência de políticas, programas, planos etc., configura-se como atividade constante, relativa às mais diversas instâncias, conteúdos e contextos organizacionais. Dentre outros, destaca-se que o próprio modelo de saúde brasileiro, o Sistema Único de Saúde (SUS), apoiou-se em material teórico fornecido pelo relatório Dawson (de origem britânica) quanto à gestão e atenção para as políticas públicas de saúde (CAMPOS, 2006). Nesse ínterim, destaca-se ainda a proposta brasileira de construção das redes regionalizadas em saúde (KUSCHNIR; CHORNY, 2010).

Embora tão presente nesta área, torna-se necessário destacar a escassez de estudos a respeito do processo de transferência de políticas públicas nesse meio. Freeman (1999) desde então ressaltava o interesse crescente no tema nos territórios das Ciências Políticas, contudo, enfatizava a dificuldade de se encontrar estudos sistemáticos no setor saúde. Nesse sentido, recorremos a uma revisão da literatura para verificar a situação nos dias de hoje. 
Medline via Ovid, Lilacs e CINAHL foram usadas como base de dados da pesquisa. As buscas foram realizadas no idioma inglês, português e espanhol, sem restrições temporais e por meio das palavras-chave 'Policy transfer' e 'Health', combinadas e traduzidas conforme necessidade. Como resultados, foram obtidos apenas 182 estudos, dos quais somente um se detinha a analisar de modo mais sistemático o processo de transferência de uma política pública, mesmo assim não pertencente à área da saúde. Assim, realizamos nova investida, agora no Science Direct. Utilizamos o termo 'Policy transfer' com vistas a detectá-lo em estudos que o tivessem na condição de palavra-chave (keyword). Como resultado, obtivemos 164 registros, dos quais apenas um com enfoque mais sistemático sobre o tema em saúde. Queremos com isso apenas enfatizar que ainda existe certa dificuldade para se encontrar material bibliográfico teórico-conceitual da transferência de política no setor saúde, o que fortalece nosso ponto de vista sobre a contribuição científica do presente trabalho.

Para a nossa proposta de análise da transferência do TDO em Porto Alegre entre as diferentes instâncias de governo e atores, adotaremos como referencial teórico o arcabouço operacional sugerido por Bissell, Lee e Freeman (2011). O nosso objetivo é tomá-lo como ferramenta de suporte para o entendimento dos elementos envolvidos num processo de transferência de uma política pública, que serão evocados neste trabalho à medida que forem observados, tanto nos discursos dos gestores e coordenadores quanto a partir dos resultados da aplicação do questionário.

Não temos a pretensão de abarcar todas as fases e elementos em nossa análise, aliás, os próprios criadores do modelo ressaltam a complexidade de se analisar em profundidade cada um deles, sugerindo que os próprios pesquisadores talvez optem por concentrar-se em alguns em vez de todos. Assim, apresentamos de forma sucinta o modelo e suas características. 


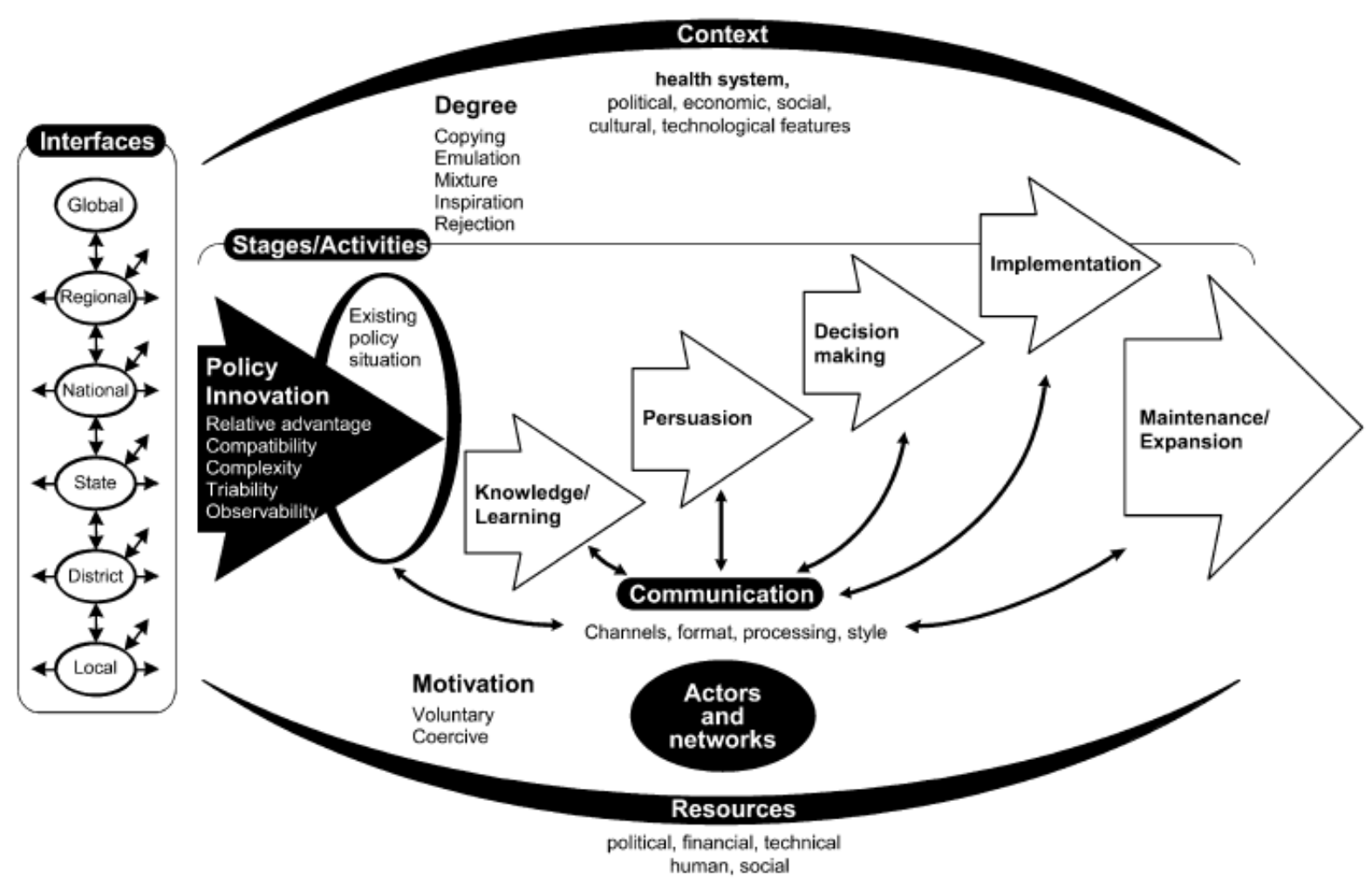

Fonte: Bissell, Lee e Freeman (2011, p. 1143)

Figura 1 - Modelo de Análise para a Transferência da Política da Saúde

Segundo os autores, há várias interfaces e níveis intercomunicantes (global, nacional, regional, etc.), pelos quais se permeiam o conhecimento e o processo de transferência de uma política. Assim, quando a proposta de política (Policy Innovation) é introduzida no cenário, deve-se analisar, dentre outros, a influência de políticas anteriores, de propostas paralelas que competem com ela e o grau ou tipo de transferência (cópia, emulação, inspiração, outros).

Com vistas à operacionalização da transferência, deve-se avaliar o tipo de conhecimento envolvido e de que maneira ele será difundido, validado, compartilhado (Knowledge/Learning) e as formas de persuasão (Persuasion) das pessoas e instituições quanto à política (o que inclui análise de motivação - tipologia coercitiva e voluntária). As principais decisões referentes à adoção ou rejeição da política devem ser analisadas, assim como as formas pelas quais ocorrerão as mudanças e o planejamento da sua implementação (Decision making). Temos ainda a avaliação do próprio momento em que se coloca a política em prática 
(Implementation) e das formas de manutenção e expansão das ações após sua instauração (Maintenance/Expansion) (BISSELL, LEE e FREEMAN, 2011).

Todo esse processo pode ser influenciado pelo contexto (político, econômico, social, cultural) e pela disponibilidade de recursos (financeiros, humanos, materiais, técnicos, outros). Ressalta-se que, embora esboçado em fases (para facilitar o entendimento), o arcabouço não pretende sugerir que o processo de transferência siga uma lógica linear ou ordem particular em que o fim de uma etapa indica necessariamente o início da outra. Há possibilidade de que nem todas as atividades se cumpram, ou que ocorram em momentos distintos (BISSELL, LEE e FREEMAN, 2011).

Optamos por este modelo na qualidade de proposta clara e de fácil entendimento dos elementos que perpassam o processo de transferência de uma política pública, bem como pelo didatismo em pesquisas operacionais no tema. Outros fatores podem reforçar a gama de motivos da nossa escolha, como por exemplo: ter sido este modelo criado a partir de uma fusão e adaptação de outros arcabouços teóricos da transferência de política e da difusão de inovação; pela contribuição na detecção de problemas e facilitadores do processo de transferência de uma política; pela flexibilidade no uso, em que se pode adotá-lo de forma retrospectiva (para examinar o passado, como ocorreu a transferência de uma política e as justificativas de sua possível não adoção) ou prospectiva (como instrumento de planejamento e acompanhamento da política, em seus momentos de implementação e expansão)(BISSELL, LEE e FREEMAN, 2011).

Por essas e outras justificativas, escolhemos o referido arcabouço teórico. Tendo feito essas considerações, abramos espaço para falar de planejamento.

\subsection{NOS DOMÍNIOS DO PLANEJAMENTO}

Pensar em planejamento de uma forma geral, seus modelos teóricoconceituais e operacionais, significa abrir precedentes para um mundo repleto de possibilidades nos mais diversos cenários de aplicabilidade. Em nosso percurso 
teórico, buscaremos enfocar o planejamento na área da saúde, alguns métodos mais enfatizados na América Latina e, principalmente, o Planejamento Estratégico Situacional (PES) de Carlos Matus, tomado como referencial teórico para o presente trabalho.

O planejamento há muito permeia as questões administrativas da humanidade. Com raízes nos domínios da economia, pode-se dizer que o capitalismo e a necessidade de aparatos organizacionais para o grande volume de capital gerado tornaram o planejamento um instrumento sistemático e racionalizador, de previsão e organização de recursos para o alcance de metas e objetivos propostos. O advento da Industrialização fortaleceu-o e qualificou-o sobremaneira enquanto instrumento valioso na administração de empresas. Contudo, no século $X X$, há um redirecionamento desse campo disciplinar que, não mais exclusivo da administração de empresas, passa a figurar ainda como instrumento de política de governo e de intervenção do Estado (RIVERA; ARTMANN, 2012).

Também em saúde o planejamento ocupa posição estratégica. O interesse pelo tema surgiu em decorrência das exigências organizacionais e do grau de complexidade crescente do processo de trabalho nesta área, embora somente na metade do século passado (com a ampliação do desenvolvimento científico/tecnológico e do trabalho em rede) é que tenha havido, de fato, difusão e reconhecimento internacional por parte dos organismos e instituições de cooperação técnica quanto à importância e necessidade de utilizá-lo na administração dos sistemas de saúde pública (TEIXEIRA, 2010).

Ao nos remetermos à América Latina, nesse sentido, partimos de um cenário em que a necessidade de maior intervenção estatal fazia-se premente (tanto em relação à promoção do desenvolvimento econômico quanto dos direitos sociais), já que tanto a Segunda Guerra Mundial quanto a crise da Depressão Econômica haviam deixado consequências preocupantes em vários países, exortando-os a buscarem novas propostas de desenvolvimento nacional. É nesse contexto desenvolvimentista que o planejamento surge como uma alternativa estratégica, em que também já podemos observar o envolvimento de alguns organismos internacionais (JESUS; ASSIS, 2011). 
Assim, no ano de 1965, tem-se um importante marco constituinte nesta área na América Latina, com a publicação científica do documento número 111 da Organização Pan-Americana da Saúde (OPAS) intitulado "Programação em Saúde, problemas conceituais e metodológicos", cujo principal objetivo residia na proposta de utilização de estratégias, métodos e princípios de planificação da área econômica em outras áreas sociais, neste caso, a saúde. Naquela ocasião, o contexto era favorável e podia-se contar com incentivos do Banco Mundial para tal empreitada (TESTA, 2004 apud JESUS; ASSIS, 2011) ${ }^{5}$. Como principal produto surgiu o Método CENDES-OPS, dentre outros que surgiriam na sequência.

A proposta CENDES-OPS, embora caracterizada pelo viés economicista, buscou a aproximação com a saúde na instância do diagnóstico. Os indicadores de saúde da população foram sendo construídos a partir da análise e levantamento sistemáticos de variáveis epidemiológicas, sociais e demográficas, permitindo-lhes obter um quadro inicial das principais doenças, agravos e grupos mais afetados, dentre outros. Embora de caráter descritivo, a principal característica do método CENDES-OPS residia em não se fixar apenas na delimitação das características sanitárias da população em sua coletividade, mas em buscar a determinação/ identificação dos fatores associados (TEIXEIRA, 2010).

Destacam-se vários pontos positivos deste método, como a proposta sistêmica de atuação, o enfoque à prevenção de danos, o incentivo à formulação de sistemas de custo etc. Pode-se dizer que, ainda hoje, a programação em saúde é influenciada por sua lógica instrumental. Todavia, há de se enfatizar algumas de suas limitações que, possivelmente o colocaram em xeque, como o excesso de tecnocracia (que o vinculou à linha normativa do planejamento, com excessiva influência da economia e administração), bem como a omissão dos aspectos políticos-institucionais (financiamento, baixa capacidade de governo e de regulação do Estado, nível de privatização, dentre outros): "o método incorreu na pretensão ilusória de patrocinar uma organização de recursos abstratos, esvaziados de sua base institucional e de racionalidade política e, como consequência, 'pagou' um preço por isso" (RIVERA; ARTMANN, 2012, p.30).

\footnotetext{
${ }^{5}$ TESTA, M. Pensar em Salud. 3. Ed. Buenos Aires: Lugar, 2004.
} 
Já em 1975, em decorrência das críticas ao planejamento normativo e ao método CENDES-OPS, assim como da preocupação com o elemento político e social no processo de planejamento em saúde, tivemos a publicação do documento intitulado "Formulação de Políticas de Saúde", pelo Centro Pan-Americano de Planejamento em Saúde (CPPS) (RIVERA; ARTMANN, 2012). De acordo com Giovanella (1991), características como a relação entre as forças sociais, os conflitos, a questão da estratégia e a análise de viabilidade no planejamento foram enfatizadas. A viabilidade passa a ser compreendida na relação daqueles que apoiam e que se opõem ao plano, ou seja, assenta-se na análise da possibilidade de execução política do plano e dos acordos que se fazem necessários para que isso aconteça. O documento apresenta uma visão funcionalista da realidade e certa normatividade da política, contudo, tem a sua distribuição proibida pela OPAS, que “[...] não assume o seu conteúdo ‘mais político'”(GIOVANELLA, 1991, p.37).

Considerando tais fatos, e a partir dos debates, discussões e reflexões críticas no domínio do planejamento na década de 1980, surgiram três principais correntes relacionadas ao planejamento estratégico em saúde, quais sejam, o Planejamento Estratégico Situacional proposto por Carlos Matus, o Pensamento Estratégico de Mário Testa e o Enfoque Estratégico da Escola de Medellín, Colômbia (RIVERA; ARTMANN, 2012).

O Enfoque Estratégico da Programação em Saúde da Escola de Medellín foi desenvolvido em 1975, com embasamento teórico no documento "Formulação de Políticas de Saúde", anteriormente publicado pela CPPS. O ponto forte deste modelo encontra-se na contraposição ao planejamento normativo e na ênfase dada às forças sociais envolvidas, bem como ao caráter dinâmico e flexível do planejamento. Podem ser elencadas sete etapas de operacionalização do modelo básico, quais sejam: 1) formulação da imagem-objetivo atrelada ao diagnóstico de situação; 2) comparação entre a imagem-objetivo e a situação inicial; 3) definição dos projetos preliminares; 4) análise da coerência e da factibilidade dos projetos; 5) análise da viabilidade; 6) definição das estratégias e 7) etapa de formalização e implementação (LANA; GOMES, 1996).

O arcabouço do Planejamento Estratégico de Mário Testa (sanitarista argentino), por sua vez, foi concatenado nas lides de 1981 e suscita como ponto 
central a problemática do poder e a discursão da sua acumulação e desacumulação entre os diferentes atores envolvidos (SANTANA; TAHARA, 2008).

Testa elabora uma tipologia do poder em saúde, com distinção de três poderes: o político (referente à defesa dos interesses dos grupos envolvidos), o técnico (uso de conhecimentos e tecnologias) e o administrativo (relativo aos processos e atividades que envolvem recursos). Na sequência, o autor desenvolve sua concepção sobre a estrutura de poder no setor saúde e ainda sistematiza o denominado "Postulado da Coerência", este compreendido a partir da relação entre projetos ou propósitos de governo, os métodos para alcance de tais propósitos (práticas de planejamento) e a organização das instituições onde as atividades do governo são desenvolvidas. O postulado da coerência é de grande importância enquanto modelo de análise que pode ser utilizado em processo de formulação e implementação de políticas na saúde (TEIXEIRA, 2010).

Já em 1982 temos o advento do Planejamento Estratégico Situacional (SANTANA; TAHARA, 2008), engendrado pelo economista chileno Carlos Matus, um dos grandes pensadores do tema cujos pressupostos têm sido largamente utilizados na área de saúde. De acordo com Rivera (1992), este é o principal enfoque representativo do planejamento na América Latina, uma das razões pelas quais o adotamos enquanto referencial teórico do presente trabalho, somado ao fato de que o Brasil foi um dos primeiros países do continente a se interessar pelo modelo Matusiano (MATUS, 1993)

Em entrevista concedida a Huertas (1996, p.12), Matus significa planejamento e a ação de planejar como sendo o

[...] pensar antes de agir, pensar sistematicamente, com método; explicar cada uma das possibilidades e analisar suas respectivas vantagens e desvantagens; propor-se objetivos. É projetar-se para o futuro, porque as ações de hoje terão sido eficazes, ou ineficazes, dependendo do que pode acontecer amanhã e do que pode não acontecer. O planejamento é a ferramenta para pensar e criar o futuro porque contribui com um modo de ver que ultrapassa as curvas do caminho e chega à fronteira da terra virgem não palmilhada e conquistada pelo homem. Essa visão ampla serve como suporte das decisões de cada dia: os pés no presente e o olhar no futuro. É portanto uma ferramenta vital. Ou sabemos planejar ou estamos condenados à improvisação. 
Para Matus, o processo de planejamento envolve vários atores, visão policêntrica e a busca de estratégias de ação e de comunicação que visem de forma consensuada à resolução do problema elencado e ao alcance das metas objetivadas. O PES é uma proposta metodológica para aplicação em contextos democráticos nos quais os atores sociais possam participar ativamente (TEIXEIRA, 2010). Matus esclarece que 0 ato de governar exige a interlocução entre três variáveis (projeto do governo, capacidade do governo e governabilidade do sistema), denominada pelo autor de "Triângulo do Governo":

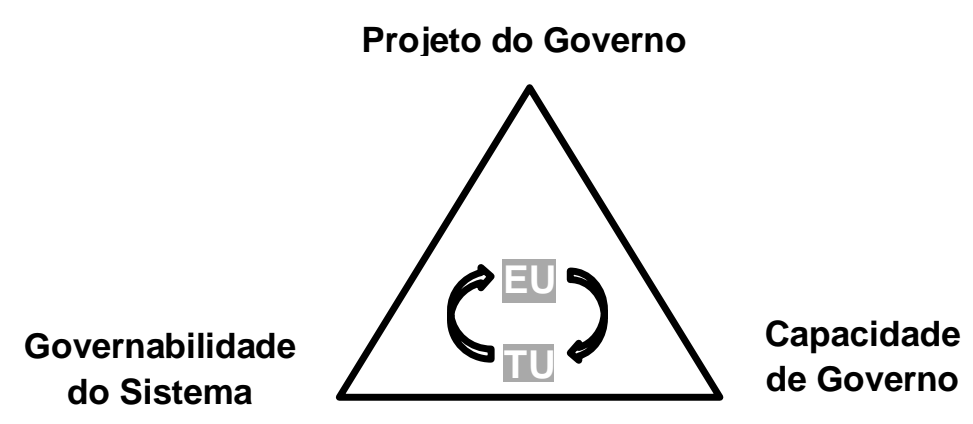

Fonte: Matus (1993, p.60, vol.1)

Figura 2 - Representação do Triângulo do Governo proposto por Carlos Matus

O "projeto do governo" está vinculado às propostas de ação de um determinado ator com vistas ao alcance dos seus objetivos. O conteúdo da proposta é produto do governante, da sua capacidade de governar e compreender a realidade. A "governabilidade" do sistema refere-se às variáveis a que este ator tem acesso, controla e não controla, na medida em que quanto mais variáveis de peso ele controla, maior a governabilidade. A "capacidade de governo" refere-se aos métodos, conjunto de técnicas utilizadas, habilidade, experiência do ator e equipe em conduzir o processo rumo ao objetivo determinado. $O$ conhecimento do planejamento e suas técnicas é um ponto fundamental na determinação da capacidade de uma equipe de governo (MATUS, 1993).

Dessa forma, Matus propõe o PES, um conjunto de métodos utilizados em diferentes momentos no processo de planejamento, estratificados por ele em "Explicativo", "Normativo", "Estratégico" e o "Tático-Operacional” (TEIXEIRA, 2010). 
O primeiro deles (Explicativo) refere-se à investigação da situação, à detecção do problema, sua descrição e análise de oportunidades de ação. $O$ segundo (Normativo) busca a definição da situação-objetivo, a decisão do que fazer no tempo político e espaço e a análise da coerência (externa e interna) das propostas políticas. No terceiro momento (Estratégico), avaliam-se as estratégias a serem operacionalizadas, analisa-se a viabilidade financeira do processo (recursos financeiros, físicos, materiais, humanos), a viabilidade política (vontade política de implementar ou não a proposta), a viabilidade técnico operacional (habilidade técnica, conhecimento para implementação das ações) e a viabilidade administrativa (capacidade de organização e gerenciamento das ações propostas). Já o momento Tático-Operacional refere-se à etapa de ação e operacionalização do plano, seu monitoramento e avaliação por meio do uso de indicadores que colaborem no julgamento dos resultados obtidos em determinado espaço e tempo por meio das atividades propostas (TEIXEIRA, 2010).

Posteriormente à elaboração do PES e buscando trabalhar a questão da operacionalização de um método complexo e sofisticado feito o PES em nível local, Matus propõe a combinação de outros dois enfoques do planejamento (o Planejamento de Projetos Orientado por Objetivos - ZOPP e o Método Altadir de Planificação Popular - MAPP), formando um sistema de planificação denominado de “Trilogia Matusiana”. O uso de cada um dos métodos está vinculado aos diferentes níveis gerenciais e de complexidade de uma instituição, estando o PES relacionado ao nível institucional Central, o ZOPP ao Intermediário e o MAPP ao Operacional/ Local (SANTANA; TAHARA, 2008).

Matus realça a importância e utilidade de se combinar os métodos em algumas instâncias. Conforme o autor, também no nível intermediário e local faz-se necessária uma análise aprofundada da viabilidade. O ZOPP e o MAPP, ao "deixar de lado" as alternativas não viáveis na situação inicial, são limitados quanto a esse quesito, diferentemente do PES, que exalça a análise da viabilidade com propriedade. Há inclusive sugestões e propostas do uso do PES em contextos operacionais-locais (SANTANA; TAHARA, 2008). Artmann (2000), por exemplo, enfatiza que a flexibilidade do arcabouço do PES possibilita sua aplicação tanto nos níveis regionais quanto locais e mesmo os setoriais, ainda que tenha sido desenhado para utilização no nível Central. Por essas e outras considerações feitas 
anteriormente, basearemos o nosso trabalho no entendimento dos momentos do planejamento conforme o delineamento teórico do PES, de Matus.

No Brasil, o PES tem sido amplamente utilizado nas instituições voltadas para a saúde, seja permeando o contexto produtivo acadêmico em alguns de seus loci (Escola Nacional de Saúde Pública - ENSP; Universidade de São Paulo - USP; Universidade Federal da Bahia - UFBA, por exemplo), seja enquanto base teórica de correntes do planejamento em saúde coletiva. O planejamento surge em paralelo à discussão da redemocratização na década de 1980, à constituição do SUS e ao surgimento da área da Saúde coletiva, em que se fez necessária a produção de bases teórico-metodológicas para fomentar o desenvolvimento do campo de Políticas, Planejamento e Gestão. As referências internacionais subsidiaram estudos e o desenvolvimento de correntes no tema. No contexto do SUS, observam-se quatro principais tendências: as Ações Programáticas em Saúde, o Planejamento Comunicativo, a Vigilância da Saúde e a Gestão Estratégica da Saúde, estas duas últimas pautadas em elementos do PES (JESUS, ASSIS, 2011).

Jesus e Assis (2011) propõem a diferenciação de nove perspectivas referentes às configurações do planejamento produzidas e operadas nos sistemas/serviços de saúde, tais quais a do planejamento como técnica para 'intervir' e 'avaliar' sistemas e serviços de saúde; o planejamento como prática social transformadora de sujeitos e coletivos; o planejamento como subsídio para a gestão democrática e para as mudanças; o planejamento como prática estruturada para a organização de sistemas e serviços de saúde; o planejamento como método de ação governamental para a tomada de decisões; o planejamento como instrumento e atividade do processo de gestão das organizações; o planejamento como meio de intervenção em ambientes complexos; o planejamento como meio de ação comunicativa e o planejamento como mediação entre a instrumentalidade e a subjetividade.

Entendemos aqui que a compreensão da etapa de planejamento do processo de transferência da política do TDO é de suma importância, na medida em que o plano é o primeiro passo para a operacionalização dessa transferência de forma organizada, qualificada e eficaz. Tomadas as perspectivas sugeridas por Jesus e Assis (2011), talvez pudéssemos incluí-lo na perspectiva do planejamento como 
método de ação governamental para a tomada de decisões e enquanto conjunto de estratégias de auxílio ao gestor.

Passemos, assim, ao enfoque do referencial teórico analítico da parte qualitativa deste trabalho.

\subsection{MICHEL PÊCHEUX E A ANÁLISE DO DISCURSO: NOS ENTREMEIOS DO SENTIDO E DA SIGNIFICAÇÃO}

De origem francesa (Tours), Pêcheux nasceu no ano de 1938 e faleceu em Paris em 1983. Considerado precursor da AD da Escola Francesa, Pêcheux dedicou-se aos estudos do sentido e suas relações com a ideologia, a materialidade linguística e a historicidade, partindo do entendimento de que o discurso é "[...] um efeito de sentidos dentro da relação entre linguagem e ideologia" (SANTOS, 2013, p.209).

Gestada na década de 1960, a Análise do Discurso preocupa-se com a relação linguística-textual, a influência do contexto histórico-social e ideológico, bem como com as condições de produção de um determinado discurso, o que a difere da Análise de Conteúdo, cujo enfoque suprime tais características e vê o texto como elemento extradiscursivo (SANTOS, 2013). Conforme nos diz Assolini (2003), a AD toma por objeto a análise que visa não apenas a interpretação, mas, sobretudo a compreensão do processo discursivo.

Falar em AD Francesa significa pensar numa área que trabalha no atravessamento constitutivo de três domínios, quais sejam, a Linguística - não enfoca a língua enquanto um sistema abstrato e sim "[...] a língua no mundo, com maneiras de significar, com homens falando, considerando a produção de sentidos enquanto parte de suas vidas, seja enquanto sujeitos seja enquanto membros de uma determinada sociedade." (ORLANDI, 2012, p.16) -, o Marxismo com o materialismo histórico e dialético - o sujeito afetado pela história e pela ideologia - e a Psicanálise - com o sujeito do inconsciente - (ORLANDI, 2012). Ferreira (2005a) 
propõe a representação do sujeito nessas três dimensões interdependentes, a partir da estrutura do nó borromeano elaborada previamente por Lacan.

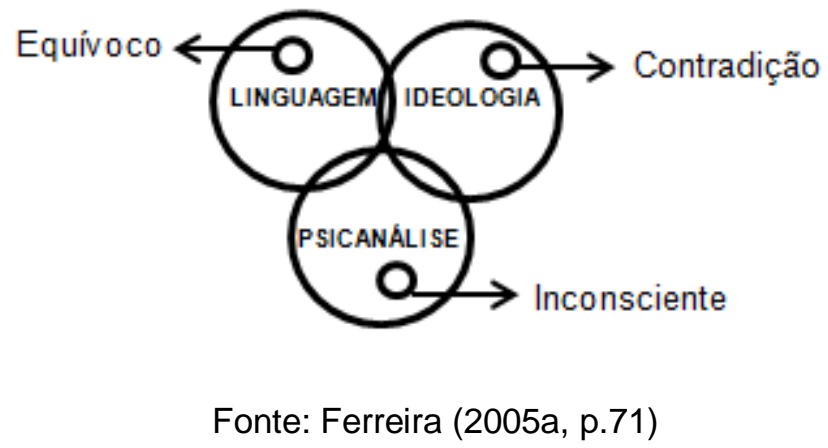

Figura 3 - Representação do sujeito no nó borromeano

O sujeito seria então afetado pelas três áreas marcando-as pelo furo (inerente à composição do ser-em-falta): "[...] o furo da linguagem, representado pelo equívoco; o furo da ideologia expresso pela contradição, e o furo da Psicanálise, manifestado pelo inconsciente" (FERREIRA, 2005a, p.71).

Além de Lacan (Psicanálise), Saussure, Benveniste (Linguística), Althusser e Karl Marx (Materialismo Histórico e Dialético) foram alguns, dentre outros teóricos, cujos pressupostos tiveram considerável influência no trabalho de Pêcheux.

Baseando-se nas noções de Saussure com relação à diferença entre a língua (sistêmica, objetiva, coletiva, o objeto de interesse da Linguística) e a fala (concreta, variável, individual, subjetiva, portanto excluída dos estudos), Pêcheux encadeia seu entendimento sobre o discurso e vai além, ao compreender que o estruturalismo saussureano é limitado e insuficiente para lidar com a questão do discurso, abrindose precedentes para se pensar a ideologia e a sua interlocução com a linguagem (SANTOS, 2013).

Nesse contexto, Benveniste (um dos precursores da Linguística da Enunciação) tem grande colaboração ao abordar a língua em funcionamento (e sem amarras exclusivas à estrutura), seu caráter coletivo e social e ainda de sustentáculo das relações entre os homens na sociedade. Destaca-se principalmente por enfocar a subjetividade no processo enunciativo, que passa a ser visto como decorrente de uma ação individual sobre a estrutura da língua (SANTOS, 2013). Guimarães (1996, 
p.99), em alusão à subjetividade na concepção de Bréal, esclarece que "o elemento subjetivo não diz respeito a uma intenção local de quem fala, mas é a presença de quem fala no que fala, e isto feito pela presença de certas formas que, já na língua, marcam a subjetividade".

Dessa forma, aproveitando-se deste ambiente de fomento à subjetividade, Pêcheux busca articular materialismo histórico (concebido a partir da teoria das formações e transformações sociais e a teoria das ideologias), linguística (os processos de enunciação, a subjetividade, os elementos gramaticais) e a teoria do discurso (processo semântico afetado pela historicidade)(SANTOS, 2013). O materialismo histórico, aliás, é um elemento robusto da primeira fase de desenvolvimento da $A D$, de um total de três, sintetizadas em alguns aspectos na sequência.

\subsubsection{PRIMEIRA FASE DA ANÁLISE DO DISCURSO FRANCESA}

O cenário político tenso e revolucionário na França que culmina com Maio de 1968 é o pano de fundo da emergência dos postulados teóricos da AD Francesa e das obras de Pêcheux, ambos carreados de sentido social, político e histórico vivenciados à época. Sob o pseudônimo de Thomas Hebert, Pêcheux publicou vários escritos na década de 60, em que deixa transparecer a influência do materialismo histórico decorrente de um seminário de que participou sobre Karl Marx, ministrado por Althusser. Essa primeira fase da AD é marcada pela análise automática de discurso e pela presença viva dos pressupostos teóricos althusserolacanianos, que permeiam toda a obra de Pêcheux (SANTOS, 2013).

É a partir de um dos seus estudos iniciais ("Reflexões sobre a situação teórica das Ciências Sociais e especialmente da Psicologia Social”, publicado em 1966) que se pode observar um movimento importante do autor no que diz respeito ao rompimento das Ciências Sociais com o Positivismo e uma aproximação com os fundamentos marxistas e humanistas, em que se destacam a subjetividade, a ideologia e a luta de classes (ZANDWAIS, 2009). É por meio do conceito de condições de produção emprestado do materialismo histórico - "[...] viria a criar as 
condições para inscrever, de modo concreto, a história na ordem do discurso e o discurso no campo da práxis" (ZANDWAIS, 2009, p.22) - que a aproximação entre as Ciências Sociais e Humanas se fortalece.

Entretanto, é a sua tese (“L'analyse authomatique du discours”, publicada em 1969) a considerada o referencial metodológico de origem da AD de Linha Francesa. Embora já procurasse distanciar-se da linguística estruturalista saussureana em alguns aspectos, reforçando as peculiaridades do discurso em outros, ressalta-se que nesse primeiro momento Pêcheux ainda se encontrava atado às questões formalistas, descritivas, funcionalistas, em que acreditava poder realizar análise com o auxílio de mecanismos automáticos. Já em 1975, mais amadurecido quanto aos seus objetivos, Pêcheux traz ao cerne de discussão a interlocução materialismo histórico, linguística e psicanálise, em que vários conceitos como Formação Discursiva (FD) e Formação Ideológica (FI) (em que pesem as ponderações althusserianas), dentre outros, começam a surgir, configurando-se em importante característica da segunda fase da AD (SANTOS, 2013).

\subsubsection{SEGUNDA FASE DA ANÁLISE DO DISCURSO FRANCESA}

Em AD, a ideologia interpela o indivíduo em sujeito (forma-sujeito histórica) e este se assujeita à língua e ao simbólico. Considera-se aqui a língua tomada enquanto materialidade discursiva, ou seja, em sua relação com a história e como ela se inscreve na história, a historicidade (ORLANDI, 2010). Esse sujeito do discurso, conforme nos diz Pêcheux, "[...] continua sendo concebido como puro efeito de assujeitamento à maquinaria da FD com a qual ele se identifica" (PÊCHEUX, 1997, p.314). Trata-se de pensar então no sujeito enquanto formasujeito e sua relação com uma dada formação discursiva. Aliás, a segunda etapa da AD foca-se precisamente no conceito de FD e suas reformulações (SANTOS, 2013).

Pêcheux (2009, p.161) define Formação Discursiva enquanto “[...] espaço de reformulação-paráfrase onde se constitui a ilusão necessária de uma 'intersubjetividade-falante' pela qual cada um sabe de antemão o que o 'outro' vai 
pensar e dizer [...]". Cazarin (2010, p.6) em referência a Pêcheux ${ }^{6}$ (1988, p.161-162) enfatiza que "[...] uma FD, segundo ele, identifica um domínio de saber e dissimula, pela transparência de sentido que nela se constitui, sua dependência com respeito ao interdiscurso das formações discursivas, intrincado no complexo das formações ideológicas".

Como se observa, Formação Discursiva e Formação Ideológica estão intimamente ligadas. Entende-se por Fls o

[...] conjunto complexo de atitudes e de representações que não são nem individuais, nem universais e que se referem mais ou menos diretamente a posições de classes em conflito umas com as outras, que têm como parte constituinte de si uma ou mais formações discursivas que se interrelacionam, determinando aquilo que se pode e se deve dizer (articulado sob a forma de uma arenga, de um sermão, de um panfleto, de uma exposição, de um programa etc.) a partir de uma posição dada em uma conjuntura dada (HAROCHE; HENRY; PÊCHEUX, ${ }^{7} 1971$, p.102-103 apud SANTOS, 2013, p.219).

Ao nos remetermos à conjuntura dada podemos relacioná-la às condições de produção de um discurso, nas quais temos as circunstâncias de enunciação (sentido estrito, o contexto imediato) e o contexto sócio-histórico-ideológico (sentido amplo) (ORLANDI, 2012).

Cabe-nos abrir um parêntese nesta seção para dizer que, no presente trabalho, consideramos os sujeitos entrevistados como pertencentes à FD Atenção Primária à Saúde. Assim, abrimos precedentes para explicar o movimento que realizamos na configuração e conceituação de tal FD.

Nesse percurso, apoiamo-nos nas sugestões metodológicas de Cazarin (2010), que configurou a FD dos trabalhadores brasileiros com base na interlocução entre historicidade, interdiscurso, memória discursiva e as diferentes posições do sujeito, na seguinte perspectiva:

\footnotetext{
${ }^{6}$ PÊCHEUX, M. Semântica e Discurso (1975). Trad. Eni Puccinelli Orlandi...[et.al.].Campinas, SP, Ed. da UNICAMP, 1988.

7 HAROCHE, C.; HENRY, P.; PÊCHEUX, M. La sémantique et la coupure saussurienne: langue, langage, discours. Langages, v.6, n. 24, 1971, p. $93-106$.
} 
talvez seja o caso de compreendermos que o interdiscurso fornece elementos para a reconstituição/restabelecimento da memória discursiva, que é da ordem do interdiscurso, mas que, para produzir sentidos, precisa ser mobilizada pela posição-sujeito. Mobilização essa que funcionaria, então, tanto como gesto de interpretação, quanto como categoria de análise, nos moldes do trabalho de Courtine $(1981)^{8}$. Isso nos levaria a aceitar, como já sinalizamos, que a memória discursiva é lacunar (pois aí interfere a posição-sujeito que a mobiliza), ao passo que o interdiscurso é saturado de sentidos - tudo está lá (CAZARIN, 2010, p.4).

Dessa forma, procuramos configurar a Formação Discursiva Atenção Primária à Saúde pela mobilização da historicidade e dos elementos próprios da área, pela consideração das diferentes e possíveis posições-sujeito que constituem tal FD e pelo acionamento da memória discursiva enquanto categoria de análise da ordem do interdiscurso.

Assim, iniciamos nosso percurso pelas raízes históricas vinculadas ao campo da Atenção Primária à Saúde (APS). Seus primórdios datam da década de 20, quando foi divulgado na Grã-Bretanha o Relatório Dawson (Lord Dawson of Penn), um "texto oficial" que discorria sobre a organização do sistema de saúde, o qual foi então dividido em três níveis: centros de saúde primários, centros de saúde secundários e hospitais-escolas. A vinculação formal entre esses níveis foi proposta e subsidiou o conceito de regionalização dos serviços de saúde, que serviu de modelo teórico para reorganização dos sistemas de saúde de diversos países (STARFIELD, 2002).

$\mathrm{Na}$ década de 50, foram observadas grandes disparidades entre países desenvolvidos e subdesenvolvidos, com predominância do enfoque curativo na saúde e com acesso dificultado a parcela significativa da população. Em reconhecimento ao grave cenário que se instalava, a OMS em 1953 na Assembleia de Saúde declarou seu interesse no fortalecimento dos serviços básicos de saúde, com vistas ao atendimento das necessidades e problemas de grande parte da população. A Atenção Primária foi então ganhando corpo, principalmente a partir das discussões iniciadas em 60, da publicação do Relatório Lalonde ("Nova perspectiva na Saúde dos Canadenses - 1974") e das observações de Halfdan Mahler, diretor

\footnotetext{
${ }^{8}$ COURTINE, J. J. Quelques problèmes theoriques et methodologiques en analyse du discours; à propos du discours communiste adressé aux chrétiens. Langages(62), juin, 1981.
} 
da OMS à época (1973-1974), que após visitar a China propôs novas estratégias em saúde (RIBEIRO, 2007).

Inicialmente os princípios da APS apresentados pela OMS estavam vinculados às experiências da década de 60 e 70 desenvolvidas em países subdesenvolvidos (Terceiro Mundo) e geralmente direcionadas ao atendimento da população carente desprovida do acesso aos cuidados médicos. Em 1977 e 1978 a OMS e o Fundo das Nações Unidas para a Infância (UNICEF) realizaram conferências regionais com especialistas na área dos Cuidados Primários em Saúde, com intuito de debater tais experiências e identificar fatores primordiais para o desenvolvimento da APS e seus efeitos nas áreas econômica, política e administrativa (RIBEIRO, 2007).

A abordagem da APS ganhou força de vez em 1977 na trigésima reunião anual da Assembleia Mundial da Saúde (com as discussões sobre a declaração "Saúde para todos no Ano 2000") e, principalmente, com a realização da Conferência de Alma Ata (1978) em que foram enunciados não apenas os princípios discutidos anteriormente em tais reuniões, mas os componentes fundamentais da Atenção Primária à Saúde, como: educação em saúde, saneamento ambiental, programas de saúde materno-infantis, prevenção de doenças endêmicas locais, tratamento adequado de doenças e lesões comuns, fornecimento de medicamentos essenciais, promoção da boa nutrição e medicina tradicional (STARFIELD, 2002). Assim, a APS foi conceituada pela Organização Mundial de Saúde como:

\begin{abstract}
Atenção essencial à saúde baseada em tecnologia e métodos práticos, cientificamente comprovados e socialmente aceitáveis, tornados universalmente acessíveis a indivíduos e famílias na comunidade por meios aceitáveis para eles e a um custo que tanto a comunidade como o país possa arcar em cada estágio de seu desenvolvimento, um espírito de autoconfiança e autodeterminação. É parte integral do sistema de saúde do país, do qual é função central, sendo o enfoque principal do desenvolvimento social e econômico global da comunidade. É o primeiro nível de contato dos indivíduos, da família e da comunidade com o sistema nacional de saúde, levando a atenção à saúde o mais próximo possível do local onde as pessoas vivem e trabalham, constituindo o primeiro elemento de um processo de atenção continuada à saúde. (WORLD HEALTH ORGANIZATION, $1978^{9}$ apud STARFIELD, 2002, p.30 - 31).
\end{abstract}

\footnotetext{
${ }^{9}$ WORLD HEALTH ORGANIZATION. Primary Health Care. Geneva: World Health Organization, 1978.
} 
Contudo, surgiram tensões relativas ao tema, por exemplo, no que diz respeito à sua execução nos países industrializados e naqueles onde o sistema de saúde se baseava na supremacia da tecnologia, da especialização e da tendência hospitalar com reflexos nos currículos das escolas de medicina, o que por sua vez, estabeleceu um conflito direto com um dos preceitos da APS de maior "proximidade com as pessoas" neste nível de saúde. Sem contar a base histórica escassa nesses países quando o assunto referia-se à orientação para a comunidade (STARFIELD, 2002).

Diante desses e outros dilemas, foram surgindo versões adaptadas dos conceitos de APS ao longo dos anos. Segundo Castro e Machado (2010), o enfoque de determinada perspectiva ou dimensão do termo relaciona-se diretamente às especificidades do sistema de saúde de cada país, seu contexto social, político e econômico, estando então sob constante tensão de interesses antagônicos. Assim, pela complexidade do assunto, optamos por focar nosso entendimento no contexto brasileiro, seu marco histórico e concepção utilizada, o que constituirá para nós o efeito fundador da FD Atenção Primária à Saúde.

Nesse sentido, Ribeiro (2007) empreende uma volta ao tempo destacando os principais fatos históricos ligados à inserção do tema APS na formulação do sistema de saúde brasileiro. Para tanto foram considerados dois períodos temporais, de 1920 a 1978 e de 1979 a 1994.

De 1920 a 1978, temos o período de reestruturação das práticas de saúde. O Departamento Nacional de Saúde foi criado para normatização das ações desempenhadas pelas várias instituições de saúde nos mais diversos níveis em SP (federal, estadual, municipal). A Reforma Paula Souza instituiu mudanças no cenário da saúde pública, além do mais, houve a criação da previdência social, em que a assistência médica passa a ser de interesse também da Saúde Pública, e o estreitamento dos laços do Estado brasileiro com o setor privado, contribuindo para uma notória mercantilização da assistência médica prestada.

Nesse contexto, germina no interior destas instituições as ideias principais da APS, e no final do período já se observa uma movimentação de instituições acadêmicas em parceria com as governamentais, no sentido de promover e desempenhar projetos assistenciais focados na assistência primária. Tais projetos 
serviram como cerne do movimento sanitário, em que se apontou a necessidade de reorganização das instituições públicas sob os moldes de um sistema e as ineficiências de tais instituições que enfrentavam a dicotomia das ações de caráter coletivo ou assistencialista. Em nível mundial tem-se a formulação da noção de APS a partir da Conferência de Alma-Ata.

De 1979 a 1994, notou-se que as diretrizes e propostas divulgadas em AlmaAta repercutiram no governo brasileiro, que buscou uma adaptação e inserção de tal conteúdo em seus domínios públicos de saúde. A crise da assistência médica observada à época também contribuiu para que se pensasse numa reestruturação e reorganização dos serviços em redes públicas integradas em sistema, surgindo assim a proposição, mais tarde convertida em SUS. A APS passa a ocupar papel central no final do período em que se propõe o Programa Saúde da Família (PSF), atualmente a Estratégia de Saúde da Família com impacto relevante nas políticas públicas.

Embora a concepção de APS tenha uma abordagem ampla, observou-se que, após as divulgações de Alma-Ata, ela passou a ser utilizada sob uma ótica seletiva, vinculada às populações rurais e pobres da área urbana. O Brasil, inicialmente, introduziu a APS no sistema de saúde sob essa égide reducionista e seletiva. Contudo, com o advento do PSF, a APS ganha papel central enquanto recurso fundamental de expansão da cobertura populacional e de contenção de custos de produção, além de principal organizador do sistema de saúde brasileiro (RIBEIRO, 2007).

Atualmente, o governo brasileiro propôs a reformulação da Política Nacional de Atenção Básica (PNAB) por meio da Portaria no 2.488 de 2011, que prevê as diretrizes e normas para organização da Atenção Básica (AB), para a Estratégia de Saúde da Família e para o Programa de Agentes Comunitários de Saúde. Nesse sentido, torna-se fundamental mencionar que a Atenção Primária à Saúde e Atenção Básica são tomadas enquanto termos equivalentes na PNAB (BRASIL, 2012).

Pelo instrumento da PNAB, a APS ou AB caracteriza-se enquanto: 
[...] um conjunto de ações de saúde, no âmbito individual e coletivo, que abrange a promoção e a proteção da saúde, a prevenção de agravos, o diagnóstico, o tratamento, a reabilitação, a redução de danos e a manutenção da saúde com o objetivo de desenvolver uma atenção integral que impacte na situação de saúde e autonomia das pessoas e nos determinantes e condicionantes de saúde das coletividades. É desenvolvida por meio do exercício de práticas de cuidado e gestão, democráticas e participativas, sob forma de trabalho em equipe, dirigidas a populações de territórios definidos, pelas quais assume a responsabilidade sanitária, considerando a dinamicidade existente no território em que vivem essas populações. Utiliza tecnologias de cuidado complexas e variadas que devem auxiliar no manejo das demandas e necessidades de saúde de maior frequência e relevância em seu território, observando critérios de risco, vulnerabilidade, resiliência e o imperativo ético de que toda demanda, necessidade de saúde ou sofrimento devem ser acolhidos (BRASIL, 2012, p.19).

Este nível de atenção à saúde é considerado a porta de entrada dos indivíduos na rede de saúde, devendo ser desenvolvido por meio dos princípios da universalidade, da acessibilidade, da integralidade da atenção, da continuidade do cuidado, do vínculo, da responsabilização, da participação social, da equidade e da humanização. Devem ser respeitados ainda os fundamentos e diretrizes vinculados à descentralização, programação, planejamento e desenvolvimento de ações com base no território adstrito, ao estabelecimento de mecanismos de acessibilidade a serviços qualificados, resolutivos e de acolhimento da população, à garantia da longitudinalidade do cuidado com a continuidade dos vínculos e da relação clínica entre profissionais e usuários de forma permanente ao longo do tempo, à coordenação da integralidade e à participação e estímulo à autonomia do usuário (BRASIL, 2012).

Dessa forma, em nosso gesto interpretativo a FD Atenção Primária à Saúde tem nos marcos históricos e conceituais apresentados o seu efeito fundador, sendo constituída pelo conjunto de saberes médicos e em saúde pública voltados para a promoção, proteção e assistência à saúde dos indivíduos e, sobretudo, da coletividade. Essa FD é mobilizada de forma diferente pelas várias posições-sujeito que a constituem. Neste caso, nos referimos aos usuários do sistema, às diversas especialidades profissionais atuantes, aos diferentes níveis de escolaridade (superior, médio, técnico) de tais profissionais e às diferentes posições que estes podem ocupar no sistema, seja enquanto responsável pela assistência ao usuário ou ainda na condição de coordenador e gestor do sistema. 
Partimos do entendimento de que a FD é constituída historicamente no interior das relações de classe e em determinadas condições de produção, sendo um espaço heterogêneo, de amplas possibilidades de configuração discursiva e de bordas permeáveis e instáveis (CAZARIN, 2010). Nesse sentido, ressaltamos a inserção de outros domínios (socioeconômico, político, cultural, etc.) no próprio conceito de saúde, e, mesmo sem entrar no campo das discussões teórico conceituais do tema, somos levados a reconhecer que qualquer FD relacionada à saúde será possivelmente atravessada por outros saberes que não aqueles estritamente vinculados ao biológico e à medicina preventiva e curativa, mas que de algum forma os influencia.

Assim, posta a perspectiva da FD Atenção Primária à Saúde que adotamos no presente trabalho, retomemos a discussão anteriormente iniciada sobre as fases da AD. Antes de entrarmos na terceira fase, ressaltamos que na segunda fase (conhecida também como a "época das tentativas") Pêcheux buscou repensar a análise automática de discurso, promovendo um deslocamento teórico no processo discursivo em que a constituição do corpus e as relações entre as máquinas discursivas estruturais e seu exterior ocuparam posição de destaque. Foi aqui que os conceitos de FD e Interdiscurso ganharam força (BRITO, 2012).

\subsubsection{TERCEIRA FASE DA ANÁLISE DO DISCURSO FRANCESA}

Se a formação discursiva foi o ponto-chave da segunda fase da $A D, 0$ interdiscurso o é da terceira (SANTOS, 2013).

Interdiscurso, como visto anteriormente, pode ser compreendido como o conjunto dos já-ditos em outro lugar (que esquecidos retornam sob a forma de préconstruídos) possibilitando todo o dizer, e o Intradiscurso refere-se ao que dizemos em um determinado momento e em dada condição de produção. Há uma relação entre aquilo que já foi dito e o que se diz, em outras palavras, entre interdiscurso e intradiscurso, que pode ser pensada sob a forma de dois eixos: o vertical (interdiscurso, os já ditos) e o horizontal (intradiscurso, eixo da formulação do dizer). O discurso encontra-se no ponto de intersecção dos eixos: "todo dizer, na realidade, 
se encontra na confluência dos dois eixos: o da memória (constituição) e o da atualidade (formulação). E é desse jogo que tiram seus sentidos" (ORLANDI, 2012, p.33).

Nesse encontro entre memória e atualidade, abrimos precedente para pensar o discurso enquanto acontecimento ou apenas estrutura, ou ainda ambos. Conforme Brito (2012, p.556):

\begin{abstract}
por ser acontecimento (o encontro entre uma atualidade e uma memória), o discurso retoma formulações anteriores e abre a possibilidade para que outros discursos sejam formulados a partir dele; por ser estrutura, o discurso é uma materialidade linguística que possibilita esse encontro, ou seja, o acontecimento discursivo só é possível porque há uma estrutura que o possibilita e que, também, é responsável pelo efeito de sentido produzido (os enunciados têm uma forma material que produz efeito de sentido).
\end{abstract}

Posto desta forma, compreende-se que o discurso é tanto acontecimento quanto estrutura. A terceira fase também é marcada pela desconstrução/ desestabilização da maquinaria do discurso, pelo fortalecimento de uma materialidade discursiva que se baseia no real da tríade - língua, inconsciente e história -, pela heterogeneidade constitutiva do discurso, em que a dispersão e o atravessamento encontram-se presentes na rede de sentidos; o interdiscurso em si é heterogêneo e formado por essa dispersão (BRITO, 2012). Segundo Santos (2013, p.221-222), ele "[...] regula os deslocamentos das fronteiras das FDs, possibilitando apagamentos, esquecimentos, paráfrases, lembranças, degenerações, deturpações dos elementos que o possibilitam".

Ao falar em esquecimento, Pêcheux 0 classifica em dois tipos: 0 esquecimento número um (esquecimento ideológico), da instância do inconsciente, onde temos a ilusão de ser a origem do dizer, os primeiros a dizer algo que, na verdade, já foi dito em outro lugar, e o esquecimento número dois (esquecimento enunciativo), onde acreditamos que só podemos dizer algo de uma maneira e não de outra (ORLANDI, 2012). O conceito de paráfrase, por sua vez, remete-nos às possibilidades das formulações a partir de um já-dito, enquanto a polissemia lida com as possibilidades do diferente, das rupturas, dos deslocamentos no processo de significação. A linguagem encontra-se sob a égide da tensão entre paráfrase (estabilização) e polissemia (equívoco) (ORLANDI, 2012). 
Cumpre-nos destacar ainda outro conceito importante para o presente trabalho, o de Formação Imaginária, entendido como as projeções da imagem que o sujeito faz quanto a si e a seu interlocutor. Para Ferreira (2005b, p.16),

as formações imaginárias se manifestam, no processo discursivo, através da antecipação, das relações de força e de sentido. Na antecipação, o emissor projeta uma representação imaginária do receptor e, a partir dela, estabelece suas estratégias discursivas. O lugar de onde fala o sujeito determina as relações de força no discurso, enquanto as relações de sentido pressupõem que não há discurso que não se relacione com outros [...] As formações imaginárias, enquanto mecanismos de funcionamento discursivo, não dizem respeito a sujeitos físicos ou lugares empíricos, mas às imagens resultantes de suas projeções.

Diante dos conceitos da $A D$ aqui retomados e outros que serão mobilizados neste estudo, esperamos abordar o nosso dispositivo analítico partindo da consideração de discurso enquanto campo movente, múltiplo, de deslizamentos, de apagamentos, de rupturas, onde se observa a correlação história, inconsciente e ideologia.

Nesse sentido, acreditamos que a $A D$ de Linha Francesa será de grande utilidade em nossa busca investigativa quanto ao entendimento, segundo a concepção dos gestores e coordenadores dos Programas de Controle da Tuberculose - estadual e municipal - e do secretário de saúde de Porto Alegre, dos aspectos do planejamento, aqui auxiliados pelo PES de Matus, e da transferência da política do TDO, compreendida a partir do modelo de Bissell, Lee e Freeman, (2011).

Ressaltamos que, embora compreendamos que tanto os modelos utilizados para o planejamento como para a transferência da política podem ser tomados enquanto protótipos do que Pêcheux denominou Universo Logicamente Estabilizado - que busca a homogeneidade lógica e a proibição da interpretação, trabalha com evidências lógico-práticas e com a simplificação unívoca, supondo que os sujeitos sabem do que é falado (PÊCHEUX, 2012) -, partimos da premissa de que eles constituem subsídios teóricos fundamentais ao entendimento dos elementos envolvidos em tais processos. Dessa forma, vamos tomá-los em nossa análise com 
tal função referencial, todavia, considerando os pressupostos da $A D$ de linha francesa e as múltiplas possibilidades de interpretação do discurso. 
4. MATERIAL E MÉTODOS 


\subsection{CONSIDERAÇÕES INICIAIS}

Este estudo é parte integrante de um projeto multicêntrico de pesquisa denominado "Avaliação da Transferência de Políticas de Saúde do Tratamento Diretamente Observado em alguns municípios da região Sul, Sudeste, Nordeste e Norte", aprovado e financiado pelo Conselho Nacional de Desenvolvimento Científico e Tecnológico (CNPq) por meio do edital Universal- CNPq $N \cong 14 / 2011$. Encontra-se ainda vinculado ao Projeto Produtividade "Gestão e organização dos serviços de saúde e atuação da enfermagem no controle da tuberculose na atenção básica", subsidiado pela mesma instituição e com vigência de 2011 a 2013.

\subsection{TIPO DE ESTUDO E ABORDAGEM}

Trata-se de estudo de abordagem mista, com componentes quantitativos e qualitativos. De acordo com Evans (2010), todos os estudos relacionados ao campo de transferência de políticas públicas deveriam adotar uma metodologia comparativa, com enfoques mistos, embora poucos o façam. Assim, partimos do entendimento de que tais métodos não são excludentes e sim complementares. $\mathrm{A}$ abordagem qualitativa complementa a quantitativa na medida em que possibilita lançar mão da intuição para um melhor entendimento do objeto de pesquisa (NEVES, 1996). Por este método, o pesquisador busca interpretar os fenômenos e como os sujeitos os significam (DENZIN; LINCOLN, 2011). No presente trabalho, optamos pelo referencial analítico da Análise de Discurso de linha Francesa, mais especificamente a vertente Pecheuxtiana, como dito anteriormente.

$\mathrm{Na}$ abordagem quantitativa utilizamos o modelo de estudo tipo inquérito epidemiológico e os softwares SPSS (versão 22) e o R (versão 3.0.2) para as análises estatísticas. 


\section{.4.3 CENÁRIO DO ESTUDO}

Porto Alegre, capital do Rio Grande do Sul, possui 1.409.351 habitantes, residentes numa área total de 496,682 $\mathrm{km}^{2}$ com densidade demográfica de 2.837,53 habitantes $/ \mathrm{km}^{2}$ (INSTITUTO BRASILEIRO DE GEOGRAFIA E ESTATÍSTICA IBGE, CENSO 2010). O município dispõe de 180 Estratégias de Saúde da Família e 717 Estratégias de Agentes Comunitários da Saúde implantadas, perfazendo uma cobertura populacional de apenas $43,83 \%$ e $29,10 \%$ respectivamente (DEPARTAMENTO DE ATENÇÃO BÁSICA - DAB, dado referente a dezembro de 2014). Em consulta realizada em fevereiro de 2015, verificamos que os centros de saúde e as unidades básicas estavam enumerados em 164 estabelecimentos (CADASTRO NACIONAL DE ESTABELECIMENTOS DE SAÚDE - CNES, 2015). A capital gaúcha encontra-se dividida em oito Gerências Distritais - GD (com base no Orçamento Participativo Municipal - PIZZINATO et al., 2012): a GD Centro; GD Noroeste/Navegantes/Humaitá/Ilha; GD Norte/Eixo Baltazar; GD Leste/Nordeste; GD Glória/Cruzeiro/Cristal; GD Sul/Centro-Sul; GD Restinga/Extremo Sul e a GD Partenon/Lomba do Pinheiro (PREFEITURA MUNICIPAL DE PORTO ALEGRE, 2010).

A tuberculose e o seu histórico de vigilância em Porto Alegre têm, dentre outros marcos, o ano de 1999, em que foram iniciadas as atividades da Coordenadoria Geral de Vigilância em Saúde (CGVS) no tema e efetivada a implantação do Sistema de Informação de Agravos de Notificação (SINAN) nas cinco unidades ambulatoriais que integravam, até então, o Programa de Controle da Tuberculose (PCT) no município, sendo elas o Centro de Saúde Navegantes, Centro de Saúde Modelo, Centro de Saúde Vila dos Comerciários (setor 15), Unidade Sanitária Restinga Velha e o Centro de Saúde Murialdo (JOBIM; WIEDERKEHR, 2000).

Em 2007, Porto Alegre contava ainda com apenas 19 Unidades de Saúde que prestavam atendimento aos casos de TB, algumas delas com grau de complexidade Il (casos de complexidade definida como mediana - unidades dispõem de baciloscopia de escarro, radiologia, teste tuberculínico, medicamentos para efeitos adversos/retratamentos e formas de encaminhamento da cultura do Bacilo de Koch; 
podem atuar como referência e contrarreferência para unidades de complexidade I, ou seja, as que lidam com procedimentos tidos como simplificados), e outras com grau III (cobertura de todos os procedimentos necessários para a operacionalização das políticas vinculadas ao PCT; inserem-se nesse âmbito o Centro de Referência Estadual e outros Centros de Referência da rede ambulatorial) (MICHELETTI, 2008).

Fomos notificados, em abril de 2014 e em janeiro de 2015, da existência de seis Centros de Referência em Tuberculose (CRTB) em Porto Alegre: o CRTB Centro, o CRTB Noroeste-Humaitá-Navegante-Ilhas (NHNI), o CRTB Leste-Nordeste (LENO), o CRTB Glória-Cruzeiro-Cristal (GCC), o CRTB Restinga e o CRTB Partenon-Lomba do Pinheiro (PLP). Conforme se pode observar, existem ainda traços centralizadores no sistema vinculados ao tratamento da doença, o que há algum tempo persiste como modelo estruturante da política no município. Vale ressaltar, porém, que em 2012 iniciou-se um processo de descentralização do atendimento, diagnóstico e tratamento da TB para as unidades básicas de saúde vinculadas à Secretaria Municipal de Saúde (SMS) do município, mas tal modelo organizativo encontra-se ainda em fase de implementação.

Por essa razão, optamos por desenvolver a pesquisa nas Unidades de Saúde Comunitária do Grupo Hospitalar Conceição, instituição federal atuante em Porto Alegre que goza de certa autonomia e protocolos próprios já estabelecidos para o direcionamento da atenção à TB nos territórios sob sua responsabilidade. Entendemos que a qualidade da pesquisa poderia ser comprometida se optássemos por incluir as unidades vinculadas à SMS, onde a descentralização das ações da TB não se encontra completamente efetivada, fato que se aplica também à política do TDO.

\subsubsection{CARACTERIZAÇÃO DO LOCAL DE ESTUDO}

O Grupo Hospitalar Conceição, na definição de Possa (2007, p.51), "é o maior complexo de saúde do sul do país com responsabilidade assistencial de parcela significativa da população da região metropolitana e referência em algumas áreas para todo o estado do Rio Grande do Sul", sendo composto, dentre outras 
unidades, pelo Hospital Nossa Senhora da Conceição, o Hospital Criança Conceição, o Serviço de Saúde Comunitária, o Hospital Cristo Redentor S.A. e o Hospital Fêmina. Destinado à prestação de serviços ao SUS, o GHC está vinculado ao Ministério da Saúde desde 1975, o que lhe confere autonomia e poder decisório sobre organização de serviços e operacionalização de políticas deste ente, independentemente do posicionamento, aceitação ou concordância dos gestores locais. Seu Serviço de Saúde Comunitária teve início na década de 80 e conta atualmente com 12 Unidades da APS localizadas na região norte de Porto Alegre (POSSA, 2007).

As atividades relacionadas à tuberculose iniciaram-se no Serviço de Saúde Comunitária em 2002, por meio da descentralização do atendimento em quatro unidades de saúde. Já em 2007, todas as demais unidades atendiam aos preceitos enfatizados pelo PCT, sendo o TDO o último componente do DOTS a ter sido implantado (abril de 2009). As Unidades de Saúde Comunitária têm trabalhado sempre em parceria com o Serviço de Pneumologia do Hospital Nossa Senhora Conceição, bem como com os Serviços de Referência do município de Porto Alegre (FERREIRA; GLASENAPP; FLORES, 2011).

$\mathrm{Na}$ perspectiva da linha de cuidado da tuberculose no GHC, observam-se diversas possibilidades de referência e contrarreferência de pacientes, em que as Unidades da APS compartilham com as demais instituições parceiras a condução e o acompanhamento do caso de TB. Assim, a Unidade de Saúde Primária torna-se responsável pela detecção dos casos novos (TB pulmonar e extrapulmonar), pelos retratamentos (TB pulmonar), pela realização da baciloscopia, pela busca de sintomáticos respiratórios, pelo tratamento com esquema básico etc. As unidades hospitalares e os Centros de Referência do município encarregam-se dos casos mais graves e com percurso desfavorável, daqueles com necessidade de tratamento medicamentoso com esquema especial, de co-infecção TB e Vírus da Imunodeficiência Humana (HIV), dentre outros, e o Hospital Sanatório Partenon se ocupa dos casos de tuberculose multirresistente (FERREIRA et al., 2013). O usuário movimenta-se nessa rede de cuidado conforme o quadro clínico que apresenta.

Para a realização do TDO, o GHC estipulou como grupo prioritário os pacientes etilistas, os moradores de rua, os encarcerados e institucionalizados 
(asilos, manicômios), os desprovidos de vínculos empregatícios, os portadores do vírus HIV, os casos de drogadição e de retratamentos pós-abandono. O cumprimento do tratamento supervisionado pelos profissionais de saúde deve obedecer à frequência de cinco observações semanais (dois meses iniciais), seguida de três a duas observações semanais até finalizar o tratamento (em pacientes com TB pulmonar)(FERREIRA; GLASENAPP; FLORES, 2011).

As unidades do Serviço de Saúde Comunitária do GHC trabalham numa perspectiva de metas definidas pelo Ministério da Saúde, que inclui a investigação dos sintomáticos respiratórios (de 70 a $80 \%$ ), a realização de diagnóstico de no mínimo $90 \%$ dos casos esperados, o alcance da cura de ao menos $85 \%$ dos casos confirmados, a redução das taxas de abandono medicamentoso para até 10\% e o aumento dos casos de TB diagnosticados pelas Unidades da APS do GHC para um percentual de 70\% (FERREIRA; GLASENAPP; FLORES, 2011).

Conforme já mencionado, as 12 Unidades da APS do Serviço de Saúde Comunitária do GHC constituíram-se o local de investigação deste estudo e seus profissionais de saúde (médicos, enfermeiros, técnicos e auxiliares de enfermagem), os sujeitos desta pesquisa.

\subsection{FONTE DE COLETA DE DADOS}

Os dados foram coletados a partir de fontes primárias (entrevistas semidirigidas e a aplicação do questionário validado intitulado "Avaliação da Transferência de Políticas - Inovação, Informação e Conhecimento em Tuberculose" - ATP-IINFOC-TB - ANEXO A) e fontes secundárias de informação (DAB; IBGE; CNES; SINAN; relatórios, boletins epidemiológicos, protocolos dos serviços locais, dentre outros).

\subsection{SELEÇÃO DOS ENTREVISTADOS}




\subsubsection{SUJEITOS DA PESQUISA E CRITÉRIO DE INCLUSÃO}

As entrevistas semidirigidas foram realizadas com um total de cinco sujeitos: dois coordenadores do PCT (estadual e municipal), dois coordenadores do Programa de Controle e Monitoramento da Tuberculose do GHC e o secretário municipal de saúde de Porto Alegre. Já o questionário ATP-IINFOC-TB foi aplicado para uma população de referência composta por todos os profissionais de saúde, abrangendo médicos, enfermeiros e técnicos/auxiliares de enfermagem vinculados às 12 Unidades de Saúde Comunitária do GHC.

Foram respeitados os critérios de inclusão do estudo, tais como a inserção apenas dos sujeitos que consentiram com a participação voluntária na pesquisa e que assinaram o Termo de Consentimento Livre e Esclarecido (TCLE) (ANEXOS B e C), bem como dos profissionais de saúde que tivessem sido treinados e/ou que trabalhassem há pelo menos seis meses com o Tratamento Diretamente Observado da TB em suas unidades. Excluíram-se automaticamente os profissionais em férias ou afastamento por licença-saúde quando da coleta de dados.

A estimativa do número total de profissionais a serem entrevistados foi realizada com base na lista de recursos humanos por unidade de saúde, fornecida pela Secretaria de Apoio Administrativo do Serviço de Saúde Comunitária do GHC. Partimos de uma estimativa inicial de 146 profissionais de saúde, já excluídos aqueles que participaram do processo de validação do questionário, conforme será esclarecido na subseção "Instrumentos de coleta de dados" apresentada na sequência. Do total estimado, 109 profissionais de saúde satisfizeram o critério de inclusão da pesquisa.

\subsubsection{INSTRUMENTOS DE COLETA DE DADOS}

O questionário ATP-IINFOC-TB constitui-se no instrumento oficial de pesquisa do projeto multicêntrico ao qual este estudo encontra-se vinculado. Trata-se de um questionário que foi submetido ao processo de validação, tendo como diretrizes 
técnicas os projetos, estudos e instrumentos validados desenvolvidos pelo DISABKIDS, grupo europeu de pesquisa que tem como principal foco de atenção a análise da qualidade de vida de crianças com diferentes graus de deficiências (BULLINGER et al., 2002). Nesta etapa, contamos com a orientação e assessoria estatística da representante do Grupo DISABKIDS da América Latina e México.

O processo de validação foi composto por três etapas principais: 1) a revisão/refinamento da literatura referente ao tema de interesse, que funcionou como embasamento teórico-conceitual para as discussões do grupo de pesquisa e elaboração do questionário; 2) a etapa de validação semântica do instrumento préconstruído, cujo objetivo consiste em torná-lo compreensível para todos os sujeitos da pesquisa (PASQUALI, 1999), bem como tornar sua linguagem mais acessível e de fácil entendimento, evitando-se múltiplas interpretações de um mesmo item pelos diferentes participantes (CUNHA; SILVA, 2009) e 3) a validação de construto, com a análise fatorial - "[...] para definir a dimensionalidade do instrumento" (PASQUALI, 1999, p.60) -, a análise empírica e da consistência interna dos itens do questionário (PASQUALI, 1999).

Para a revisão da literatura foram utilizadas palavras-chave ("Information", "Knowledge", "Innovation", "Policy Transfer", "Public Health" e "Management of Knowledge") isoladas ou combinadas entre si nos idiomas inglês, espanhol e português. As buscas ocorreram nas bases de dados do CINAHL e Medline via Pubmed e contemplaram estudos publicados do período de 2000 a 2012 . Foi obtido um total de 105 artigos de interesse, os quais foram retidos para análise do texto completo pelo grupo de pesquisa. Vários encontros e reuniões sucederam-se após o refinamento literário, com o propósito de aprimoramento e elaboração do instrumento da pesquisa.

O questionário foi inicialmente estruturado com 49 itens distribuídos entre três dimensões de abordagem (Informação, Conhecimento e Inovação). A escala de Likert modificada foi escolhida para o julgamento dos itens pelos sujeitos da pesquisa, com opções que variaram do "discordo totalmente" ao "concordo totalmente" (discordo totalmente; discordo; não concordo nem discordo; concordo; concordo totalmente, não se aplica). 
$\mathrm{Na}$ validação semântica, esse questionário inicial foi aplicado a 24 profissionais de saúde (médicos, enfermeiros, técnicos e auxiliares de enfermagem) nos quatro cenários da pesquisa multicêntrica, sendo seis deles pertencentes à Unidade de Saúde Divina Providência do GHC, em Porto Alegre. Nesta etapa, além do questionário, os sujeitos foram convidados a preencher formulários de impressões gerais e específicas sobre o instrumento de pesquisa e responder às seguintes questões: Você gostaria de mudar alguma coisa no questionário? Você gostaria de acrescentar alguma coisa no questionário? Teve alguma questão que você não quis responder? Se sim, por quê?

O questionário sofreu algumas modificações em decorrência das análises e resultados obtidos com a validação semântica. O número de itens foi reduzido de 49 para 47 e a escala de Likert readaptada, agora com as seguintes opções: discordo; discordo parcialmente; indiferente; concordo parcialmente; concordo; não se aplica.

Em seguida, desenvolveu-se a etapa de validação de construto, com a reaplicação do questionário para 101 profissionais, dos quais 20 pertenciam a Porto Alegre (Unidade de Saúde Conceição). Após as análises estatísticas, o questionário assumiu sua estrutura final (ANEXO A), com 39 itens distribuídos nas dimensões "Informação" (nove itens), "Conhecimento" (10 itens) e "Inovação" (20 itens), que foram escolhidas enquanto subsídio teórico que perpassa o tema de transferência de políticas públicas.

Ressaltamos que o instrumento ATP-IINFOC-TB não foi elaborado com intuito de investigar qual profissional dispõe de mais informação e conhecimento ou ainda qual inova mais a sua prática. Trata-se de instrumento que aborda processos e elementos (fluxo da informação, frequência, tipo de veiculação, atores envolvidos, tipo de material utilizado, estratégias de trabalho, etc.) relacionados à transferência da política do TDO sob a perspectiva de cada uma das dimensões em suas singularidades.

Uma vez realizadas as considerações do instrumento da pesquisa quantitativa, cabe-nos discorrer sobre a vertente qualitativa e os roteiros de entrevistas empregados. Discriminamos três roteiros no presente trabalho, um deles direcionado ao secretário municipal de saúde, outro destinado aos coordenadores dos programas de tuberculose (ambos com foco na transferência da política) 
(ANEXOS D e E) e um terceiro endereçado tanto aos coordenadores quanto ao secretário de saúde, este último com abordagem prioritária do planejamento do processo de transferência da política (ANEXO F). Uma vez elaborados, todos os roteiros de entrevistas passaram por processo de avaliação de especialistas na área de Análise do Discurso, com vistas ao seu aperfeiçoamento e qualificação.

\subsubsection{PRODUÇÃO DO MATERIAL DE ANÁLISE}

$\mathrm{Na}$ abordagem qualitativa, foram utilizadas entrevistas semidirigidas e audiogravadas com os coordenadores dos programas de controle da tuberculose e o secretário municipal de Saúde de Porto Alegre. Tais entrevistas ocorreram entre os meses de outubro de 2013 e janeiro de 2014. Na ocasião, a doutoranda deslocou-se até o local de serviço dos sujeitos da pesquisa e utilizou-se de um diário de campo para registrar impressões adicionais sobre o ambiente de trabalho e possíveis interações entre os diferentes profissionais do setor. Os áudios das entrevistas foram transcritos e posteriormente analisados, juntamente com as observações do diário de campo e das condições de produção do discurso dos entrevistados.

Ressalta-se que a opção pelo enfoque semidirigido ou semiestruturado da entrevista deve-se ao fato de este permitir ao pesquisador certo direcionamento, com vistas ao atendimento dos objetivos propostos na pesquisa. Esse método parte de um roteiro inicial preestabelecido, que pode ser ampliado pela inserção de novos questionamentos (SILVA; CAMARGO; PADILHA, 2011).

$\mathrm{Na}$ abordagem quantitativa, os questionários foram aplicados aos profissionais de saúde em abril e maio de 2014. Elaborou-se uma planilha eletrônica e banco de dados com o auxílio do Microsoft Excel (versão 2010) e do software estatístico SPSS versão 22. Devido às peculiaridades de organização institucional do GHC, foi solicitado aos profissionais de saúde que considerassem, no instrumento de pesquisa, o termo "coordenação do PCT" como sendo a coordenação imediata do serviço. 


\subsection{DISPOSITIVOS E PROCEDIMENTOS DE ANÁLISE}

A Beta regressão, a descrição das frequências das variáveis e a distribuição da média, mediana e desvio-padrão foram alguns dispositivos estatísticos utilizados para a análise dos dados obtidos com a aplicação do instrumento ATP-IINFOC-TB. No que se refere aos dados relacionados à transferência da política do TDO, foram criados para sua análise a média padronizada e os escores padronizados, calculados pelas respectivas expressões:

$$
\begin{gathered}
\text { Média }{ }_{\text {Padronizada }}=\frac{\text { Media }- \text { Minimo }}{\text { Máximo }- \text { Mínimo }} \\
\text { Escore }_{\text {Padronizado }}=\frac{\text { Media }- \text { Minimo }}{\text { Máximo }- \text { Mínimo }} \times 100
\end{gathered}
$$

Os valores mínimo e máximo são representados por 1 e 5, respectivamente, e a média, um valor entre 1 e 5 , de tal forma que a Média Padronizada é um valor compreendido entre o intervalo 0 e 1 . Já o Escore Padronizado corresponde à média padronizada multiplicada por 100 , sendo, portanto, fornecido em percentual. Para a análise do escore padronizado em relação à escala de Likert adotamos a seguinte correlação dos resultados: discordo (0\%), discordo parcialmente (25\%), indiferente (50\%); concordo parcialmente (75\%); concordo (100\%).

Com relação à modelagem de dados em um intervalo $(0,1)$, Ferrari e Cribari Neto (2004) propuseram o modelo de regressão Beta, destacado pela flexibilidade da distribuição, que é a base desse modelo. Conforme se observa, a distribuição pode assumir uma variedade de formas e, dependendo dos valores dos parâmetros, ela pode ser assimétrica à direita, à esquerda, centralizada ou uniforme (CRIBARINETTO; ZEILEIS, 2010). 
Nesse modelo, os parâmetros do modelo são interpretados em termos da média $(\mu)$ e há a vantagem adicional de acomodar assimetria e heterocedasticidade (variância não constante). A função densidade de probabilidade é dada por:

$$
f(y ; \mu, \phi)=\frac{\Gamma(\phi)}{\Gamma(\mu \phi) \Gamma((1-\mu) \phi)} y^{\mu \phi-1}(1-y)^{(1-\mu) \phi-1}
$$

com $0<\mathrm{y}<1,0<\mu<1$ e $\phi>0$. Onde $\mu$ representa a média e $\phi$ é conhecido como o parâmetro de precisão. Escreve-se que $y \sim \beta(\mu, \phi)$ com valor esperado $E(y)=\mu$ e Variância $\operatorname{Var}(y)=\mu(1-\mu) /(1+\phi)$. Para uma dada média fixa tem-se que quanto maior a precisão menor a Variância e vice-versa.

Seja $y_{1}, \ldots, y_{n}$ uma amostra aleatória de uma distribuição Beta, $y_{i} \sim \beta\left(\mu_{i}, \phi\right)$. O Modelo de Regressão Beta é definido como:

$$
g\left(\mu_{i}\right)=x_{i}^{T} \beta
$$

onde $\beta$ denota o conjunto de parâmetros desconhecidos, $x_{i}$ é o vetor de variáveis independentes e $\mathrm{g}($ ) é a função de ligação que relaciona a média com as covariáveis. Uma extensão do modelo de regressão foi introduzida por Smithson and Verkuilen (2006) no sentido de também permitir um modelo de regressão para o parâmetro de precisão.

Nessa abordagem, tem-se que $y_{i} \sim \beta\left(\mu_{i}, \phi_{i}\right)$ e o Modelo de Regressão Beta estendido é definido como:

$$
\begin{aligned}
& g\left(\mu_{i}\right)=x_{i}^{T} \beta \\
& h\left(\phi_{i}\right)=z_{i}^{T} \gamma
\end{aligned}
$$


onde $\beta$ e $y$ denotam respectivamente o conjunto de parâmetros desconhecidos para a média e a precisão, $x_{i}$ e $z_{i}$ são os vetores de variáveis independentes respectivos para $\mu$ e $\varphi, g()$ e $h()$ são as funções de ligação que relacionam respectivamente a média e a precisão com os seus respectivos conjuntos de covariáveis. Estas não precisam ser necessariamente as mesmas para a média e a precisão.

Como medidas de diagnóstico do modelo foram utilizados os resíduos do modelo, a distância de Cook e os valores da matriz de pontos de Alavanca (conhecida como matriz H). A distância de Cook é uma medida de influência que mede o efeito na estimativa dos parâmetros devido à retirada de um determinado ponto do conjunto dados. O cálculo é feito para cada ponto do banco de dados. Os pontos mais distantes (maiores) são os considerados mais influentes. A matriz H verifica qual é a influência que o valor observado tem sobre o respectivo valor ajustado do modelo.

Um valor é considerado com um alto resíduo quando apresenta um valor absoluto (em módulo) superior a 3. Já um ponto é considerado influente quando o valor da matriz de pontos de Alavanca é maior do que $2^{*} \mathrm{p} / \mathrm{n}$ (PAULA, 2010), onde "p" é o número de parâmetros do modelo ajustado e " $n$ " é o número de observações do banco de dados.

A variável dependente foi a média padronizada para a qual foi assumida a distribuição Beta, e as variáveis independentes utilizadas foram os Domínios com 3 categorias (Informação, Conhecimento e Inovação) e Categoria profissional com 4 categorias (Médico, Enfermeiro, Técnico de Enfermagem e Auxiliar de Enfermagem).

Nos ajustes dos modelos foram testadas as inserções individuais e conjunta das variáveis Domínios e Categoria Profissional no modelo de regressão beta padrão, e também foi testado o ajuste do modelo de regressão beta estendido com as mesmas variáveis. Em todos os modelos foi testado ainda o teste de normalidade para os resíduos com o intuito de verificar se o modelo ajustado conseguiu ajustar adequadamente os dados.

A partir do modelo escolhido foram calculados os valores preditos médios da média padronizada para as categorias das variáveis presentes e também a variabilidade associada a cada uma delas. 
Para efetuar os ajustes do modelo de regressão beta foi utilizada a função "betareg", desenvolvida por Cribari-Neto e Zeileis (2010), do programa R versão 3.0.2. Em todas as análises foi adotado o nível de significância de $5 \%$ (alfa = 0.05).

No plano qualitativo da pesquisa, após transcrição das entrevistas, organizouse um corpus de pesquisa composto pelos recortes de sequências discursivas do material empírico bruto e pelas análises das condições de produção do discurso dos entrevistados. Esse movimento inicial de delineamento e constituição do corpus abriu precedentes para que pudéssemos prosseguir com os procedimentos de análise da AD de Linha Francesa, descritos por Orlandi (2012) como sendo um percurso de três etapas:

a) A passagem da superfície linguística para o objeto discursivo, também conhecido como processo de-superficialização. Nessa etapa, considera-se que o corpus sofreu um tratamento inicial por meio de uma análise superficial e busca-se trabalhar com a materialidade linguística (como se diz, quem diz, o que é dito, as circunstâncias de enunciação etc.) e com o rompimento da ilusão do esquecimento número 2.

b) A passagem do objeto discursivo para a formação discursiva: enfoca-se a formação das famílias parafrásticas, sua relação com o dizer (o que foi dito, o que não foi dito, e o que poderia ser dito), o delineamento das formações discursivas e afiliações às redes de sentido, que influenciará no processo de significação do/pelo sujeito de "x" enquanto "x" e não "y".

c) A passagem do processo discursivo para a formação ideológica: analisa-se a correlação entre as formações discursivas, as relações de sentido, o processo de significação, os efeitos metafóricos e a formação ideológica.

Há que se considerar ainda, no processo analítico, a inter-relação entre descrição e interpretação, tomadas como um batimento, um pulsar contínuo. Não há processo descritivo sem uma interpretação vinculada a ele e, por isso, faz-se importante a existência de dispositivos teóricos que intervenham na relação do analista com o objeto analisado, posicionando-o no espaço entre descrição e interpretação. São múltiplas as possibilidades de interpretação de um corpus de 
pesquisa, que pode ser modificado a cada (re) leitura que fazemos e em relação ao ponto de vista de quem o analisa, aos objetivos do trabalho e à pergunta que o organiza (ORLANDI, 2012). Nesse sentido, pode-se dizer que a metáfora, a paráfrase, a polissemia, a hesitação, o silenciamento, foram alguns dentre outros dispositivos teórico-analíticos que mobilizamos em nosso percurso interpretativo relacionado ao discurso dos coordenadores e gestores entrevistados.

\subsection{ASPECTOS ÉTICOS DA PESQUISA}

Em consonância com as exigências da Declaração de Helsinque, o presente trabalho foi submetido à avaliação e aprovação de Comitês de Ética da Pesquisa (CEPs) (ANEXOS G, $\mathrm{H}$ e I). Nesse sentido, podemos enumerar três CEPs que tiveram participação efetiva nesta etapa: o da Secretaria Municipal de Saúde de Porto Alegre (Processo №. 001.008442.12.6, aprovado em 27 de março de 2012), o do Grupo Hospitalar Conceição (CAAE: 01649012.9.0000.5530, aprovado em 12 de julho de 2012) e o CEP da Escola de Enfermagem de Ribeirão Preto da Universidade de São Paulo (EERP/USP). Nessa oportunidade, o estudo foi aprovado enquanto subprojeto do multicêntrico "Avaliação da Transferência de Políticas de Saúde do Tratamento Diretamente Observado em alguns municípios da região Sul, Sudeste, Nordeste e Norte" (CAAE 01197312.3.0000.5393, datado de 02 de outubro de 2013), conforme já descrito.

Foram obtidas as autorizações para a coleta de dados e entrevistas (ANEXOS $\mathrm{J}, \mathrm{K} \mathrm{e} \mathrm{L}$ ), as quais foram realizadas mediante assinatura do TCLE, com garantia de anonimato e sigilo em respeito aos preceitos éticos da Resolução no 466/12 do Conselho Nacional de Saúde.

\subsection{FINANCIAMENTO DA PESQUISA}


O CNPq foi a principal agência de fomento e financiamento deste estudo, que dispôs também de auxílio financeiro proveniente de outras instituições, visando subsidiar pesquisas paralelas relacionadas à TB desenvolvidas durante a elaboração deste trabalho. Nesse sentido, cabe-nos destacar a colaboração do Banco Santander e da Pró-Reitoria de Pós-Graduação da Universidade de São Paulo (PRPG - USP), que possibilitaram a realização de um curso de revisão sistemática da literatura na Inglaterra (Universidade de Nottingham) e o desenvolvimento do protocolo e da própria revisão sistemática que foi inserida no presente trabalho, conforme mencionado em seção prévia. 
A análise foi estruturada em seções de conteúdo qualitativo e quantitativo, com vistas a facilitar o entendimento. Iniciaremos pelo enfoque qualitativo, mais especificamente com o tema de transferência da política do TDO, seguido do planejamento e posteriormente das análises quantitativas. Antes, contudo, tratemos das condições de produção do discurso.

\subsection{DO CONTEXTO IMEDIATO AO CONTEXTO SÓCIO-HISTÓRICO DO DISCURSO DA TUBERCULOSE}

Partimos do entendimento de condições de produção do discurso enquanto circunstâncias de enunciação (contexto imediato) e o contexto sócio-históricoideológico (sentido amplo), como dito previamente.

Assim, cumpre-nos compartilhar peculiaridades acerca do contexto imediato dos coordenadores e gestores que podem ter refletido em seus discursos. Listamos, inicialmente, os elementos da instância do ambiente de trabalho que foram registrados no momento da entrevista, tais como as interrupções por colegas e com propósito de atender ao telefone; a sobrecarga de trabalho e preocupações outras que pressionavam os entrevistados, colocando-os em luta constante contra o relógio; a disposição espacial das mesas e assentos (organizados em ambientes compartilhados, em alguns casos), que pode ter influenciado suas respostas diante da proximidade de terceiros, e o barulho, principalmente nestes ambientes compartilhados.

Pensamos ainda na instância da formulação do discurso. Nesse contexto, ressaltamos a interferência das formações imaginárias de posição e poder na hierarquia constitutiva das relações de trabalho, ou seja, falamos de coordenadores e gestores que ocupam posições de comando, autoridade e supremacia na relação de força com os seus comandados. Essa tensão constitutiva do cargo, das relações de trabalho, os aspectos decorrentes da posição que se ocupa e do poder inerente a ela se refletem também nos discursos em voga. 
Com relação ao contexto sócio-histórico da tuberculose, resgatamos a memória vinculada a sua existência. Sabe-se que a TB é uma doença secular (há indícios de casos em múmias e em ancestrais humanos, o Homo erectus - UJVARI, 2008), tão antiga quanto o estigma que carrega consigo.

Tempos atrás, ser diagnosticado com tuberculose equivalia a uma sentença de morte. Não raro escondia-se do próprio doente o fato de ele ter a doença, ocultando-a também dos familiares, inclusive depois de consumado o óbito do parente contaminado. Há relatos de pessoas que temiam pronunciar o termo "tuberculose", imaginando que tal procedimento culminaria no agravamento do quadro do doente. $O$ fato é que, até recentemente, a tuberculose era semelhante a um câncer sob o ângulo biotipológico e somente com o advento da patologia celular e do microscópio é que se firmou a diferenciação das concepções dessas duas doenças (SONTAG, 1984).

Reconhecida como "moléstia social" desde meados do século passado, a Peste Branca ou Tísica (como era conhecida a TB) devastou por muito tempo a sociedade, estando os tuberculosos, pectários, "fracos do peito" entregues a todo grau de tuberculofobia que desde então vigorava. Tida como uma ameaça às pretensões da sociedade urbano-industrial, a TB teve muitas "soluções" (dentre elas o isolamento físico e social) engendradas pela elite capitalista, no Brasil em particular, aquela pertencente às capitais do Rio de Janeiro e São Paulo. Sem demora, a Tísica foi logo vinculada a países pobres e vista como um risco considerável aos sadios e abastados da sociedade (BERTOLLI FILHO, 2001).

Ainda hoje a tuberculose é uma doença negligenciada, com uma memória histórico-social atrelada ao preconceito e ao estigma e, em nosso país, é concebida como "[...] um problema presente e ficante há longo tempo" (RUFFINO-NETO, 2002, p.51).

Esses agravantes, somados ao grave quadro epidemiológico da TB em Porto Alegre, à dificuldade de realização do TDO, ao momento de reformulação e descentralização da política de atendimento da tuberculose nas unidades da Atenção Primária da prefeitura e às características peculiares de operacionalização e autonomia do GHC são alguns elementos que podem ter condicionado a produção do discurso dos entrevistados. Dessa forma, levando-se em consideração as 
condições de produção anteriormente mencionadas e partindo de uma perspectiva discursiva que se inscreve na FD Atenção Primária à Saúde, passemos às análises.

\subsection{A TRANSFERÊNCIA DA POLÍTICA DO TDO: SEUS ELEMENTOS NA MALHA DA SIGNIFICAÇÃO}

A análise do corpus, obtido das entrevistas dos coordenadores e gestores da TB e do secretário municipal de saúde, permitiu-nos organizar os recortes em três blocos discursivos de interesse e em alusão a alguns elementos do processo de transferência de políticas sugeridos por Bissell, Lee e Freeman (2011), sendo eles: Motivação e tipologia (coercitiva ou voluntária); Contexto (histórico, sociocultural, político e econômico) e a Rede e os atores.

\subsubsection{MOTIVAÇÃO E TIPOLOGIA: COERCITIVA OU VOLUNTÁRIA}

Vários podem ser os fatores motivacionais e razões que levam as pessoas a se inserirem no campo da transferência de política (DOLOWITZ, 2003). Para Bissell, Lee e Freeman (2011), falar em motivação nessa área significa fazer referência a algum lugar existente entre o ser forçado (coercitivo) e à ação voluntária.

Nesse sentido, Dolowitz e Marsh (2003) enfatizam que é quase impossível, com exceção dos casos de domínio estrangeiro direto, haver uma coerção total (de um indivíduo ou país) num contexto de transferência de política. Em geral, o lugar da motivação estará sempre num ponto do que ele denominou "spectrum", cujos limites são representados pelo tipo voluntário de um lado e o coercitivo do outro, e o continuum preenchido por, dentre outros, os subtipos semivoluntário e semicoercitivo. Dificilmente serão alcançados os pontos extremos desse spectrum, já que todos os atores envolvidos no processo agem com mais ou menos racionalidade, sendo praticamente impossível para alguém ser completamente racional ou totalmente irracional nessas circunstâncias. Há que se considerar ainda 
que o afastamento dos pontos extremos implicará, em muitos casos, em necessária "negociação" entre os que transferem a política e aqueles que irão implementá-la.

Sendo assim, analisemos como se manifesta o fator motivacional da transferência do TDO nas sequências discursivas (SD) que se seguem.

Em SD1, o Sujeito 2, quando solicitado a falar sobre a sua experiência na discussão da transferência da política do TDO com outros coordenadores do Programa da Tuberculose, responde o seguinte:

\section{Sequência Discursiva nํ1:}

L.1 "Hum..., em princípio as pessoas sempre perguntam: mas é preciso mesmo?

L.2 o paciente toma tão bem e tal..., então não é assim, a gente sabe que 6

L.3 meses de tratamento é muito complicado, se a gente tiver alguém do serviço

L.4 de saúde responsável por isso é muito melhor. Então é, a gente começa com

L.5 sensibilização, depois a gente começa a cobrar, depois a gente começa a

L.6 rever os livros de registros dos pacientes de tuberculose e pergunta: esse

L.7 paciente era HIV positivo, por que ele não fez TDO?"(Sujeito 2).

A hesitação em sua concepção enunciativo-discursiva é o marco de abertura da SD1, e pode ser observada pelo emprego do "Hum (L.1)", seguida do momento de pausa na atividade discursiva. Nessa interrupção carreada de tensão, o sujeito busca (re)formular, organizar a sua fala, domesticando deslizamentos, vencendo resistências e negociando com seus diversos outros constitutivos; o fenômeno hesitativo enquanto campo das múltiplas possibilidades do dizer, da deriva de sentidos, é também um indício de autoria do sujeito que se propõe a evitar a instalação da dispersão na conversação por meio da adoção de uma unicidade ilusória do seu discurso (NASCIMENTO; CHACON, 2008).

Após a pausa discursiva, o Sujeito 2 busca guiar o interlocutor no fio lógico aparente do seu enunciado. Ele tenta estabelecer um ordenamento temporal ("em 
princípio" - L.1), entretanto, esbarra na falha, no real e na opacidade da língua e deixa nas entrelinhas a continuidade da sequência interrompida: "em princípio as pessoas sempre perguntam: mas é preciso mesmo? O paciente toma tão bem e tal...". Também não se pode afirmar quem o sujeito dessa sentença ("as pessoas") representa, ou seja, quem de fato questiona a necessidade do TDO. Nesse ponto do discurso, abre-se um leque de múltiplas possibilidades, em que podem figurar tanto os profissionais de saúde como os familiares, cuidadores, os próprios coordenadores locais da TB ou ainda todos eles.

Observa-se, num dado momento ("em princípio"), a resistência ao TDO manifestada pelo questionamento ("mas é preciso mesmo?") e enfatizada por meio do conector argumentativo "mas", que reforça o sentido de oposição. Contudo, não se pode afirmar ou refutar a existência dessa resistência num período outro que não "em princípio", ficando a cargo do interlocutor significar os muitos "não-ditos" ditos pela implicitação e pelo silêncio do sujeito (reticências na sentença "O paciente toma tão bem e tal..."). Compreende-se o silêncio enquanto "a matéria significante por excelência, um continuum significante (ORLANDI, 2007, p.29)", que se abre à derivação de sentidos, aos deslizamentos e ressignificações. Já as implicitações configuram um artifício discursivo por meio do qual o sujeito visa manter a ordem vigente, evitar o embate e a refutação direta de suas proposições (LAGAZZI, 1988).

A existência de algum grau de resistência ao TDO, conforme discutida anteriormente, nos leva de certa forma a pensar numa tipologia coercitiva de transferência da política do Tratamento Diretamente Observado da Tuberculose em Porto Alegre. Contudo, é a cobrança ("a gente começa a cobrar" - L.5) empreendida pelo sujeito enquanto coordenador que fortalece esse ponto de vista. Dolowitz e Marsh (1998) esclarecem que a transferência voluntária de uma política é aquela onde há o desejo, a aceitação e a participação ativa dos agentes envolvidos na implementação de mudanças, enquanto a forma coercitiva é caracterizada pela força e imposição da adoção de uma política. Assim, partimos do pressuposto de que a cobrança é um meio coercitivo de instigar o cumprimento de algo pelos sujeitos, sendo desnecessária em contextos de motivação e aceitação voluntária de um propósito. 
O aspecto motivacional do processo de transferência da política do TDO pode também ser observado em SD1 quando o sujeito anuncia sua ação de sensibilização em relação aos profissionais de saúde ("a gente começa com sensibilização"). Embora haja a tentativa de comoção e motivação dos profissionais de saúde por parte do sujeito-coordenador-gestor, percebemos pelo deslizamento e contradição os indícios de comprometimento desse processo em sua fala quando este salta de forma antitética da sensibilização (conotação positiva) para a cobrança (conotação negativa).

O próprio questionamento "esse paciente era HIV positivo, por que ele não fez TDO?” (L.6; L.7) pressupõe a não realização em algum momento do Tratamento Supervisionado pelos profissionais de saúde. Sendo assim, a interrogação passa a corporificar também a cobrança, o que nos leva uma vez mais a pensar em algum grau de coerção na transferência e operacionalização da política. Há que se observar que esse contexto de questionamento abre-se a duas possibilidades, uma em que ele pode remeter a um diálogo com terceiros, provavelmente os profissionais de saúde, e a outra em que ele pode ser tomado como um monólogo do Sujeito 2, que, após rever os livros de registro, questiona consigo mesmo as razões de uma possível quebra na integralidade da assistência e da descontinuidade na prestação de cuidados ao paciente com TB-HIV.

Nessa passagem, é importante observar que os livros de registros (L.6) podem assumir a forma própria do elemento de controle: eles não apenas servem de registro do que é feito ou não, mas dispõem de informações de quem o fez ou deixou de fazer, da hora, do local, do receptor, dentre outras, favorecendo o controle e corroborando a manutenção da ordem lógica estatuída pelo sistema.

Acrescentamos ainda que, se a hesitação é o marco inicial do discurso do Sujeito 2, a tensão o é da "finalização". Aqui, uma vez mais, detemo-nos a analisar o ponto de interrogação (L.7) compreendido agora enquanto materialização linguística do confronto e da assimetria entre a vontade política do coordenador e a dos profissionais de saúde. Fortalecemos esse ponto de vista ao analisarmos novamente a sentença ("esse paciente era HIV positivo, por que ele não fez TDO?" - L.6; L.7). Pode-se observar um efeito de encadeamento automático, em que ter HIV-TB pressupõe necessariamente o Tratamento Diretamente Observado, assim o 
emprego do "por que" e do "não" funcionam não apenas como elementos de contestação, mas esboçam a diferença entre as determinações e as vontades.

Abrimos espaço para abordar também os traços do discurso autoritário (a partir da posição assumida pelo sujeito) caracterizado pela presença de um agente exclusivo do discurso, o exagero, o assujeitamento ao comando. Aquele onde as possibilidades de reversibilidade tendem à nulidade, e a polissemia é reprimida (ORLANDI, 1996a). Nesse sentido, observa-se que o Sujeito 2 deixa pistas da imagem que ele faz sobre a posição de autoridade instituída: os coordenadores/gestores ("a gente") são quem sensibiliza, cobra, revê, em suma, detém o poder que o cargo lhes confere. A própria repetição do termo "a gente" ao longo do trecho selecionado deixa vestígios da lógica de dominação hierárquica nas relações de trabalho. A esse respeito, Lagazzi (1988, p.21) nos diz que:

Essas relações hierarquizadas e autoritárias de comando-obediência, presentes nas mais diversas situações e diferentes contextos sociais, levam as pessoas a se relacionarem dentro de uma esfera de tensão, permeada por direitos e deveres, responsabilidades, cobranças e justificativas.

Quanto à concepção de poder, Machado $2009^{10}$ (apud GAUDENZI; ORTEGA, 2012, p.29), nos diz que, segundo Foucault, este

[...] não pode ser entendido como algo que o indivíduo simplesmente cede ao soberano, mas deve ser compreendido como relação de forças em uma determinada sociedade, em um vínculo prático que une o poder e o objeto do poder. Não haveria, assim, os detentores do poder de um lado e os que se encontram alijados dele do outro, pois o poder entendido desta forma, a rigor, não existe; o que existe são práticas ou relações de poder. O poder, para Foucault, não pode ser localizado em uma única instituição, ou no Estado, pois é determinado por um jogo de saberes que respaldam o fazer da dominação de uns indivíduos sobre outros e, sendo uma relação, está necessariamente em todas as partes.

Para refletir um pouco mais sobre o poder, a tensão constitutiva das relações interpessoais, de forças e de interesses antagônicos e do elemento coercitivo nesse contexto, analisemos a SD2 que se segue. Na ocasião, o Sujeito 3 é questionado

\footnotetext{
${ }^{10}$ MACHADO, R. Foucault, a ciência e o saber. Rio de Janeiro: Jorge Zahar, 2009.
} 
sobre as inovações na política da tuberculose relacionadas à transferência da política do TDO. Embora tenha revelado a existência de algumas inovações, ele interrompe suas explanações para abordar entraves ao processo, destacar a alta rotatividade, bem como a demissão em massa dos profissionais da saúde, colocando-se da seguinte maneira:

\section{Sequência Discursiva no 2:}

L.1 “... imagina o empenho que esses profissionais não têm pra trabalhar né,

L.2 então eles não conseguem se empenhar, porque eles vão ser demitidos

L.3 $\underline{\text { mesmo }}$, eles não vão continuar trabalhando. E isso acaba contaminando os

L.4 demais componentes da equipe que acabam se solidarizando com aqueles

L.5 que vão sair. Então é, é uma situação assim bem complicada de a gente

L.6 conseguir implementar tecnologias novas, pra nós aqui novas antigas né,

L.7 mas pra nós novas" (Sujeito 3).

O que se observa nessa SD é uma inversão na relação de forças: o coordenador/gestor passa a ocupar uma posição desfavorável comparada à do profissional de saúde, subordinado que assume o não fazer em oposição a uma vontade de seu superior. O gatilho desse desequilíbrio no campo vetorial de forças é representado pelo fator demissão, que apresenta uma relação inversamente proporcional ao fator empenho: quanto maior o risco daquele, menor este; uma analogia de causa e efeito.

As sucessivas repetições do operador discursivo "não" (L.1 - L.3) refletem a tensão presente no discurso do sujeito: ele se posiciona como aquele que vincula o risco de demissão à falta de empenho ("imagina o empenho que esses profissionais não têm pra trabalhar né" - L.1), refutando o entendimento dos que veem no risco de demissão um fator motivacional e de estímulo ao aumento da produtividade, com vistas à manutenção do cargo pelo trabalhador, por exemplo. Assim, o "não" passa a demarcar a tensão entre posições diferentes. 
A tensão no discurso é reflexo ainda do grau de dependência da postura do outro. O coordenador/gestor depende do profissional de saúde para alcançar o sucesso na implantação da política, logo, o fato de ele, o profissional, não se empenhar para trabalhar desencadeia instabilidades entre interesses que se opõem ("Então é, é uma situação assim bem complicada de a gente conseguir implementar tecnologia novas" - L.5; L.6). Não obstante a falta de empenho, o sujeito nos chama atenção para a difusão dessa postura entre os trabalhadores ao citar um processo de "contaminação" (L.3) dos demais componentes da equipe.

A menção do termo "contaminar" (L.3) nos remete à influência do domínio saúde no discurso do sujeito. Assim, ao discorrer sobre as ações e o empenho dos profissionais para trabalhar e inovar no campo da tuberculose, ele evoca um termo científico geralmente utilizado com denotação negativa (de disseminação, contágio e veiculação de microrganismos patogênicos) e o contextualiza em sua fala, transferindo sua carga semântica ao discurso em questão. Pêcheux (1975 ${ }^{11}$, apud ORLANDI, 1996b, p.29-30) nos diz que

\begin{abstract}
"[...] o sentido existe exclusivamente nas relações de metáfora (transferência), realizadas em efeitos de substituição, paráfrases, formações de sinônimos, dos quais certa formação discursiva vem a ser historicamente o lugar mais ou menos provisório. Esse lugar - a formação discursiva - de realização da transferência não é, no entanto, a causa, porque o sentido não se engendra a si próprio, ele produz no non-sens".
\end{abstract}

Assim, em "e isso acaba contaminando os demais componentes da equipe que acabam se solidarizando com aqueles que vão sair" (L.3 - L.5), podemos observar não apenas as relações de metáfora (transferência) no discurso do sujeito, mas igualmente o desconforto do coordenador/gestor em relação à postura da falta de empenho que se multiplica entre os profissionais.

A ironia, manifestada no emprego da palavra "solidarizando", também fortalece esse ponto de vista. A incompatibilidade dessa palavra de efeito positivo com relação ao termo "contaminando", de efeito negativo, leva-nos a perceber que o sujeito busca não apenas eufemizar o seu discurso por meio dos deslizamentos e do jogo de atenuação ("solidarizar" é empregado após "contaminar"), mas igualmente

\footnotetext{
${ }^{11}$ PÊCHEUX, M. Vérités de La Palice, Maspero, Paris, 1975.
} 
exprimir seu descontentamento frente à postura dos profissionais de saúde. Assim, a contradição e a extravagância se manifestam para demonstrar o antagonismo e 0 incômodo, afinal, é incomum alguém se solidarizar ao saber que vai ser contaminado ou após ser contaminado. Aí se encontra a ironia.

Outro ponto a ser discutido refere-se à utilização dos verbos no gerúndio (contaminando; solidarizando), o que abre precedentes para se pensar em situação ainda em andamento, algo não finalizado, ou seja, não se pode afirmar que o risco de desemprego, a falta de empenho dos profissionais, a multiplicação desse comportamento entre eles e o antagonismo de interesses em relação ao TDO são agravantes do passado e não mais do momento atual das unidades de saúde em Porto Alegre.

O sujeito deixa pistas, inclusive, sobre o contexto de implantação da política do TDO no município (“Então é, é uma situação assim bem complicada de a gente conseguir implementar tecnologias novas, pra nós aqui novas antigas né, mas pra nós novas..." - L.5 - L.7). Por meio de artifícios antitéticos (tecnologias novas antigas), ele busca demonstrar que, mesmo que o TDO tenha quase 20 anos de existência (como visto anteriormente em outras seções do trabalho), apenas recentemente ele tem sido enfatizado como estratégia de controle da TB em Porto Alegre. Tanto que o GHC o introduziu em seus serviços a partir de 2009, e a descentralização da política para todas as unidades de Atenção Primária (da Prefeitura) encontra-se ainda em andamento.

A SD2 também nos remete à possibilidade de algum grau de coerção na transferência da política do Tratamento Diretamente Observado da tuberculose, seja pelo embate entre o coordenador/gestor e os profissionais de saúde (que nos chama atenção para o antagonismo de interesses), ou pela postura pouco participativa assumida por esses profissionais, fator diretamente vinculado ao campo motivacional.

Por fim, abordamos um terceiro recorte que ratifica o nosso ponto de vista quanto à existência de algum grau de coerção na transferência e operacionalização do TDO em Porto Alegre. Nessa SD, o sujeito destaca não apenas a resistência dos profissionais de saúde em relação à implantação/descentralização da política da tuberculose e do TDO, como também dos gestores. Vejamos: 


\section{Sequência Discursiva nº3:}

L.1 "Também na área gestora, existia não era, era, era um grupo pequeno, tu

L.2 entende? Mas existiam algumas pessoas importantes dentro da área técnica

L.3 a gestão que não acreditavam tanto na política que tava sendo implantada.

L.4 Então isso criava também uma barreira porque as pessoas vão tentar passar

L.5 aquilo para alguém, né, quando elas não acreditam naquilo que tão passando.

L.6 (Sujeito 5).

A resistência quanto à implantação/descentralização e operacionalização da política da tuberculose e do TDO é agora compartilhada entre gestores e trabalhadores da saúde. Se em SD1 e SD2 vemos uma responsabilização dos profissionais de saúde, em SD3 vemos também o envolvimento de outros atores nesse contexto. O Sujeito 5 deixa pistas de que, possivelmente, a insatisfação e a descrença permeiem inclusive o próprio fluxo de transferência da política entre os diferentes níveis governamentais, seja de coordenador/gestor para coordenador/gestor ou destes para os profissionais de saúde, multiplicando o descontentamento, a oposição e comprometendo a qualidade do processo ("Então isso criava também uma barreira porque as pessoas vão tentar passar aquilo para alguém, né, quando elas não acreditam naquilo que tão passando." - L.4; L.5).

Observa-se ainda que, embora em número reduzido ("era um grupo pequeno"), os gestores que resistem às mudanças propostas na política da tuberculose possuem certo grau de influência, podendo ser o diferencial nesse sentido. O sujeito nos convoca a partilhar da sua lógica ("tu entende?"), na qual a dimensão numérica de gestores que resistem não reflete a dimensão de poder que eles exercem ("Mas" - L.2), ou seja, o número reduzido não está atrelado ao ter pouca influência. Ele ainda encontra na repetição do termo "era" a pausa necessária para a (re)formulação do seu discurso, esquivando-se da dispersão e dos deslizamentos ("existia não era, era, era um grupo pequeno, tu entende? Mas existiam algumas pessoas importantes dentro da área técnica" - L.1; L.2). 
Com relação à motivação na transferência e operacionalização do TDO, pode-se observar certo comprometimento e enfraquecimento deste elemento nos processos em questão ("não acreditavam tanto na política que tava sendo implantada" - L.3). Essa perspectiva é reforçada pela negação em oposição ao advérbio de intensidade (tanto), evidenciando a descrença em detrimento da crença na política. Descrença esta que, aliás, assume a condição de uma dentre outras barreiras conjunturais ("Então isso criava também uma barreira..." - L.4).

Dessa forma, diante dos trechos aqui apresentados e das características que despontaram em nossas análises, reforça-se o entendimento de que tenha havido ou que haja algum grau de coerção na transferência e implantação da política do Tratamento Diretamente Observado da tuberculose em Porto Alegre, seja pela resistência (dos profissionais e dos gestores), pela insatisfação ou ainda pela descrença, que se traduzem em inércia e desqualificação do processo. Contudo, ressaltamos nossa impossibilidade de precisar a localização do elemento motivacional no "spectrum" mencionado por Dolowitz e Marsh, ou seja, o quão próximo do semicoercitivo ou do completamente coercitivo. Restringimo-nos apenas a dizer que o componente motivacional esteve/está em algum momento no domínio da coação.

\subsubsection{CONTEXTO SÓCIO-HISTÓRICO, POLÍTICO E CULTURAL}

Os aspectos sócio-históricos, políticos e culturais são alguns dentre muitos elementos contextuais que podem influenciar a política da tuberculose e do TDO, sua implantação, transferência e operacionalização em determinado local.

Como visto anteriormente, a TB é uma doença cuja memória encontra-se atrelada a estigmas e preconceitos e desde há muito assume o posto de grave problema negligenciado na saúde pública de diversos países.

Ribeiro (2006, p.388), por exemplo, ao falar da constituição do povo brasileiro e do Brasil Sulino no século XVIII, destaca o registro de casos da doença já naquela 
época, chamando-nos atenção para as condições precárias que envolviam a população gaúcha e a matuta (de origem açoriana) que se instalou no sul:

\begin{abstract}
Alguns contingentes desses matutos especializaram-se em atividades produtivas novas, surgidas com a ampliação do mercado nacional. Tais são os núcleos de pescadores da costa e de mineiros de carvão do interior. Uns e outros vivem nas mais precárias condições, constituindo, provavelmente, um dos contingentes brasileiros mais vitimados pela tuberculose e pela mortalidade infantil. Também as massas matutas e gaúchas marginalizadas caíram numa cultura da pobreza que acabou por uniformizá-las pela singeleza do seu equipamento de vida e de trabalho [...].
\end{abstract}

Ainda no século XXI, a TB constitui-se em motivo de grande preocupação em algumas regiões do sul do país, principalmente em Porto Alegre, que figura como uma das capitais brasileiras com maior ocorrência da doença. Estudos apontam que, no Rio Grande do Sul, o aumento do número de casos de TB a partir de 1992 e a permanência das altas taxas de incidência a partir de 2000 tenham sido decorrentes da ampliação dos índices de pobreza nos centros urbanos e da disseminação da Síndrome da Imunodeficiência Adquirida (Aids) (FERREIRA; GLASENAPP; FLORES, 2011). Somam-se a esses fatores sociais alguns elementos políticos, tais como a desestruturação administrativa dos serviços de saúde na década de 80 , a desmotivação dos servidores públicos (incluídos os do Programa de Controle da Tuberculose) e o conturbado processo de municipalização da saúde a partir de 1990 (OTT; JARCZEWSKI, 2007).

Para Barcelos (2014), o problema da saúde em Porto Alegre de forma geral passa pela ineficiência do SUS, atrelado à baixa cobertura das ESFs e aos problemas estruturais que acometem a Secretaria da Saúde, como a insuficiência de recursos humanos, baixa remuneração, diminuta adesão aos programas, áreas físicas precárias, aparelhos obsoletos, atendimento demorado e grandes filas de pacientes. Segundo o autor, embora a grande maioria dos municípios brasileiros aplique até mais do que $15 \%$ do seu orçamento na saúde (percentual preconizado pela Emenda Constitucional - EC - no 29), nem sempre os estados colaboram nesse sentido. O Rio Grande do Sul, por exemplo, chegou a ser considerado um dos que menos investem em saúde (próximo de 5\% - dado de março de 2010, enquanto a EC n 29 determina que o percentual seja de 12\%). 
Outro aspecto que pode influenciar no processo de transferência de uma política pública refere-se ao contexto cultural. Quando remontamos ao gauchismo ou à identidade gaúcha, deparamo-nos com uma história rica em batalhas, confrontos, resistência, bravura e um território culturalmente diversificado (um mosaico étnicocultural de imigrantes e nativos)(NETO; BEZZI, 2008).

Para os tradicionalistas, a cultura gaúcha está atrelada à tradição, aos valores gaúchos genuínos, tidos como os "verdadeiros". Os adeptos dessa corrente buscam sempre a afirmação dos seus costumes e da sua identidade cultural, com vistas à distinção do Rio Grande do Sul do resto do Brasil. Trata-se de um grupo de intelectuais que se utilizou do conhecimento para o exercício do poder, com o estabelecimento de normas, diretrizes e manuais sobre a tradição gaúcha. O tradicionalismo, contudo, foi alvo de críticas e protestos por parte de outros grupos, como ocorreu, por exemplo, no Movimento Gaúcho em Defesa da Cultura, enfraquecido a partir de 1983 pelo reduzido número de participantes. Várias têm sido as formas de se pensar a cultura gaúcha e a definição do que ela seja é polêmica e pouco pacífica (OLIVEN, 1985).

Neto e Bezzi (2008) propõem pensá-la em relação a uma dinâmica socioespacial que divide o Rio Grande do Sul em quatro regiões culturais, cada uma delas vinculada a determinados grupos sociais e étnicos, seus valores e suas identidades: na região cultural 1, teríamos as etnias nativa, espanhola, açoriana, africana e portuguesa. Nela encontram-se os primeiros habitantes do estado, a gênese, a matriz cultural do gaúcho típico, do churrasco, do chimarrão, da bombacha e das músicas que representam o "Rio Grande". Destacam-se o apego ao tradicionalismo, à terra e à família; na região cultural 2, teríamos os alemães e as suas marcas da "germanidade", seus costumes típicos adaptados ao estado, numa configuração então teuto-gaúcha; na região cultural 3, os italianos e a conformação ítalo-gaúcha; e na região cultural 4, as etnias mistas com alemães, italianos e, principalmente, poloneses. Somam-se às regiões culturais as denominadas ilhas culturais (alemã, italiana, mista e polonesa).

O que se observa são "[...] 'vários' gaúchos, diferenciados na forma e no que se refere às peculiaridades, mas que também mantêm traços comuns, relativos ao tradicionalismo e ao nativismo" (NETO; BEZZI, 2008, p.136). Para Oliven (1985, 
p.90), o Rio Grande do Sul é um caso "[...] sui generis de regionalismo, como uma experiência separacionista inclusive". Entretanto, o renascimento do interesse pela tradição do estado passa apenas pela vontade de afirmação das "coisas gaúchas" e de uma identidade regional e não mais por interesses separatistas, como na tradição farroupilha.

Todas essas particularidades da cultura gaúcha, sua constituição multiétnica, a influência das batalhas, o caráter de resistência, as tentativas separatistas, a liderança e o destacado papel político de muitos gaúchos (Getúlio Vargas, João Goulart, Leonel Brizola, etc.), a influência do tradicionalismo, o apego à terra, dentre outros fatores que constituem a personalidade do gaúcho, devem ser levados em consideração quando pensamos na transferência do TDO, uma política externa de propositura internacional. Acrescentam-se a esses fatores os de caráter sóciohistórico vinculados à memória da tuberculose, bem como os elementos políticos, e outros, que podem influenciar de forma importante na aceitação, implementação e operacionalização da política no município.

Assim, vejamos a sequência discursiva que se segue. Em SD4, por exemplo, o Sujeito 4, ao ser questionado sobre barreiras no processo de implantação e descentralização do TDO, responde da seguinte maneira:

\section{Sequência Discursiva nำ:}

L.1“... a questão, hum, de baixa cobertura, de não ter como atividade legítima

L.2 $\underline{\text { sua a questão da tuberculose, muito menos o TDO }}$, a alta rotatividade dos,

L.3 hum, profissionais...claro que não se perde aquele conhecimento, uma

L.4 pessoa que vai sair de uma estratégia e pode ir pra outra, mas, hum, fica

L.5 complicado é um complexo hum, de Sísifo que eu digo sempre, quando a

L.6 gente acha que rolou a pedra até o topo da montanha ela rola montanha

L.7 abaixo e a gente vai de novo, então, [risos] é mais ou menos isso que, que

L.8 atrapalha tá." (Sujeito 4). 
Na seção anterior sobre tipologia da transferência, vimos traços de resistência à política do TDO, a falta de empenho, a descrença em sua operacionalização, assim como a manifestação de alguns problemas estruturais que podem ter contribuído nesse sentido, tais como o fator desemprego. Também na SD4, o Sujeito 4 nos apresenta entraves conjunturais que reforçam o ponto de vista dos outros sujeitos discursivos, como a baixa cobertura populacional, a alta rotatividade dos profissionais nas unidades e o descaso com a tuberculose e o TDO. Conforme se observa, as questões relacionadas à doença, seu combate e controle assumem caráter de atividades ilegítimas ("de não ter como atividade legítima sua a questão da tuberculose, muito menos o TDO" - L.1; L2), contudo, não se pode precisar quem é responsabilizado nesse processo, já que a ausência do sujeito na sentença nos abre um leque de possibilidades.

Todavia, essa falta de legitimidade pode ser decorrente não apenas da perpetuação da memória sócio-histórica da doença, atrelada ao estigma, ao preconceito e ao medo, mas também do fato de esta ser uma doença negligenciada (comum principalmente em países subdesenvolvidos e em desenvolvimento SOUZA; VASCONCELOS; 2005), que não dispõe, em muitos serviços de saúde, da qualidade estrutural e organizacional necessária ao seu controle e tratamento (PROTTI et al., 2010), o que acaba desmotivando e limitando aqueles que precisam lidar com ela em sua prática.

Além da memória sócio-histórica da TB, o Sujeito 4 evoca a memória mitológica em seu discurso, aqui exemplificada pelo mito de Sísifo. Conforme nos diz Achard et al. (2010, p.10), para Pêcheux a memória não pode ser concebida

[...] como uma esfera plena, cujas bordas seriam transcendentais históricos e cujo conteúdo seria um sentido homogêneo, acumulado ao modo de um reservatório: é necessariamente um espaço móvel de divisões, de disjunções, de deslocamentos e de retomadas, de conflitos de regularização... Um espaço de desdobramentos, réplicas, polêmicas e contra -discursos.

São justamente as múltiplas possibilidades de interpretação desse campo movente que nos interessam, bem como, neste caso, os implícitos e efeitos de 
metáfora que vinculam o mito de Sísifo ao processo de transferência e implementação da política da TB e do TDO.

Conforme evidenciado pela mitologia Grega, Sísifo recebeu como castigo do deus Zeus a incumbência de empurrar uma pesada pedra até o topo de uma alta montanha, da qual ela sempre rolava de volta, obrigando-o a ter que reiniciar o seu árduo trabalho (ROCHA; GOIS, 2010). Ao se apoiar na mitologia grega, o Sujeito 4 desloca-se da sua FD Atenção Primária a Saúde e, por meio da metáfora, busca significar pela transferência da carga semântica aos elementos discursivos.

Neste percurso interpretativo, tratamos de abordar a própria complexidade do processo de transferência da política do TDO, esboçada inicialmente na forma de treinamento e capacitações de profissionais que são posteriormente remanejados ou demitidos do cargo, culminando na descontinuidade do ciclo teórico-prático no ambiente de trabalho. Em tal contexto, o sujeito não apenas expressa seu descontentamento ("hum, fica complicado" - L.4; L.5), como destaca uma possível repetibilidade da ação pelo uso do adjunto adverbial de frequência "sempre" (L.5): não é a primeira vez que ele fala e chama atenção para este fato.

Com relação à utilização do mito de Sísifo, podemos pensá-lo em três contextos distintos: o que se refere ao processo de transferência do TDO em si, o que se relaciona ao contexto político-institucional de gestão da TB e do TDO e outro vinculado à implementação da política da TB na região. Ressalta-se que os personagens, imagens, figuras e elementos mitológicos (Sísifo, pedra, montanha, outros) constituem-se em efeitos metafóricos de vastas possibilidades interpretativas, sendo assim, restringimo-nos a compreendê-los apenas no domínio das três perspectivas contextuais mencionadas.

Tomando o mito enquanto representação do processo de transferência da política do TDO do coordenador para o profissional de saúde, teríamos na pedra a representação da política do TDO, de conteúdo explicativo bem delineado, pronta para ser "entregue" a terceiros. Já o Sísifo pode ser a encarnação do próprio coordenador, com suas atribuições e responsabilidades de transferência da política, ou seja, a incumbência do rolamento da pedra até o topo da montanha. O alto da montanha pode remeter à esfera governamental onde se situam os profissionais de saúde e onde deve chegar o coordenador (Sísifo). O trajeto até o ápice da 
montanha, enquanto o percurso de planejamento, preparação, análise e avaliação de estratégias de convencimento que permitam ao coordenador divisar com eficácia o alto da montanha. $\mathrm{O}$ advento do rolamento da pedra montanha abaixo nos leva a pensar na não aceitação da política do TDO pelos profissionais de saúde e na resistência em sua operacionalização.

Na segunda perspectiva do mito, contextualizamo-lo em referência ao cenário político-institucional de gestão da política da TB e do TDO. Nesse sentido, foram registrados, em vários momentos das entrevistas, relatos de entraves institucionais que dificultam o trabalho com tais políticas, alguns deles já citados e outros adicionais, como a carência de recursos humanos, inadequabilidade das estruturas físicas e a falta de apoio financeiro.

Assim, se associarmos o discurso do Sujeito 4 ao contexto políticoinstitucional, aos seus entraves, à resistência gestora relatada no bloco anterior, sobre a tipologia e motivação, e pensarmos no mito de Sísifo como metáfora de uma relação entre coordenadores e gestores dos diferentes níveis hierárquicos governamentais, poderíamos compreender a pedra como o produto resultante do trabalho e da ação dos coordenadores/gestores de viés pró-política (Sísifo), o cume da montanha como símbolo de outras instâncias de governo (superiores ou não) de viés oposicionista, o percurso trabalhoso até o topo da montanha como o reflexo dos impeditivos burocráticos, das dificuldades de negociação no processo e da luta para fazer com que a política da TB e do TDO avance. Já o rolamento da pedra montanha abaixo poderia figurar como a falta de apoio dos que resistem e se opõem, manifestada como entraves institucionais e carências de recursos de toda sorte.

Nesse sentido, vale lembrar que poderíamos ter um comprometimento do processo de transferência da política do TDO como resultado dessa relação conflituosa entre coordenadores/gestores de viés pró-política e dos oposicionistas, posto que entraves institucionais e a privação de recursos passam a integrar tal cenário. Segundo Ogden (2003), tanto a mobilização de interesses (fator motivacional) quanto de recursos (fator estrutural) são fases cruciais num processo de transferência de política pública. 
E, finalmente, a terceira perspectiva de utilização do mito está vinculada ao processo de implementação da política da tuberculose na região. Nesse contexto, teríamos na pedra a própria política da TB e, no trajeto ao topo da montanha, a representação do esforço desprendido por coordenadores/gestores (Sísifos) para assegurar o sucesso da sua implementação, o alcance das metas de cura, abandono etc., regulamentadas por protocolos e manuais nacionais e internacionais. Contudo, a pedra sempre rola no sentido contrário, o que pode ser visto como a ilegitimidade da questão da tuberculose e os reflexos decorrentes de tal postura, ou ainda como o próprio retrocesso da política da TB quando se pensa na capital gaúcha, que, aliás, tem experimentado nos últimos anos uma redução significativa da eficácia dos seus programas de controle, de acordo com Micheletti et al. (2014).

Seja em uma ou outra, ou em ambas as propostas de interpretação do mito grego, o que nos chama atenção é a insistência do Sujeito-Sísifo no processo: "a gente vai de novo, então, [risos] é mais ou menos isso que, que atrapalha tá" (L.7; L.8). Embora haja entraves político-institucionais e resistência por parte de alguns profissionais de saúde, gestores, coordenadores, ele, o Sujeito 4, Sísifo por ocasião ou ainda por natureza (bravura e resistência; influência cultural gaúcha), empreende incessantemente sua luta ("a gente vai de novo").

Contudo, o problema não se restringe ao rolar da pedra montanha abaixo, isso é "mais ou menos" o que atrapalha, restando ao interlocutor significar os muitos implícitos nessa afirmativa. Aqui, observa-se uma correlação entre o pragmatismo com o praticalismo enfatizado na concepção Jamesiana (KINOUCHI, 2007) - e a dialética - sob o ponto de vista da contradição: ao mesmo tempo em que o sujeito acredita ser capaz de descrever a problemática da TB e da política do TDO por meio de artifícios práticos e objetivos - por exemplo, pelo emprego da metáfora de Sísifo -, ele se dá conta da impossibilidade de representar todos os elementos do processo, e o praticalismo se torna insustentável, abrindo espaço para os deslizamentos e implícitos.

Assim, ainda que os esquecimentos "1" e "2" se manifestem "naturalmente" e que 0 sujeito busque o controle dos elementos, sua ordem, significação, reproduzindo de forma autoritária o status quo da sua lógica ("tá" - L.8), pode-se observar a hesitação ("que, que") e a contradição ao demonstrar que o problema vai 
além do que foi dito ("é mais ou menos isso que, que atrapalha tá"). Conforme nos diz Orlandi (2012, p.50), essa é a forma-sujeito histórica marcada pela contradição: "é um sujeito ao mesmo tempo livre e submisso", que crê na possibilidade do tudo dizer, contudo submetido, assujeitado à língua.

Ainda sobre Sísifo, Camus (2004, p.141) ${ }^{12}$ apud Rocha e Gois (2010, p.474) conclui da seguinte maneira em sua obra:

Deixo Sísifo na base da montanha! As pessoas sempre reencontram seu fardo. Mas Sísifo ensina a fidelidade superior que nega os deuses e ergue as rochas. Também ele acha que está tudo bem. Esse universo, doravante sem dono, não Ihe parece estéril nem fútil. Cada grão dessa pedra, cada fragmento mineral dessa montanha cheia de noite forma por si só um mundo. A própria luta para chegar ao cume basta para encher o coração de um homem.

Como se observa, não obstante os muitos percalços do trajeto e do esforço empenhado com a pedra, não é a subida ao topo da montanha que incomoda Sísifo, mas o retorno dela à base. Estudos demonstram que Camus interpreta o sofrimento de Sísifo na descida da pedra enquanto o momento de conscientização da sua condição e do seu funesto destino (FLANDOLI, 2009).

Ao transferirmos essas suposições para o cenário do Sujeito 4 em relação à TB e ao TDO, talvez possamos pensar que não é o esforço de transferir, divulgar e implementar tais políticas que o incomoda, mas sua impotência frente à resistência, à ausência de legitimidade e negligência com que elas são tratadas, culminando no agravamento do cenário epidemiológico da doença.

No bloco de análise que se segue, teremos a oportunidade de analisar um pouco mais os atores e a rede envolvidos na transferência da política do TDO.

\footnotetext{
${ }^{12}$ Camus, A. O mito de Sísifo. Rio de Janeiro: Record, 2004.
} 


\subsubsection{A REDE E OS ATORES}

Conforme o modelo para a análise da transferência de uma política de saúde elaborado por Bissell, Lee e Freeman (2011), torna-se fundamental investigar quem (atores e rede) e quais níveis ou arenas estão envolvidos nesse processo. Os atores e a rede compreendem as instituições, as organizações, os indivíduos e os grupos formais ou informais. Geralmente, eles apresentam graus diversificados de influência, poder, recursos e interesses, assim como variadas formas de aprendizado, adaptação e implantação de uma política.

Evans (2010) nos diz que, além da identificação dos atores da transferência, é importante definir o sistema de crenças que eles defendem, os recursos que eles carregam consigo para o processo de aprendizagem voltado à política, seu papel no processo de transferência e o tipo de transferência que eles procuram realizar. Principalmente, levar em consideração o papel fundamental que eles desempenham na esfera da comunicação e da transferência de informações e conhecimentos (NEWMARK, 2002).

Com relação aos níveis ou arenas, o que se observa é um enfoque de múltiplas perspectivas, com o envolvimento de espacialidades políticas nos domínios internacionais, transnacionais, nacionais, regionais e locais. A transferência não assume característica unidirecional, podendo percorrer os mais diversos caminhos que interconectam tais níveis (EVANS; DAVIES; 1999).

No Brasil, as interfaces que lidam com a transferência de políticas de saúde são representadas pelos níveis nacional (o Ministério da Saúde), estadual (em nosso caso, a coordenação estadual do PCT do Rio Grande do Sul), regional e local (a coordenação do programa da TB do GHC e do PCT municipal). Como visto anteriormente, focaremos apenas no nível estadual e local para a análise da transferência do TDO, assim como no nível Meso e Micro de gestão da política.

Importante ressaltar que a ausência de uma rede coesa vinculada à transferência de uma política pode representar um obstáculo considerável no processo. Destaca-se também a receptividade dos atores políticos e da opinião pública, a capacidade de assimilação cultural de novas propostas políticas, a 
existência de recursos humanos qualificados e de sistemas efetivos de monitoramento e avaliação, dentre outros (EVANS, 2010).

A questão da coesão da rede pode ser observada na SD que se segue. $\mathrm{Na}$ ocasião, o Sujeito 2 foi questionado sobre estratégias utilizadas na transferência do TDO, e após breve momento de explicação de tais dispositivos (reuniões, encontros mensais de educação permanente, palestras, discussões), ele introduz o assunto sobre a rede:

\section{Sequência Discursiva no 5:}

L.1 “...essa transferência de tecnologia que tu dizes da que passa do nível central

L.2 para o estadual, para o regional, ôxe...Deus queira que fosse, esses 3 níveis

L.3 funcionantes e que a rede fosse quente né [risos], e pudessem se falar e que

L.4 tudo realmente funcionasse, mas pessoas como eu que são experientes,

L.5 acabam servindo de esquentadores da rede né e telefonando pra um e

L.6 telefonando pra outro e fazendo contato e dizendo: insiste lá com a unidade

L.7 tal porque ela é tua referência, ela é que tu tem que resolver o problema,

L.8 então...esses são os métodos" (Sujeito 2);

Observa-se que o sujeito inicialmente esboça um possível trajeto da política do TDO e alguns níveis governamentais envolvidos (“...essa transferência de tecnologia que tu dizes da que passa do nível central para o estadual, para o regional" - L.1; L.2), demonstrando-nos ter ciência do que se trata. Contudo, não apenas como demonstração do seu conhecimento, essa retomada no assunto pode ser pensada ainda enquanto artifício empregado para angariar respaldo e enfatizar a fundamentação lógica do seu ponto de vista. Nesse sentido, apoiando-se no mecanismo da antecipação - em que o sujeito se coloca na posição do ouvinte, supondo com antecedência o efeito de suas palavras (ORLANDI, 2012) -, o Sujeito 2 pode ter imaginado que, se o interlocutor soubesse que ele realmente está a par do tema e não figura como mero espectador (antes é uma "pessoa experiente", 
"esquentador da rede"), haveria chances de fortalecer sua credibilidade e facilitar sua argumentação.

Assim, na sequência, o sujeito nos fornece indícios da fragmentação do sistema, mobilizando a surpresa e a ironia por meio da marca linguística "ôxe..." (L.2) (atípico da cultura gaúcha; expressão peculiar da cultura nordestina), que no discurso enfatiza o comprometimento da integração, e pela evocação do elemento religioso ("Deus queira que fosse esses 3 níveis funcionantes" - L.2; L.3), com o intuito de dimensionar a dificuldade do processo. A invocação do discurso religioso pode ser pensada sob a égide maniqueísta do bem e do mal, em sua respectiva correlação com a rede coesa ("Deus queira") e a fragmentada.

Já o adjetivo quente ("e que a rede fosse quente né [risos]" - L.3) remete à presença da sinestesia no discurso, ou seja, uma figura da linguagem caracterizada pela imputação de impressões sensoriais a objetos (SILVA; OLIVEIRA; OLIVEIRA, 2013). Nessa linha, tal adjetivo pode ter sido empregado com o sentido de não apenas referenciar o grau de coesão da rede envolvida na transferência do TDO, mas também expressar a dinâmica do processo.

Convém observar que na concepção do Sujeito 2, a rede não figura como "funcionante" nem como "quente", estando seus elementos da comunicação comprometidos ("e pudessem se falar e que tudo realmente funcionasse" - L.3; L4). Contudo, ele se aproveita da carga semântica atribuída ao adjetivo quente e se coloca na posição de esquentador da rede, ou seja, embora a engrenagem esteja desgastada e talvez nem funcione, ele procura movimentá-la, telefonando pra um e pra outro, por isso a conjunção de oposição "mas" ("mas pessoas como eu que são experientes, acabam servindo de esquentadores da rede né e telefonando pra um e telefonando pra outro e fazendo contato" - L.4 - L.6). Observa-se que o sujeito estabelece a sua posição imaginária no sistema ("pessoas como eu") e abre precedente ("né") para se pensar numa relação de causalidade entre o ser experiente e, portanto, esquentador de rede ("acabam servindo").

Outro ponto interessante diz respeito à inserção de uma terceira pessoa em seu discurso, induzindo-nos a pensar na possibilidade de um diálogo entre o coordenador/gestor e um interlocutor fictício ("fazendo contato e dizendo: insiste lá com a unidade tal porque ela é tua referência, ela é que tu tem que resolver o 
problema, então..." - L.6 - L.8). Ainda que não se possa precisar quem seja tal interlocutor (se profissionais da saúde, outros coordenadores, gestores, outros), não se pode deixar de considerar que a ele é delegada a incumbência de solucionar determinados entraves. Além disso, o Sujeito 2 deixa indícios de uma possível lógica organizativa na divisão de tarefas: tu resolve o problema na unidade e pessoas como eu servem de esquentador de rede.

Nessa SD, observam-se traços do discurso autoritário do sujeito, por exemplo, no emprego dos verbos insistir e ter no modo imperativo ("insiste lá"; "tu tem que"). Por ocasião do verbo insistir, somos levados a retomar o elemento motivacional envolvido na transferência e operacionalização do TDO. Insistir pode denotar persistência na busca de algo ainda inatingido, todavia, nesse recorte textual, o seu valor semântico pode vincular-se ao contexto tanto de forma positiva (a resistência e a luta do sujeito coordenador/gestor e do interlocutor fictício por melhorias), quanto de forma negativa (expressão da exaustão e da descrença que afetam o interlocutor fictício frente aos problemas do sistema, fazendo-se necessária a intervenção de um fator externo - uma ordem - para que este cumpra o que lhe compete).

Segundo Lotufo e Miranda (2007, p.1146),

o propósito primordial da gestão em saúde é a produção de decisões, que desencadeia o processo de intermediação e implementação das políticas. Há muita complexidade e subjetividade envolvidas nesses processos de gestão. Os sistemas de direção, assim como o processo e os arranjos para a tomada de decisões, envolvem motivações, interesses, racionalidades imbricadas, intuição (e experiência intuitiva), conhecimentos, capacidades cognitivas, habilidades, qualidade estratégica, controle de capitais e recursos (tempo, informações, tecnologias, financiamento).

Assim, não há como negar a importância do fator motivacional na gestão em saúde e nos processos de transferência e de implementação de políticas públicas. Raciocínio similar pode ser aplicado à política da TB e do TDO. Ainda com relação à rede e ao fator motivacional, vejamos um segundo recorte discursivo em que o Sujeito 3, ao ser questionado sobre a descentralização e implantação do TDO, pondera da seguinte maneira: 


\section{Sequência Discursiva no 6 :}

L.1 “... Então nós enfrentamos uma resistência muito grande na descentralização do L.2 atendimento e também na implementação do TDO, porque os profissionais têm

L.3 sempre encarado isso como uma sobrecarga de trabalho, um trabalho a mais L.4 que eles vão ter que fazer. Então assim, a estratégia tá de descentralizar o L.5 atendimento com a, hum, repassando a responsabilização sobre a situação da L.6 tuberculose naquele território. Eles estão se enxergando como atores do, de L.7 todo sistema, como responsáveis por Porto Alegre estar do jeito como está. Tá L.8 certo? Então foi a estratégia que nós encontramos e isso tem surtido efeito tá."

\section{L.9 (Sujeito 3);}

Aqui, a resistência em trabalhar com o TDO é ação claramente atribuída aos profissionais de saúde, que veem na atividade uma sobrecarga de trabalho. Nesse sentido, o Sujeito 3 busca destituir os coordenadores/gestores de qualquer vinculação com movimentos de resistência, situando-os na condição de sujeitos passivos da ação ("Então nós enfrentamos uma resistência" - L.1). Sem embargo, ao expandirmos o entendimento desta situação para o campo da luta de classes na concepção marxista (proletariado $X$ burguesia), veremos que o sujeito da sentença "nós" adquire ares de multiplicidade e de definição pouco precisa.

Se os profissionais de saúde figuram como a representação da anarquia e do anarquismo (ou seja, "linhas de fuga"; "fluxos de resistências na sociedade de controle" - PASSETI, 2007, p.40), a eles é também imputada a culpa pelo desequilíbrio no cenário epidemiológico de Porto Alegre em relação à tuberculose ("Eles estão se enxergando como atores do, de todo sistema, como responsáveis por Porto Alegre estar do jeito como está" - L.6; L.7).

O Sujeito 3 não apenas os culpabiliza pelo contexto da TB no município como parece ver na descentralização uma oportunidade de transferir a responsabilidade da operacionalização e dos resultados da política para os profissionais ("Então assim, a estratégia tá de descentralizar o atendimento com a, hum, repassando a responsabilização sobre a situação da tuberculose naquele território" - L.4 - L.6). 
Observa-se que, se tomarmos o "então" enquanto conjunção conclusiva, tal como o "logo", perceberíamos que o sujeito conclui o seu raciocínio justificando sua ação (o repasse da responsabilidade do controle da TB), com base no comportamento resistente dos profissionais e na suposta culpa que eles possuem pelo quadro epidemiológico da doença em Porto Alegre. Assim a incumbência de solucionar o problema recairia sobre aqueles sabidamente culpados.

Mediante tais considerações, 0 fato de os profissionais de saúde reconhecerem-se enquanto atores do sistema (L.6; L.7) parece-nos adquirir dupla significação: ora temos a impressão de que eles se enxergam na condição do trabalhador que vai fazer a diferença no programa, por isso a responsabilização no controle da doença (o bom sujeito de Pêcheux), ora inferimos que eles possuem ciência da sua "rebeldia" e das consequências que ela tem acarretado para a saúde no município, insistindo em tal comportamento por "sempre" (L.3) encarar o TDO como uma sobrecarga de trabalho (o anarquista; o mau sujeito de Pêcheux).

Pêcheux (2009, p.199) define o 'bom sujeito', como sendo aquele do assujeitamento consentido, ou seja, "o interdiscurso determina a formação discursiva com a qual o sujeito, em seu discurso, se identifica, sendo que o sujeito sofre cegamente essa determinação...”, já o 'mau sujeito', vincula-se à contestação, revolta, dúvida e contra-identificação com a formação discursiva imposta. No setor saúde, de uma forma geral, espera-se naturalmente que os profissionais desempenhem ações com vistas à prevenção, cura e controle das doenças. Assim, qualquer forma de oposição e descumprimento de tal entendimento poderá ser tomada à condição de rebeldia, questionamento e desidentificação, em nosso caso, com a FD Atenção Primária à Saúde.

O Sujeito 3 ainda nos fornece pistas sobre a participação dos profissionais de saúde na formulação de uma estratégia, quando a coloca no domínio do "nós", ou seja, da classe que ele representa: "Tá certo? Então foi a estratégia que nós encontramos e isso tem surtido efeito tá." (L.7; L.8). Aqui, observa-se novamente como o sujeito do discurso estabelece seu imaginário de posição e poder, levandonos a crer na possibilidade de processos decisórios verticalizados caracterizados pela nula ou reduzida participação de outros atores do sistema (outros profissionais, a população e seus representantes, etc.). 
Não obstante, percebemos traços do discurso autoritário do sujeito ("tá certo?"; "tá") e da antecipação dos resultados positivos produzidos pela estratégia adotada ("e isso tem surtido efeito tá."- L.8). Essa antecipação pode ser vista como artifício para refrear objeções e refutações do interlocutor, já que as chances de se questionar uma estratégia exitosa parece-nos bem menor do que aquela fadada ao fracasso. No entanto, não é possível discriminar de forma acurada quais sejam tais resultados. O que se observa é a busca de estabilização do discurso por meio de uma sentença fechada e pouco explicativa, características também presentes na língua de madeira.

Conforme Gadet e Pêcheux (2004) ${ }^{13}$ apud Grangeiro (2008), a língua de madeira, considerada dura, fechada e hermética, caracteriza-se pelo uso de inúmeros códigos (como na língua do direito e da política), o que a torna de difícil entendimento para aqueles que não estejam inseridos nesses campos de saberes. Assim, observa-se que o Sujeito 3 busca silenciar por meio de expressões pouco explicativas ("isso tem surtido efeito"; qual efeito?) e se furta a problematizar os resultados do processo, tornando-os "palavras inaudíveis" a todos que não estejam vinculados ao seu departamento ou setor de serviço.

Dessa maneira, acreditamos que a resistência por parte dos profissionais de saúde e de alguns coordenadores e gestores em lidar com a política do TDO, a fragmentação da rede, a descrença, o comprometimento do fator motivacional, assim como os entraves político-institucionais e financeiros observados podem ter influenciado ou ainda influenciem de forma importante o controle da tuberculose em Porto Alegre, refletindo o cenário epidemiológico preocupante constatado atualmente. O que se percebe é uma desqualificação do processo com base no escasseamento de alguns elementos tidos como fundamentais na transferência de uma inovação, como a mobilização de interesses, a vontade política e os entraves institucionais e estruturais, dentre outros.

Há que se considerar, todavia, alguns avanços, relatados pelos sujeitos no momento da entrevista, em relação à política do TDO, que nos levam a crer em iminentes transformações, como: maior envolvimento da família e de outros

\footnotetext{
${ }^{13}$ GADET, F.; PÊCHEUX, M. A língua inatingível. Trad. Betânia Mariani e Maria Elizabeth Chaves de Mello. Campinas: Pontes, 2004.
} 
membros do convívio do paciente em seu tratamento; instituição do genograma e da rede social significativa em algumas unidades do município (por esta última, buscase mapear em quatro quadrantes as principais pessoas do convívio do doente amizades, família, relações de trabalho/escolares, relações comunitárias/de serviço - e em três círculos que se inscrevem nos quadrantes, o tipo de relação que ele estabelece com tais pessoas - relação íntima, relações com menor grau de aproximação/compromisso e relações ocasionais -; a partir daí traça-se o grau de proximidade e importância de cada um em relação ao paciente - FERREIRA et al., 2013); o estabelecimento de sistema de premiações e condecorações direcionado aos profissionais que apresentam o melhor desempenho; a criação do prontuário morador de rua; o fortalecimento das discussões sobre o tema com capacitações e rodas de conversa, dentre outros.

Assim, embora convivamos em Porto Alegre com um contexto epidemiológico sabidamente desfavorável em relação à TB e ao TDO, acreditamos nas melhorias advindas não apenas desses avanços anteriormente relatados, mas do processo de descentralização do atendimento dos casos de TB para todas as unidades da Atenção Primária da Saúde do município, o que poderá resultar em modificações de cenário com prováveis efeitos positivos.

Todavia, ressaltamos serem ainda indispensáveis profundas transformações no que diz respeito ao estigma, ao preconceito e à negligência que a TB carrega consigo, bem como em relação à falta de interesse e vontade política de alguns atores envolvidos no combate à doença. Finalmente, porém não menos importante, destaca-se a necessidade de apoio infraestrutural, financeiro e institucional conforme requisitado em cada etapa/ação de controle da TB, sem os quais dificilmente serão alcançados os resultados, a qualidade e o comprometimento almejados. 


\subsection{NO CAMINHO DO PLANEJAMENTO E NO PLANEJAMENTO DO CAMINHO}

Dizia Peter Drucker (1962) que "o planejamento não diz respeito a decisões futuras, mas às implicações futuras de decisões presentes" (DRUCKER ${ }^{14}$ apud SAUAIA; SYLOS, 2000, p.5). De maneira que muitos resultados podem ser influenciados pela forma como o hoje foi projetado, organizado, concebido. Assim, o plano volta a ser o passo inicial do caminho pelo qual se busca formular ações estratégicas com fins ao sucesso e alcance de objetivos pré-estabelecidos.

Nesse sentido, buscamos em nossas análises investigar indícios da realização ou não do planejamento (pelos coordenadores/gestores) da transferência da política do TDO para os profissionais de saúde, bem como possíveis elementos e recursos mobilizados nesse processo.

O Sujeito 1, por exemplo, quando interrogado sobre a realização do planejamento para a transferência da política do TDO em sua respectiva coordenação, respondeu da seguinte forma:

\section{Sequência Discursiva no 7:}

L.1"É o que a gente viu em 2008 é que um dos problemas é do programa era a

L.2 questão da adesão né. E, e aí a gente começou a discutir: bom como é que

L.3 se faz pra que os pacientes possam né, chegar, até o final do tratamento né,

L.4 não abandonar, no primeiro e segundo mês de tratamento? E, e é claro a

L.5 gente já, se for pra literatura tu vê publicações e a própria Organização

L.6 Mundial de Saúde fala em TDO há muitos anos né. Então, a partir disso a

L.7 gente começou a discutir com as equipes a possibilidade de TDO e com a

L.8 gerência do serviço e aí 2009 foi o ano que o, é, o Fundo Global tava

L.9 atuando e tinha também várias discussões incentivando a implantação do

L.10 Tratamento Diretamente Observado e aí, eu digo: bom é a oportunidade

\footnotetext{
${ }^{14}$ DRUCKER, P. F. Prática de administração de empresas. Rio de Janeiro: Fundo de Cultura, 1962.
} 
L.11 da gente, hum, conseguir recurso que é uma coisa que a gente não

L.12 consegue, pra fazer capacitação pra todo mundo..." (Sujeito 1);

Ao pensarmos nos momentos do PES de Matus (Explicativo, Normativo, Estratégico, Tático-operacional), observamos que o sujeito parte inicialmente de um problema (momento explicativo) do âmbito da operacionalização da política (a adesão do paciente ao tratamento - L.2), para indiretamente chegar num problema da ordem da transferência da política do TDO (falta de recurso para a capacitação). A baixa adesão e a necessidade de reversão do quadro, o aporte teórico internacional da OMS sobre o TDO (L.5; L.6) e o incentivo, inclusive financeiro, do Fundo Global, parece-nos compor o quadro de problemas e oportunidades, respectivamente, que impulsionaram o planejamento e a execução da transferência do TDO.

Contudo, ainda que haja indícios de um ponto de partida (problema) e dos atores envolvidos no processo, conforme discutiremos adiante, nota-se pouca clareza e detalhamento no que se refere à etapa do planejamento da transferência do TDO. Não se pode afirmar sobre a sistematização do processo e o seu grau de formalização, que ainda nos parece incipiente e pouco aprofundado.

O sujeito deixa pistas dos atores supostamente envolvidos no processo, neste caso os coordenadores ("a gente começou a discutir" - L.7), a equipe de saúde ("a gente começou a discutir com as equipes a possibilidade de TDO" - L.7), a gerência do serviço (L.8) e o apoio do Fundo Global. Entretanto, novamente não se pode precisar se o conteúdo dessa discussão incorpora aspectos outros que não somente a possibilidade de realização do TDO (L.7). Parece-nos que o termo "discutir" referese mais à implantação do TDO (discutir a "possibilidade de TDO" - L.7; "várias discussões incentivando a implantação do Tratamento Diretamente Observado" L.9; L.10) do que ao planejamento do momento da transferência da política em si.

A capacitação, enquanto um possível elemento do processo de transferência, surge em correlação direta com a falta de recursos, aliás, problema este já apontado em outras oportunidades no presente trabalho. Contudo, o que nos chama atenção é o efeito de interconexão que o sujeito procura estabelecer entre problemas ou 
pontos de partida, oportunidades e pontos almejados, e a falha nesta busca de controle e linearidade do processo de significação. Abaixo listamos de forma resumida três possíveis formas de entendimento sobre a importância da transferência e implantação do TDO:

1) O sujeito vislumbra a possibilidade de melhoria da adesão do paciente ao tratamento partindo da disponibilidade de recursos financeiros do Fundo Global para a capacitação dos profissionais sobre o TDO, bem como do incentivo da OMS e do apoio da literatura, ou seja, o ponto de partida é a possibilidade de financiamento da capacitação profissional, e o ponto almejado torna-se a melhoria da adesão do paciente;

2) O sujeito vislumbra a capacitação dos profissionais de saúde na política como uma possível alternativa ao problema da baixa adesão dos pacientes, associado ao incentivo oferecido pela OMS à prática do TDO, ao aporte teórico circulante sobre o assunto e ao apoio do Fundo Global (inclusive financeiro), ou seja, o ponto de partida é a baixa adesão do paciente e o ponto almejado torna-se a capacitação dos profissionais de saúde ("aí, eu digo: bom é a oportunidade da gente, hum, conseguir recurso que é uma coisa que a gente não consegue, pra fazer capacitação pra todo mundo..." L. 10 - L.12);

3) O sujeito parte do problema relacionado tanto à baixa adesão quanto à falta de recursos financeiros e vislumbra a qualificação do processo por meio da possibilidade de capacitação dos profissionais em TDO, do incentivo da OMS e do apoio da literatura e do Fundo Global, ou seja, o ponto de partida torna-se tanto a baixa adesão ao TDO ("E, e aí a gente começou a discutir: bom como é que se faz pra que os pacientes possam né, chegar, até o final do tratamento né, não abandonar, no primeiro e segundo mês de tratamento?" - L.2 - L.4) quanto a falta de recursos financeiros para a capacitação ("aí, eu digo: bom é a oportunidade da gente, hum, conseguir recurso que é uma coisa que a gente não consegue, pra fazer capacitação pra todo mundo..." - L.10 - L.12), e o ponto almejado torna-se a correção de ambas as situações. 
Não se pode precisar o que de fato motivou o sujeito, porém, em meio às hesitações ("hum" - L.11 e "bom" - L.2; L.10), observa-se que os problemas e objetivos já não mais dispõem de "assentos fixos", e o substantivo "oportunidade" passa a assumir caráter polissêmico: de conseguir recursos financeiros, de promover a capacitação dos profissionais, de melhorar a adesão dos pacientes, de implantar o TDO.

Embora o Sujeito 1, em outra ocasião da entrevista, tenha relatado a existência de um projeto para sensibilizar as equipes e implantar o TDO, pouco foi abordado sobre os elementos e a elaboração do planejamento para a execução da transferência da política. Todavia, tal assunto é ainda menos notório no discurso do Sujeito 2, que, ao ser perguntado sobre as estratégias e recursos mobilizados para formular e executar este plano, responde em determinado momento o seguinte:

\section{Sequência Discursiva nำ 8:}

L.1 “...primeiro foi transformar a tuberculose em prioridade, depois eleger grupos

L.2 de risco pra TDO, já que em princípio parecia que não tínhamos pernas pra

L.3 fazer pra todos os pacientes, e agora vamos chegar no ponto de fazer pra

L.4 todos os pacientes. No início, a gente não tinha comida lá na Unidade

L.5 Sanitária pro paciente, não tinha auxílio alimentação nem auxílio

L.6 transporte. Isso foi das primeiras coisas que a gente planejou conseguir

L.7 e foi suficiente..." (Sujeito 2);

Assim como ocorreu com Sujeito 1, parece-nos que também aqui 0 planejamento de que trata o sujeito é aquele vinculado muito mais à implantação da política do TDO do que ao processo de execução de sua transferência junto aos profissionais de saúde. A factibilidade e a viabilidade do processo são tomadas em função de elementos como os auxílios alimentação e transporte do paciente, ou seja, vinculados ao domínio da operacionalização da política ("não tinha auxílio 
alimentação nem auxílio transporte. Isso foi das primeiras coisas que a gente planejou conseguir e foi suficiente..." - L.5 - L.7).

Não se observa nenhum movimento no sentido de buscar estratégias e recursos que dizem respeito ao planejamento da atividade de transferência do conteúdo da política para os profissionais de saúde, tais quais os canais de comunicação, os recursos humanos e financeiros necessários, o mapa político dos atores, os objetivos e metas propostos, aspectos de motivação dos profissionais em relação à política, os recursos infraestruturais e físicos envolvidos no processo de transferência, o plano de ação, dentre outros. Antes parte-se com o intuito de "chegar no ponto de fazer pra todos os pacientes" (L.3; L.4).

Se os elementos referentes ao planejamento da transferência da política não foram deixados à parte de forma voluntária pelo sujeito, eles o são de forma involuntária, quando levamos em consideração a simplificação do processo ao qual ele se refere e à sinalização dos seus limites pelo dito "a gente planejou conseguir e foi suficiente..." (L.6; L.7). Uma suficiência vinculada ao auxílio alimentação e transporte e destacada, talvez, em seu efeito abrupto de interrupção e contenção.

Assim, o "não ter perna" ("em princípio parecia que não tínhamos pernas pra fazer pra todos os pacientes" - L.2; L.3), além de reforçar a ausência dos recursos infraestruturais, humanos e financeiros diversos indispensáveis à implementação do Tratamento Diretamente Observado, pode, em função da incipiência ou até inexistência da etapa de planejamento da transferência da política, esboçar uma "limitação" do "corpo gestor e institucional" no que se refere às atividades dessa natureza.

Aliás, parece-nos subsistir ainda certa dificuldade por parte dos coordenadores, gestores e profissionais de saúde, de forma geral, no que diz respeito à realização do planejamento estratégico das ações e da tomada de decisão em algumas áreas da saúde. Segundo Ronzani e Silva (2008), quando se trata da Atenção Primária e mais especificamente das Estratégias de Saúde da Família, a deficiência e/ou até inexistência dessa atividade reflete inclusive na comunicação entre profissionais e usuários. Por sua vez, a pesquisa avaliativa desenvolvida por Santos (2012) sobre o princípio da integralidade na rede de Unidades Básicas de Saúde (UBS) de Salvador obteve resultados na dimensão 
"organização dos serviços e das práticas" que o levaram a concluir não apenas sobre a falta de planejamento como também de monitoramento pelos profissionais e gerentes das unidades.

Dessa forma, a associação dessa carência na área do planejamento à escassez do aporte teórico sobre transferência de políticas públicas na literatura nacional talvez seja um dos fatores que explique a incipiência e/ou até inexistência da atividade de planejamento para a transferência do TDO, conforme observado nos discursos dos gestores e coordenadores aqui analisados. Importante mencionar que tal observação assume para nós a feição de elemento a ser incluído no processo de aperfeiçoamento, qualificação e direcionamento dos serviços e ações voltadas à política da TB e do TDO em Porto Alegre, longe, contudo, de qualquer atribuição depreciativa ou punitiva dos trabalhos desenvolvidos por tais sujeitos.

Dando continuidade às nossas análises, apresentamos outra SD extraída do discurso do Sujeito 2, que, ao ser perguntado sobre a periodicidade com que o plano elaborado para a transferência do TDO é revisado, responde da seguinte forma:

\section{Sequência Discursiva nº 9:}

L.1 "Olha [risos], infelizmente não tem uma periodicidade fixa como a gente

L.2 gostaria, ele é visto quando se vê a emergência lotada, os isolamentos

L.3 lotados, muitos casos de tuberculose, aí o pessoal...pra mim é um

L.4 telefonema assim: ah! tu és muito experiente, $\underline{\text { tu }}$ sabes de todos os fluxos, $\underline{\text { tu}}$

L.5 conhece a rede, vem nos ajudar aqui que nos estamos preocupados com a

L.6 tuberculose, aí recomeça de novo: aí a gente...mas a gente tem um plano

L.7 pronto, olha aqui é só aplicar. Ah! Então vamos ver o que fazemos primeiro

L.8 [risos], e assim vai." (Sujeito 2);

A ironia que se irrompe do princípio desta SD (Olha [risos] - L.1) nos permite entrever as possibilidades de conflito e contradição do sujeito. Quando consideramos a sentença "Olha [risos], infelizmente não tem uma periodicidade fixa 
como a gente gostaria" (L.1; L.2), notamos as fronteiras tênues da ambivalência que se instala, no que concerne o plano e a periodicidade da sua avaliação.

A tensão nesse caso reside na luta semântica do "gostaria" $e$ do "infelizmente", entre o que o sujeito quer e o que se possui, entre o ideal e o real, entre o positivo e o negativo, ou seja, múltiplas entoações numa voz capturada ideologicamente e que se faz individual tanto quanto coletiva, singular tanto quanto plural. Conforme Pacífico e Romão (2010, p.4),

[...] o sujeito é sempre capturado ideologicamente a ocupar um lugar no discurso assumindo-o como seu, como evidente e moldado ao seu pensamento e à sua condição. O mecanismo que garante tal amálgama é a ideologia, mecanismo tecelão de uma série de sentidos naturalizados para o sujeito a partir da posição que ele ocupa socialmente.

Embora diante da ilusão de unicidade, torna-se necessária reconhecer a existência dos "outros" no discurso do sujeito, seja pelas manifestações involuntárias e naturalizadas da ideologia, do interdiscurso e da FD ou de forma voluntária ("a gente gostaria" - L.1; L.2), em apologia aos que concordam com a sua linha de raciocínio, ainda que não se possa afirmar a quem o sujeito se refere: se integrantes da coordenação, ou da equipe de profissionais de saúde, a ambos ou ainda outros.

A tensão dessa sentença estende-se também ao campo prático operacional do planejamento, em que o "infelizmente" passa a corporificar a limitação, a assistematização da atividade propriamente dita e, quiçá, até a passividade do sujeito para a reversão do quadro. Sabe-se que a avaliação periódica do plano configura-se como oportunidade ímpar de qualificação do processo, de direcionamento para a tomada de decisão e de adequação dos meios para o alcance das metas objetivadas. Contudo, conforme se observa, ainda existe longa distância entre o querer ("a gente gostaria" - L.1; L.2) e o fazer (“infelizmente” - L.1).

Novamente o planejamento de que trata o sujeito parece-nos muito mais direcionado à operacionalização da política de controle da TB do que à transferência da política do TDO, com o agravante de ainda assim não ser utilizado como uma ferramenta de prevenção da doença, mas para fins emergenciais e quiçá de 
improvisação ("ele é visto quando se vê a emergência lotada, os isolamentos lotados, muitos casos de tuberculose..." - L.2; L.3).

Assim como em SDs apresentadas na seção prévia da transferência da política do TDO, o Sujeito 2 também aqui coloca-se como "esquentador da rede", permitindo-nos entrever como é construída sua lógica de autoridade, posição e poder, seja pelas sucessivas repetições do pronome "tu", ou ainda pela adjetivação do sujeito: experiente, sabe de todos os fluxos, conhece a rede ("aí o pessoal...pra mim é um telefonema assim: ah! tu és muito experiente, tu sabes de todos os fluxos, tu conhece a rede, vem nos ajudar aqui que nos estamos preocupados com a tuberculose" - L.3 - L.6).

Na sequência dessa sentença, o dizer "aí recomeça de novo" (L.6) instala novo conflito semântico no discurso do sujeito, já que não se pode precisar o que é reiniciado, se a mobilização do plano para enfrentamento da situação ou a conscientização dos demais atores sobre a existência do plano, ou se ambos. A continuidade da ação e o caráter cíclico, sugeridos no discurso do sujeito, leva-nos a pensar sobre o Mito de Sísifo, abordado anteriormente na seção da transferência do TDO. Nesse sentido, parece-nos que também em relação ao planejamento a "pedra" em algum momento tende a "rolar montanha abaixo".

Contudo, ao enunciar "mas a gente tem um plano pronto, olha aqui é só aplicar" (L.6; L.7), percebe-se um ponto nevrálgico do discurso: seja qual for o propósito do plano estatuído, persiste certo desconhecimento de outras pessoas vinculadas diretamente à sua operacionalização. Se o envolvimento e participação de outros atores no planejamento é uma das máximas do PES de Matus, parece-nos que neste contexto ela passa a assumir papel secundário. Tal desconhecimento pode ser ratificado pela entoação de surpresa desses "outros" (“Ah!" - L.7) e pela busca de entendimento e priorização de ações ("Então vamos ver o que fazemos primeiro" - L.7).

E, se a ironia introduz essa SD, ela também a finaliza "[risos], e assim vai" (L.8), deixando-nos indícios de um ciclo incerto de continuidade e configuração: não se sabe o que se perpetua, se a falta de periodicidade da avaliação do plano, ou o acionamento repetido do Sujeito 2 pelos outros atores do processo em busca de 
ajuda e esclarecimentos, se a aplicação repetida deste plano em situações emergenciais, ou ainda todos eles.

E para finalizar nossas análises na linha do planejamento, apresentamos a SD 10 extraída (em dois momentos distintos) de uma mesma resposta do Sujeito 3 à pergunta sobre estratégias, recursos financeiros, humanos, físicos e organizacionais utilizados para formular e executar o plano da transferência do TDO.

\section{Sequência Discursiva no 10:}

\section{Momento 1}

L.1 "Hum, como nós não, não em termos financeiros pra poder executar, nós

L.2 estamos executando basicamente com custo zero. Tudo que nós estamos,

L.3 nós conseguimos adquirir foi ampliar a aquisição de vales transporte até pra

L.4 transporte dos próprios profissionais para a execução do TDO, ou

L.5 eventualmente de algum paciente à Unidade de Saúde quando isso é L.6 necessário tá...”.

\section{Momento 2}

L.7 “... material, nós estamos utilizando xerox, nós não conseguimos imprimir

L.8 nenhum material específico para essa capacitação até o momento, então o

L.9 custo basicamente é de alimentação para a realização da, das

L.10 capacitaç̃es tá. O planejamento todo feito com base territorial entre a, a

L.11 Gerência do local e o Centro de Referência do território." (Sujeito 3);

No momento 1, o Sujeito 3, assim como os demais, parece abordar elementos voltados para a execução do TDO ("aquisição de vales transporte até pra transporte dos próprios profissionais para a execução do TDO, ou eventualmente de algum paciente" - L.3 - L.5). Contudo, no momento 2, observamos um redirecionamento do discurso com incorporação de elementos alusivos ao processo de transferência da política, como por exemplo, a menção do termo "capacitação". 
Tanto em 1 quanto em 2 não foram observados indícios que remetessem à atividade do planejamento da transferência do TDO. No momento 1, a própria execução da política parece não ter sido precedida por um planejamento adequado com ênfase na análise de viabilidade financeira, por exemplo, já que, conforme o Sujeito, "nós estamos executando basicamente com custo zero" (L.1; L.2). Em 2, o xerox é o próprio reflexo da contradição ("material, nós estamos utilizando xerox, nós não conseguimos imprimir nenhum material específico para essa capacitação até o momento" - L.7; L.8), ou seja, o fim destinado ao seu uso foge, ainda que momentaneamente, ao propósito da capacitação do TDO. Além disso, não se pode precisar qual planejamento foi realizado entre a Gerência do local e o Centro de Referência do território.

Interessante notar também o reducionismo conceitual do termo transferência de política pública que ganha conotação de "capacitação" tanto para o Sujeito 3 quanto para o Sujeito 1, conforme SD previamente apresentada nesta seção. De acordo com Tasca, Ensslin e Ensslin (2012, p.652),

[...] os processos sociais, como o processo de capacitação, envolvem pessoas, valores e suas percepções, ou seja, são situações consideradas complexas por abarcarem múltiplos e conflitantes critérios (Beinat, 1995; Roy e Vanderpooten, 1996) ${ }^{15}$. Problemas complexos, segundo Ensslin $(2009)^{16}$, usualmente envolvem: (i) conhecimentos interdisciplinares; (ii) múltiplos atores; (iii) informações difusas, incompletas e desorganizadas; (iv) dinamicidade; (v) responsabilidade profissional; (vi) conflitos de interesses; entre outros dessa natureza.

Se retomarmos o arcabouço de Bissell, Lee e Freeman (2011), veremos que a complexidade do processo de transferência de uma política pública se estende para além dos elementos evocados numa capacitação, perpassando dimensões contextuais, políticas, culturais, econômicas, tecnológicas, de comunicação, dentre outras. Torna-se importante reconhecer a capacitação como uma das etapas deste processo para que não se incorra no erro de tomá-la como o todo.

\footnotetext{
${ }^{15}$ BEINAT, E. Multiattribute value functions for environmental management. Amsterdam: Timbergen Institute Research Series, 1995.

ROY, B.; VANDERPOOTEN, D. The European school of MCDA: emergence, basic features and current works. Journal of Multicriteria Decision Analysis, v. 5, n. 16, p. 22-38, May 1996.
}

${ }^{16}$ ENSSLIN, L. Notas de aula da disciplina MCDA I. Florianópolis: Programa de Pós-Graduação em Engenharia de Produção da Universidade Federal de Santa Catarina, 2009. 
Já o planejamento, se este é tido à custa de ferramenta indispensável em qualquer nível de operacionalização de ações, propostas, serviços, estratégias e políticas na saúde e em outras áreas, parece-nos que mais uma vez ele foi preterido pelo sujeito do discurso no que se refere à transferência do TDO. O pronome indefinido "tudo" (L.2) e o advérbio "basicamente" (L.9), por exemplo, evocam complementos que limitam e atrelam a ação do sujeito à instância da execução da política (aquisição de vales transporte e alimentação) sem, contudo, deixar-nos pistas do percurso planejado para a sua transferência.

\subsection{DO DISCURSO AOS NÚMEROS: RESULTADOS PROVENIENTES DA APLICAÇÃO DO INSTRUMENTO ATP-IINFOC-TB AOS PROFISSIONAIS DE SAÚDE}

Dos 109 profissionais de saúde que satisfizeram ao critério de inclusão, $77,06 \%$ pertenciam ao sexo feminino e $22,94 \%$ ao sexo masculino. A maioria dos participantes possuía de 30 a 59 anos $(87,16 \%)$ e pertencia à categoria médica $(37,61 \%)$, seguida dos enfermeiros $(22,94 \%)$, auxiliares de enfermagem $(22,02 \%)$ e técnicos de enfermagem $(17,43 \%)$.

Conforme se observa, os itens 3, 32 e 21 destacaram-se como sendo aqueles com menor média e escore padronizado segundo as respostas dos participantes $(2,04$ [25,97\%]; 2,53 [38,25\%] e 2,86 [46,53\%] respectivamente. Tabela 1). Isso significa que eles tendem a discordar quanto à existência de uma participação popular em discussões do TDO na unidade de saúde, quanto à utilização dos recursos da comunidade (grupo de apoio, associação de moradores, grupos de autoajuda, outros) como forma de incentivo à adesão do doente ao TDO e ainda sobre a disponibilidade e existência de uma infraestrutura adequada para prestar assistência ao doente em TDO (salas, equipamentos etc.). Assim, podemos dizer que, na concepção dos profissionais de saúde entrevistados, tais apontamentos surgem como alguns pontos críticos passivos de melhorias no que se refere à transferência e operacionalização da política do TDO. 
Tabela 1 - Representação das médias e dos escores padronizados das respostas dos participantes por item do instrumento ATP- IINFOC-TB. Porto Alegre, 2014.

\begin{tabular}{cccccc}
\hline $\begin{array}{c}\text { No } \\
\text { item }\end{array}$ & Mínimo & Máximo & Média & $\begin{array}{c}\text { Escore } \\
\text { padronizado }\end{array}$ & $\begin{array}{c}\text { Desvio } \\
\text { Padrão }\end{array}$ \\
\hline 23 & 1 & 5 & 4,69 & 92,36 &, 891 \\
28 & 1 & 5 & 4,66 & 91,44 &, 738 \\
19 & 1 & 5 & 4,60 & 89,91 &, 904 \\
10 & 1 & 5 & 4,51 & 87,85 &, 994 \\
18 & 1 & 5 & 4,49 & 87,27 &, 803 \\
11 & 1 & 5 & 4,45 & 86,21 &, 993 \\
2 & 1 & 5 & 4,42 & 85,42 & 1,078 \\
6 & 1 & 5 & 4,39 & 84,80 & 1,055 \\
1 & 1 & 5 & 4,39 & 84,67 & 1,074 \\
38 & 1 & 5 & 4,39 & 84,63 &, 952 \\
16 & 1 & 5 & 4,31 & 82,64 & 1,256 \\
33 & 1 & 5 & 4,29 & 82,18 & 1,059 \\
39 & 1 & 5 & 4,24 & 80,90 & 1,074 \\
12 & 1 & 5 & 4,17 & 79,25 & 1,320 \\
24 & 1 & 5 & 4,15 & 78,74 & 1,219 \\
34 & 1 & 5 & 4,12 & 78,01 & 1,266 \\
20 & 1 & 5 & 4,10 & 77,62 & 1,151 \\
17 & 1 & 5 & 4,10 & 77,57 & 1,236 \\
9 & 1 & 5 & 4,10 & 77,55 & 1,380 \\
7 & 1 & 5 & 4,04 & 75,94 & 1,242 \\
8 & 1 & 5 & 4,02 & 75,47 & 1,138 \\
5 & 1 & 5 & 3,98 & 74,52 & 1,269 \\
14 & 1 & 5 & 3,85 & 71,26 & 1,280 \\
36 & 1 & 5 & 3,79 & 69,71 & 1,297 \\
4 & 1 & 5 & 3,73 & 68,16 & 1,540 \\
25 & 1 & 5 & 3,58 & 64,58 & 1,467 \\
29 & 1 & 5 & 3,58 & 64,52 & 1,406 \\
26 & 1 & 5 & 3,58 & 64,39 & 1,530 \\
35 & 1 & 5 & 3,56 & 64,00 & 1,438 \\
15 & 1 & 5 & 3,37 & 59,31 & 1,566 \\
27 & 1 & 5 & 3,27 & 56,71 & 1,580 \\
13 & 1 & 5 & 3,18 & 54,40 & 1,478 \\
22 & 1 & 5 & 3,16 & 53,94 & 1,578 \\
37 & 1 & 5 & 3,13 & 53,13 & 1,505 \\
30 & 1 & 5 & 3,11 & 52,67 & 1,662 \\
31 & 1 & 5 & 3,07 & 51,68 & 1,566 \\
21 & 1 & 5 & 2,86 & 46.53 & 1,632 \\
32 & 1 & 5 & 2.53 & 38,28 & 1,573 \\
3 & 1 & 5 & $(2,04$ & 95,97 & 1,455 \\
\hline & & & & & \\
\hline
\end{tabular}


Por outro lado, os itens 23, 28 e 19 foram aqueles com maior média e escore padronizado observados, ou seja, 4,69 (92,36\%), 4,66 (91,44\%) e 4,60 (89,91\%), respectivamente. Dessa forma, os profissionais de saúde tendem a concordar que o TDO requer a elaboração de um plano de cuidado individual para o doente de TB, que a equipe de saúde entende que o TDO é uma prática que qualifica a assistência ao doente de TB e que o sucesso dessa política requer a incorporação de outras instituições e ações que vão além das do setor saúde.

Se nos propusermos a analisar a distribuição das respostas dos participantes por dimensão tomando como referência os escores padronizados, teríamos gráficos box-plot conforme as figuras 4,5 e 6.

$\mathrm{Na}$ dimensão "Informação" (Figura 4), a média geral dos escores das respostas foi de $72,7 \%$, e a mediana, $77,8 \%$, com $50 \%$ das respostas acima desse valor e as demais 50\% abaixo. Cinco por cento das respostas dos participantes (em relação aos menores escores observados) possuem escores padronizados que vão do $0 \%$ ao $22,2 \%$. Já os $5 \%$ de respostas com maiores escores observados partem do $97,2 \%$ podendo chegar aos $100 \%$.

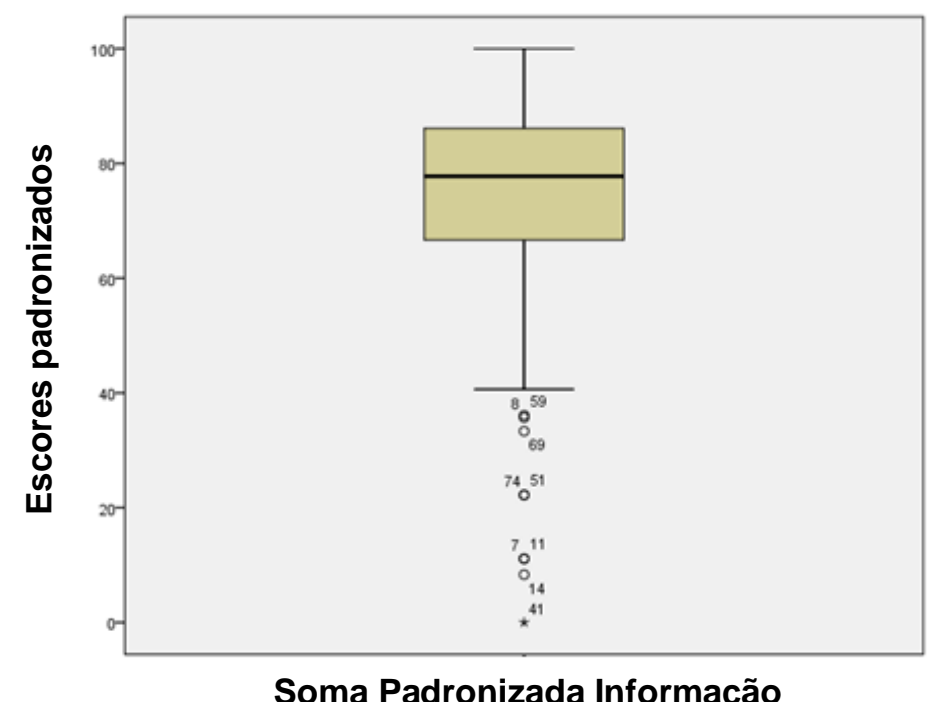

Figura 4 - Box-plot da distribuição dos escores padronizados das respostas dos participantes segundo a dimensão Informação. Porto Alegre, 2014. 
O valor observado da média geral dos escores padronizados na dimensão "Conhecimento" foi de $77,8 \%$, já a mediana, de $79,5 \%$ (Figura 5 ). Os $5 \%$ das respostas com os menores escores padronizados obtiveram valores que partiram do $18,8 \%$ ao $53,3 \%$, já os $5 \%$ das respostas com os maiores escores padronizados variaram do $97,6 \%$ ao $100 \%$.

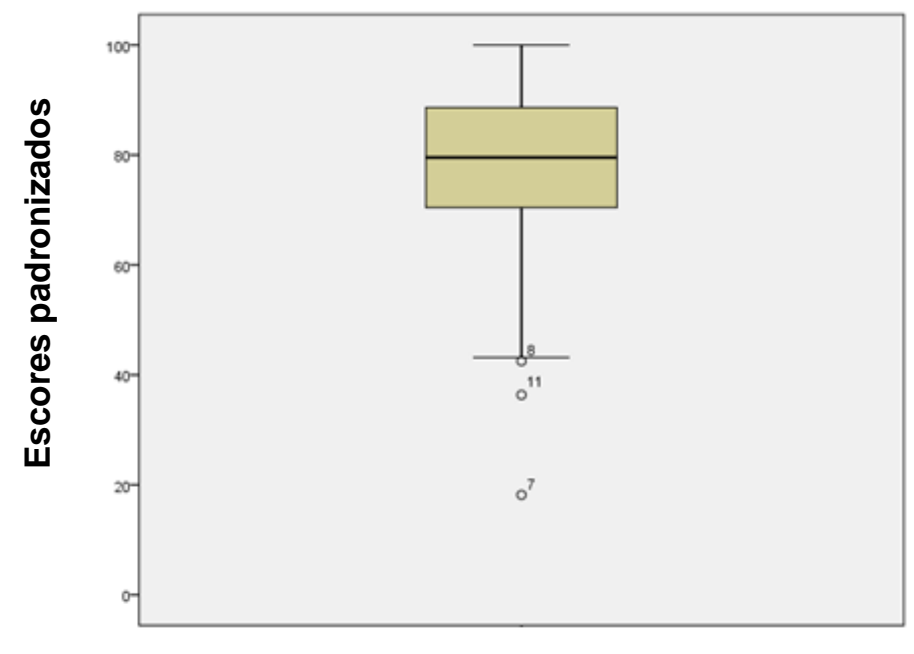

Soma Padronizada Conhecimento

Figura 5 - Box-plot da distribuição dos escores padronizados das respostas dos participantes segundo a dimensão Conhecimento. Porto Alegre, 2014.

$\mathrm{Na}$ dimensão "Inovação", a média geral dos escores padronizados foi de $67,7 \%$, e a mediana, $68,9 \%$. Os $5 \%$ das respostas com menores escores padronizados observados possuem valores entre 2,5\% e 35\%, já a porção dos 5\% das respostas com os maiores escores observados possuem valores entre $93,8 \%$ e $100 \%$. 


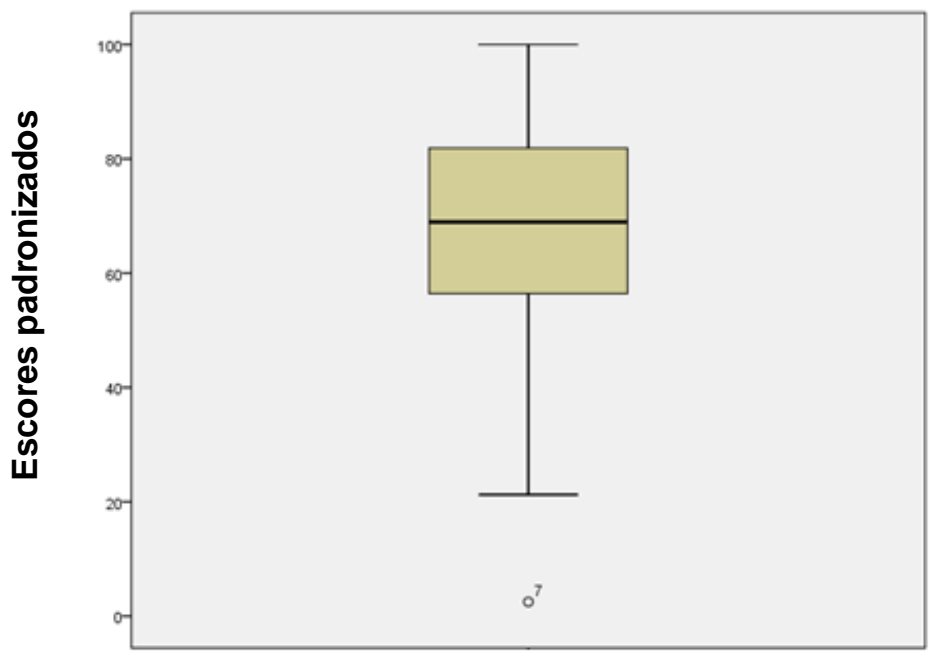

Soma Padronizada Inovação

Figura 6 - Box-plot da distribuição dos escores padronizados das respostas dos participantes segundo a dimensão Inovação. Porto Alegre, 2014.

Com relação à distribuição dos escores padronizados por dimensão e por categoria profissional, observamos que a categoria médico apresentou, na dimensão "Informação", valores de mediana similares à categoria dos enfermeiros (75\% ambas), seguidas dos auxiliares de enfermagem (80,6\%) e dos técnicos de enfermagem (82,14\%), (Figura 7 ).

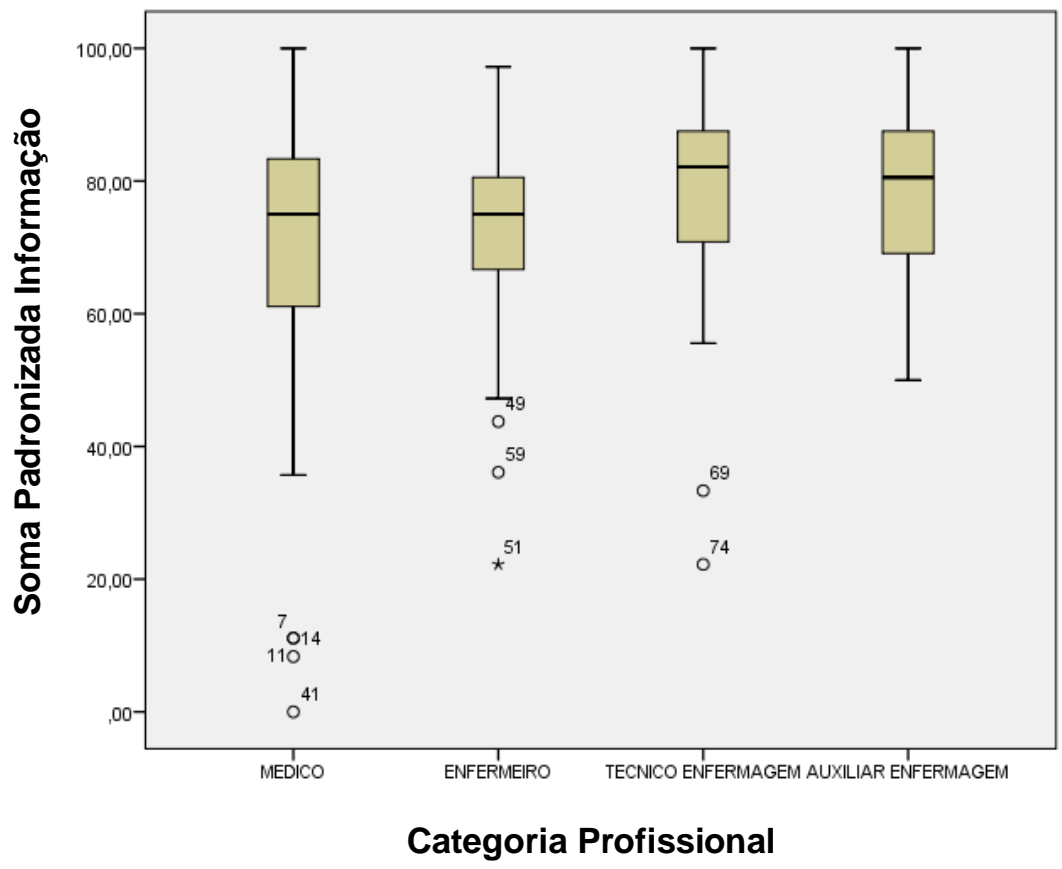


Figura 7 - Box-plot da distribuição dos escores padronizados das respostas dos participantes na dimensão Informação e segundo a categoria profissional.

Porto Alegre, 2014.

Esse mesmo tipo de análise aplicada à categoria "Conhecimento" nos permitiu observar medianas de $75 \%, 79,5 \%, 80,7 \%$ e $83,8 \%$ para técnicos de enfermagem, enfermeiros, médicos e auxiliares de enfermagem, respectivamente, conforme a Figura 8.

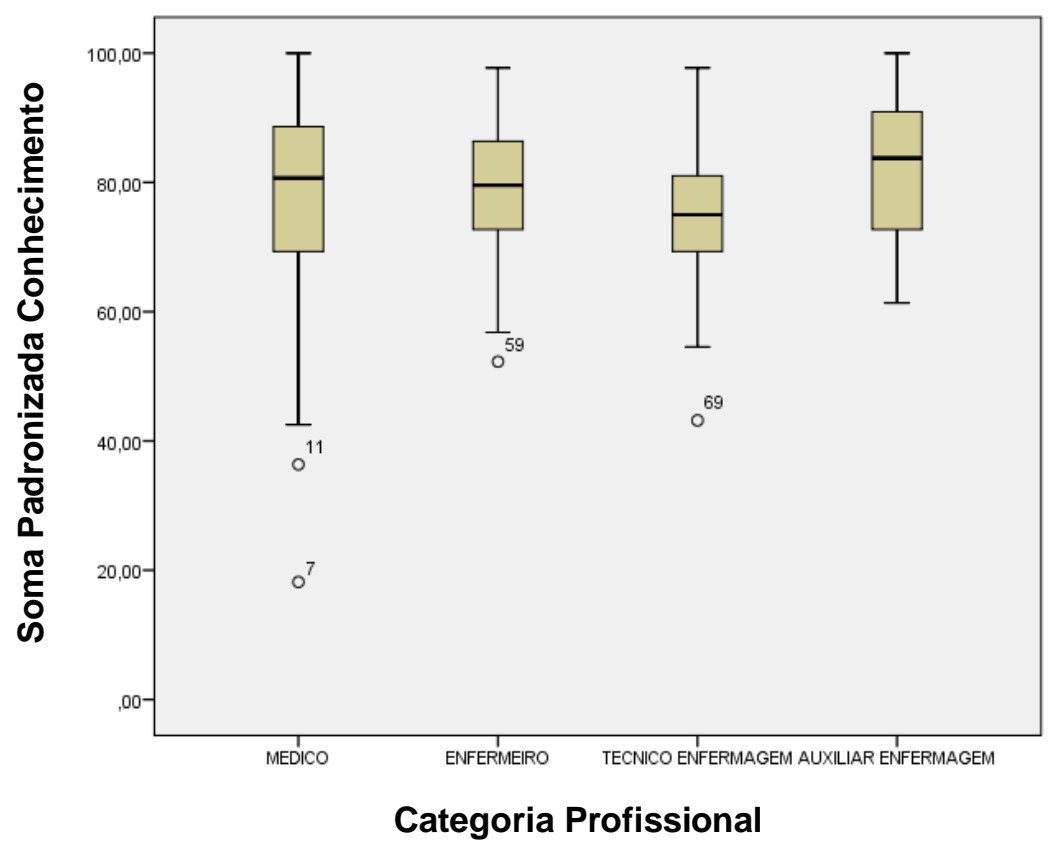

Figura 8 - Box-plot da distribuição dos escores padronizados das respostas dos participantes na dimensão Conhecimento e segundo a categoria profissional. Porto Alegre, 2014.

Já na dimensão "Inovação", as medianas alcançaram valores de 60\%, 66,3\% $70 \%$ e $80,6 \%$ para enfermeiros, técnicos de enfermagem, médicos e auxiliares de enfermagem, respectivamente (Figura 9) 


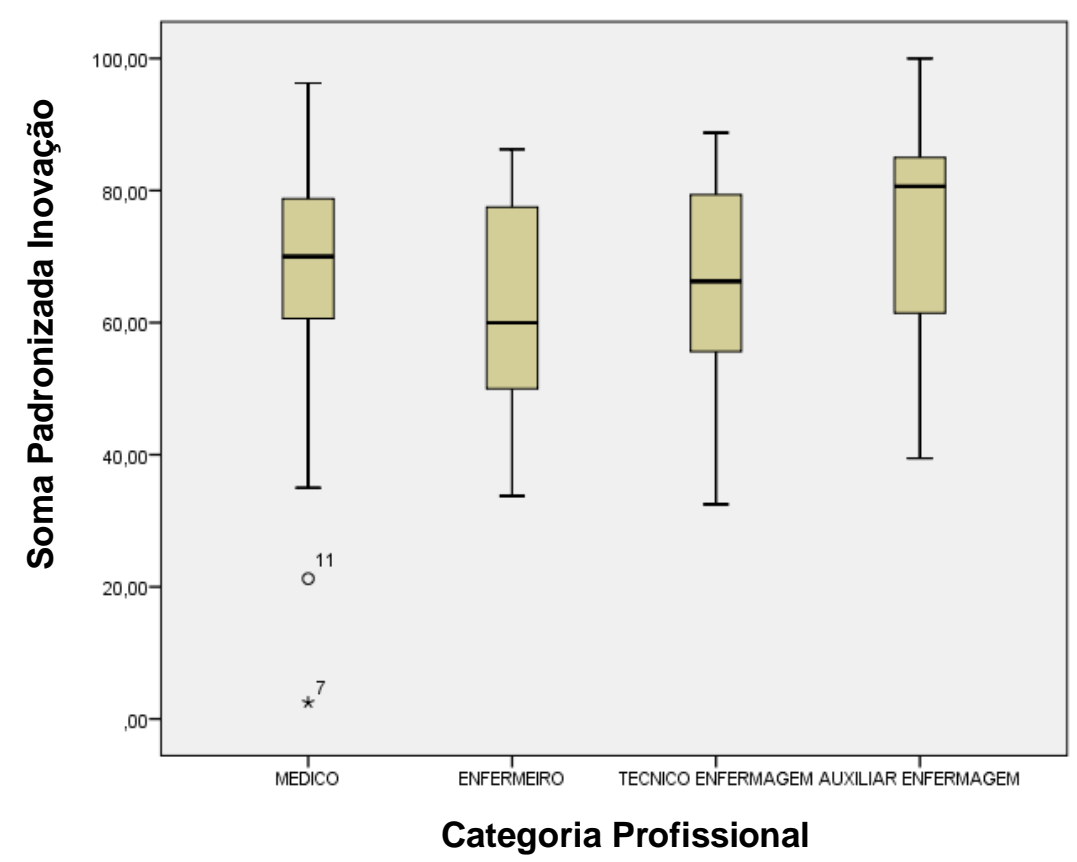

Figura 9 - Box-plot da distribuição dos escores padronizados das respostas dos participantes na dimensão Inovação e segundo a categoria profissional. Porto Alegre, 2014.

Dentre os outliers ou valores aberrantes - "observações que apresentam um grande afastamento das restantes ou são inconsistentes com elas." (FIGUEIRA, 1998, p.1) -, destacamos o sujeito com ID funcional № 7, o qual apareceu em todos os boxplots apresentados, seja na análise de cada dimensão isoladamente ou ainda por categoria profissional. Conforme se pode observar, tal sujeito pertence à categoria médica, e, em análise específica, constatamos que respondeu "discordo" na quase totalidade dos itens, alcançando escores finais consideravalmente baixos.

Antes de darmos início à análise com o modelo de regressão Beta foram adotados alguns procedimentos operacionais. Os dados relacionados aos escores dos domínios foram empilhados, ou seja, as 109 observações de cada domínio foram empilhadas e posteriormente se criou uma coluna denominada domínio, resultando no total de 327 valores.

Para a análise realizada com o uso do modelo de regressão Beta, os valores localizados nos extremos (valores iguais a 0 ou a 1) foram desconsiderados. No banco de dados foram encontradas 7 observações nesse sentido (0 [41] e 1 [33, 84, $96,128,202$ e 310]). Isso corresponde a 2,14\% (7/327) dos dados, assim, o banco utilizado para a análise ficou com 320 observações. 
Após tais reconfigurações, obtivemos uma distribuição assimétrica à esquerda (Figura 10) no que diz respeito aos escores padronizados das respostas dos participantes, considerando a totalidade das três dimensões (“Informação", "Conhecimento" e "Inovação") e das categorias profissionais. Nessa distribuição, a moda encontra-se entre 0,8 (80\%) e 0,9 (90\%), a média geral corresponde a 0,72 (72\%) e o desvio padrão a 0,17 (17\%).

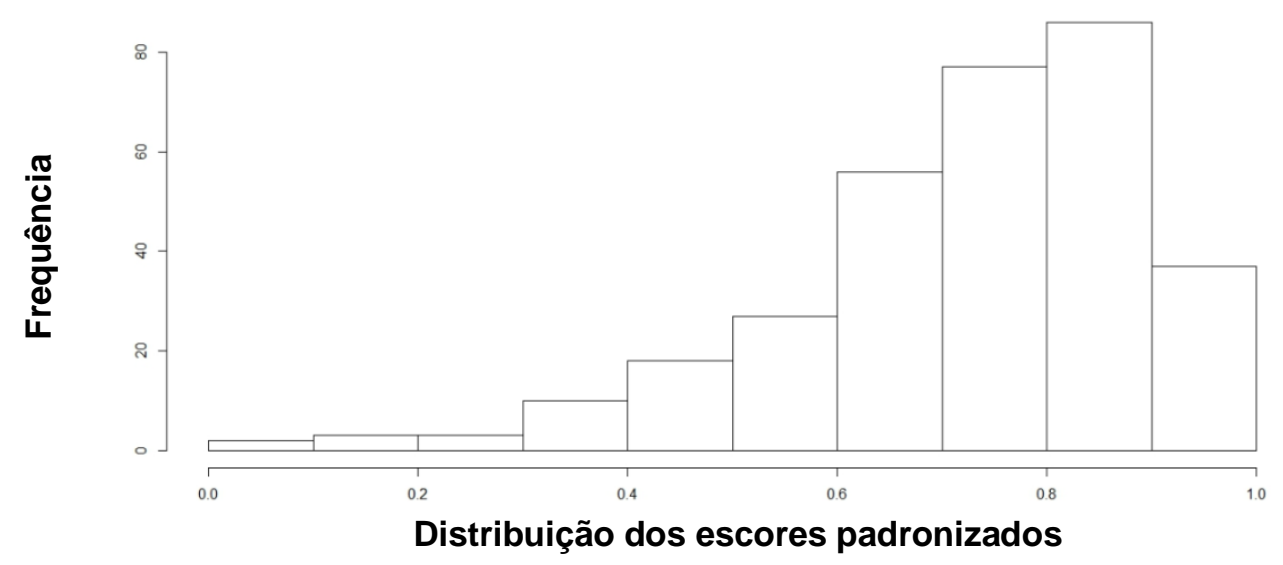

Figura 10 - Distribuição geral dos escores padronizados segundo as respostas dos participantes. Porto Alegre, 2014.

A Tabela 2 apresenta os testes de Normalidade de Shapiro-Wilk e Kolmogorov-Smirnov. Em ambos os testes constata-se a rejeição da hipótese nula de Normalidade dos dados, razão adicional que fortalece a proposta de utilização do modelo de regressão Beta.

Tabela 2 - Teste de Normalidade dos escores padronizados do modelo. Porto Alegre, 2014.

\begin{tabular}{lcc}
\hline & Shapiro-Wilk & Kolmogorov- Smirnov \\
\hline Estatística & 0.9216 & 0.6050 \\
p-valor & 0,0000 & 0,0005 \\
\hline
\end{tabular}

O ajuste do modelo, considerando-se ambos os fatores, categoria profissional e domínios, pode ser observado na Tabela 3. O intercepto do modelo representa o 
efeito da categoria profissional "médico" e domínio "conhecimento". Nesse sentido, pode-se dizer que, dentre as categorias profissionais, apenas a de auxiliar de enfermagem tem efeito estatisticamente significante quando comparada à de médico, considerando-se um mesmo domínio; já com relação aos domínios, o de inovação apresentou significância estatística em relação ao conhecimento, considerando-se uma mesma função.

Tabela 3 - Estimativa dos parâmetros do modelo de regressão Beta. Porto Alegre, 2014.

\begin{tabular}{lcccc}
\hline & Estimativa & Desvio padrão & Estatística & $\boldsymbol{p}$-valor \\
\hline (Intercept) & 1,0457 & 0,0983 & 10,6400 & 0,0000 \\
FUNCAO_inf_sENFERMEIRO & 0,0585 & 0,1164 & 0,5030 & 0,6150 \\
FUNCAO_inf_sTECNICO & 0,0898 & 0,1283 & 0,7000 & 0,4841 \\
FUNCAO_inf_sAUXILIAR & 0,3472 & 0,1225 & 2,8350 & 0,0046 \\
Dominios_sinformacao & $-0,1877$ & 0,1113 & $-1,6870$ & 0,0917 \\
Dominios_sinovacao & $-0,4519$ & 0,1089 & $-4,1510$ & 0,0000 \\
(phi) & 6,1033 & 0,4597 & 13,2800 & $<2 \mathrm{e}-16$ \\
\hline
\end{tabular}

De acordo com as medidas de diagnóstico apresentadas na Figura 11, observa-se que os pontos 219 (médico, dimensão inovação, 0,0250) e 318 (auxiliar de enfermagem, dimensão inovação, 0,9861) foram considerados pontos influentes e com alto resíduo, portanto foram removidos do modelo.
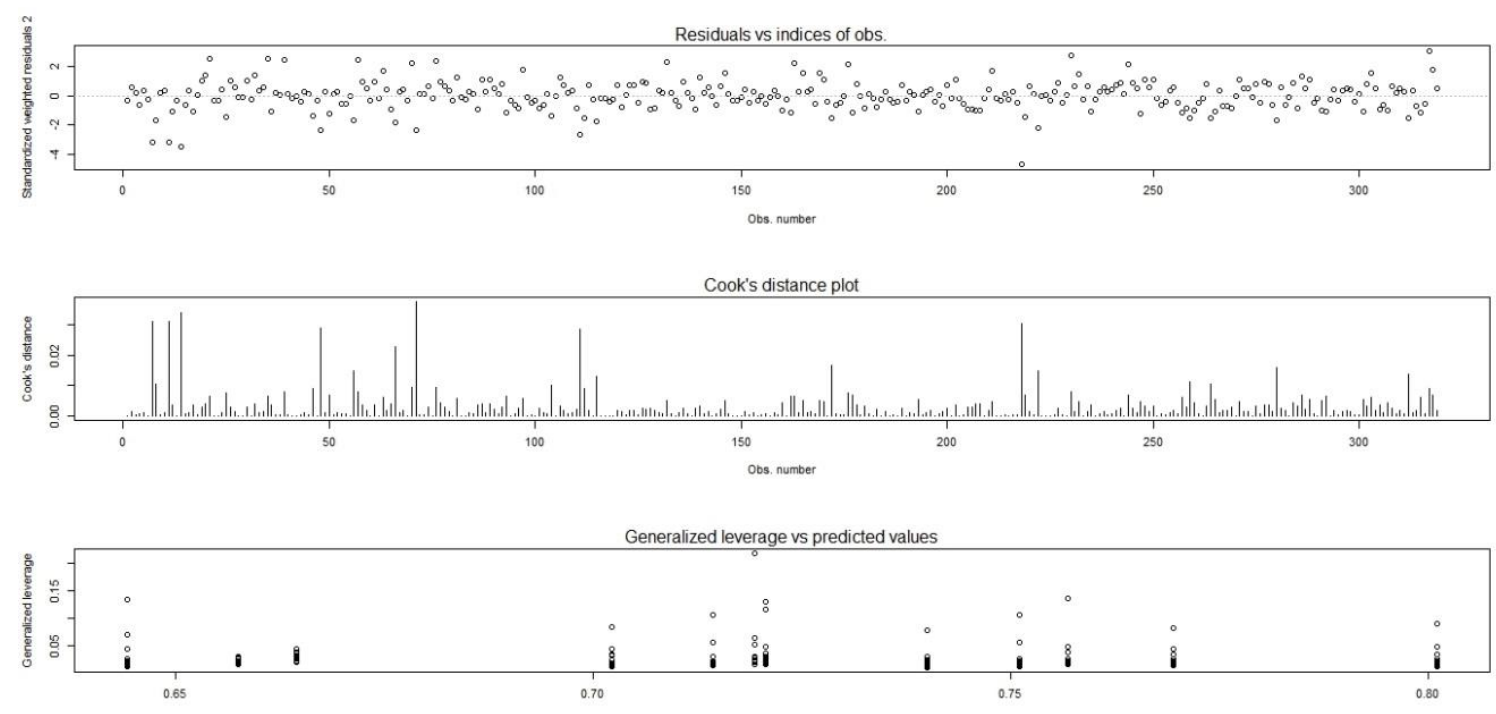
Figura 11 - Representação dos resíduos do modelo, da distância de Cook e da matriz de influência (matriz H). Porto Alegre, 2014.

Um novo ajuste foi realizado após tais exclusões, e os resultados obtidos podem ser visualizados na Tabela 4 . Nota-se que as estimativas relacionadas às categorias foram mais afetadas, contudo, a remoção dos pontos não afetou a significância dos parâmetros estimados.

Tabela 4 - Estimativa dos parâmetros do modelo de regressão Beta após a exclusão dos valores aberrantes ou outliers. Porto Alegre, 2014.

\begin{tabular}{lcccc}
\hline & Estimativa & Desvio padrão & Estatística & $\boldsymbol{p}$-valor \\
\hline (Intercept) & 1,0890 & 0,0960 & 11,3500 & $2 \mathrm{E}-16$ \\
FUNCAO_inf_sENFERMEIRO & 0,0269 & 0,1134 & 0,2370 & 0,8123 \\
FUNCAO_inf_sTECNICO & 0,0587 & 0,1249 & 0,4700 & 0,6385 \\
FUNCAO_inf_sAUXILIAR & 0,2816 & 0,1197 & 2,3530 & 0,0186 \\
Dominios_sinformacao & $-0,1902$ & 0,1083 & $-1,7560$ & 0,0791 \\
Dominios_sinovacao & $-0,4471$ & 0,1063 & $-4,2050$ & 0,0000 \\
(phi) & 6,6105 & 0,5011 & 13,1900 & $<2 \mathrm{e}-16$ \\
\hline
\end{tabular}

Ao realizar o teste de normalidade para os resíduos, os resultados demonstraram que eles ainda não apresentavam distribuição normal ( $p$-valor 0,0001 - Shapiro-Wilk; $p$-valor 0,2162 - Kolmogorov-Smirnov). Uma possível solução para a questão foi a realização do modelo de regressão Beta estendido e a modelagem também do parâmetro de precisão (phi).

$\mathrm{Na}$ Tabela 5 temos o ajuste do modelo considerando-se ambos os fatores, categoria profissional e domínios para ambos os parâmetros da média e da precisão. A categoria auxiliar de enfermagem apresentou significância estatística tanto para a média quanto para a precisão. Em relação a esta última, a categoria enfermeiro também apresentou significância estatística. Já com relação aos domínios, o da "Informação" passou a ser significante tanto para a média quanto para a precisão, enquanto "Inovação" não se mostrou estatisticamente significante para a precisão. 
Tabela 5 - Estimativa dos parâmetros do modelo de regressão Beta (Heterocedástico). Porto Alegre, 2014.

\begin{tabular}{lcccc}
\hline \multicolumn{1}{c}{ Coeficientes Beta } & Estimativa & Desvio padrão & Estimativa & $\boldsymbol{p}$-valor \\
\hline (Intercept) & 1,0739 & 0,0992 & 10,8220 & 0,0000 \\
FUNCAO_inf_sENFERMEIRO & 0,1333 & 0,1186 & 1,1240 & 0,2609 \\
FUNCAO_inf_sTECNICO & 0,1190 & 0,1313 & 0,9060 & 0,3650 \\
FUNCAO_inf_sAUXILIAR & 0,4461 & 0,1230 & 3,6280 & 0,0003 \\
Dominios_sinformacao & $-0,2900$ & 0,1145 & $-2,5320$ & 0,0113 \\
Dominios_sinovacao & $-0,5258$ & 0,1049 & $-5,0140$ & 0,0000 \\
& & & & \\
phi & & & & \\
(Intercept) & 1,8773 & 0,1632 & 11,5040 & 0,0000 \\
FUNCAO_inf_sENFERMEIRO & 0,4289 & 0,1971 & 2,1760 & 0,0295 \\
FUNCAO_inf_sTECNICO & 0,3502 & 0,2165 & 1,6170 & 0,1058 \\
FUNCAO_inf_sAUXILIAR & 0,5537 & 0,2047 & 2,7060 & 0,0068 \\
Dominios_sinformacao & $-0,5558$ & 0,1860 & $-2,9890$ & 0,0028 \\
Dominios_sinovacao & $-0,3158$ & 0,1842 & $-1,7140$ & 0,0865 \\
\hline
\end{tabular}

De acordo com as medidas de diagnóstico apresentadas na Figura 12, observa-se que novamente os pontos 219 (médico, dimensão inovação, 0,0250) e 318 (auxiliar de enfermagem, dimensão inovação, 0,9861) foram considerados pontos influentes e com alto resíduo, logo, foram removidos do modelo.
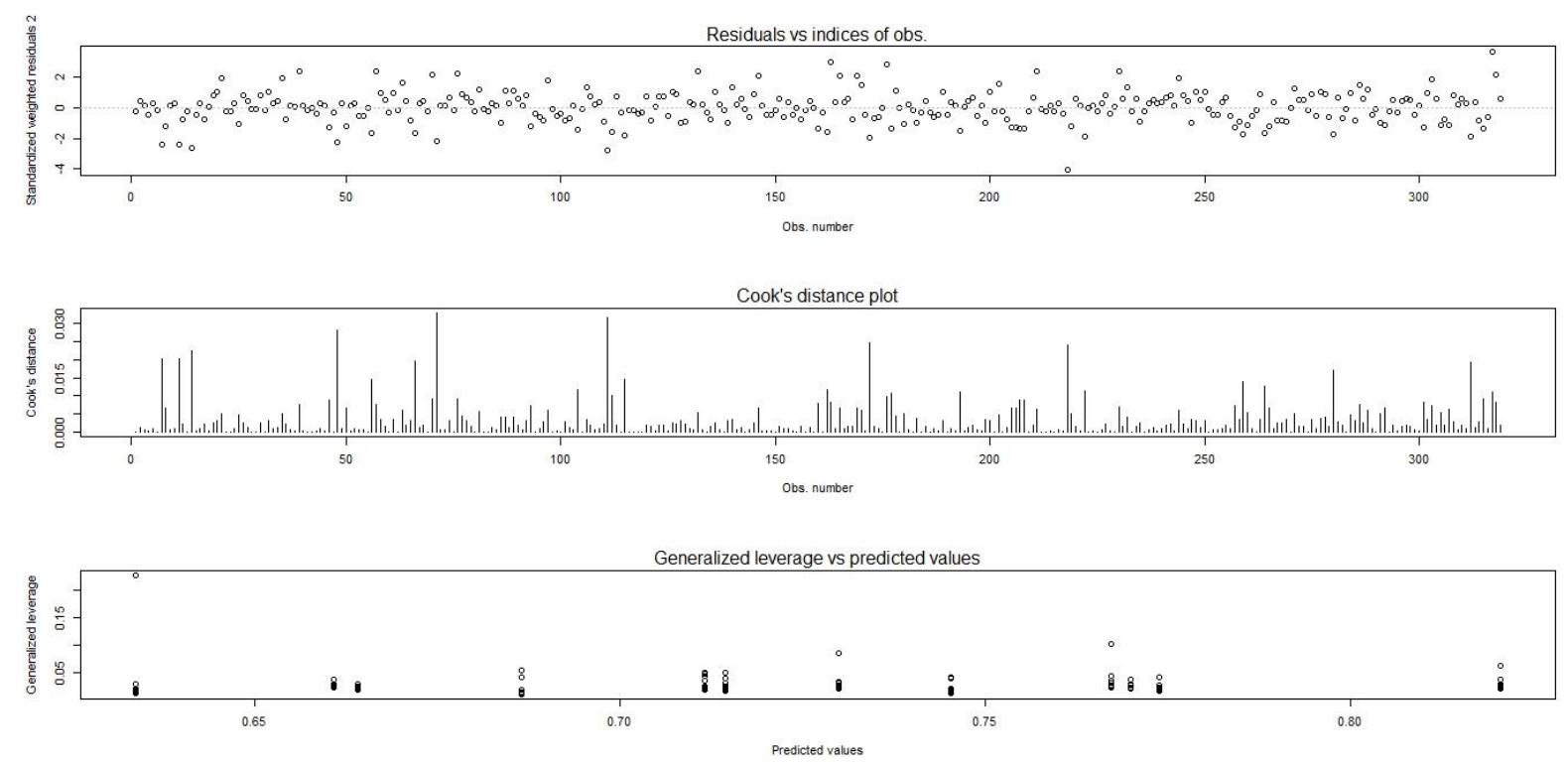

Figura 12 - Representação dos resíduos do modelo, da distância de Cook e da matriz de influência (matriz H) após novo ajuste. Porto Alegre, 2014 
Outro ajuste foi realizado sem esses pontos e os resultados apresentados conforme Tabela 6.

Tabela 6 - Estimativa dos parâmetros do modelo de regressão Beta (Heterocedástico) após exclusão dos valores aberrantes ou outliers. Porto Alegre, 2014.

\begin{tabular}{lcccc}
\hline \multicolumn{1}{c}{ Coeficientes Beta } & Estimativa & Desvio padrão & Estatística & p-valor \\
\hline (Intercept) & 1,1157 & 0,0957 & 11,6550 & 0,0000 \\
FUNCAO_inf_sENFERMEIRO & 0,0528 & 0,1155 & 0,4570 & 0,6475 \\
FUNCAO_inf_sTECNICO & 0,0211 & 0,1254 & 0,1680 & 0,8663 \\
FUNCAO_inf_sAUXILIAR & 0,3557 & 0,1173 & 3,0310 & 0,0024 \\
Dominios_sinformacao & $-0,2748$ & 0,1142 & $-2,4060$ & 0,0161 \\
Dominios_sinovacao & $-0,4757$ & 0,0998 & $-4,7650$ & 0,0000 \\
& & & & \\
phi & & & & \\
(Intercept) & 1,9819 & 0,1643 & 12,0620 & 0,0000 \\
FUNCAO_inf_sENFERMEIRO & 0,2634 & 0,1979 & 1,3310 & 0,1833 \\
FUNCAO_inf_sTECNICO & 0,2834 & 0,2189 & 1,2940 & 0,1955 \\
FUNCAO_inf_sAUXILIAR & 0,4807 & 0,2065 & 2,3270 & 0,0200 \\
Dominios_sinformacao & $-0,6026$ & 0,1865 & $-3,2310$ & 0,0012 \\
Dominios_sinovacao & $-0,1140$ & 0,1867 & $-0,6110$ & 0,5415 \\
\hline
\end{tabular}

Nota-se que as estimativas relacionadas às categorias foram mais afetadas, e a função enfermeiro deixou de possuir significância estatística para a precisão, enquanto as estimativas dos domínios não sofreram alteração de significância estatística.

Uma vez realizado o teste de normalidade para os resíduos, observamos que eles agora não mais apresentam rejeição da hipótese nula de normalidade, já que o valor de $p$ é maior que o a ( $p$-valor 0,0868 - Shapiro-Wilk; $p$-valor 0,5579 Kolmogorov-Smirnov), o que indica que o ajuste encontrado foi satisfatório.

A partir desse ajuste encontrado, apresentamos na Tabela 7 os valores preditos pelo modelo para a média $(\mu$ ) e o desvio padrão (a raiz quadrada da variância, que é calculada através de $\mu$ e $\varphi$ ). 
Tabela 7 - Valores preditos para o modelo em relação à média e ao desvio padrão segundo os domínios e as categorias profissionais. Porto Alegre, 2014.

\begin{tabular}{|c|c|c|c|}
\hline Domínio & Categoria & $\begin{array}{c}\text { Média da } \\
\text { média } \\
\text { padronizada }\end{array}$ & Desvio \\
\hline Informação & Médico & 0,7096 & 0,1828 \\
\hline Informação & Enfermeiro & 0,6666 & 0,1536 \\
\hline Informação & Técnico & 0,7571 & 0,1315 \\
\hline Informação & Auxiliar & 0,7031 & 0,1824 \\
\hline Conhecimento & Médico & 0,7532 & 0,1501 \\
\hline Conhecimento & Enfermeiro & 0,6986 & 0,2058 \\
\hline Conhecimento & Técnico & 0,6547 & 0,1739 \\
\hline Conhecimento & Auxiliar & 0,7629 & 0,1316 \\
\hline Inovação & Médico & 0,6595 & 0,1530 \\
\hline Inovação & Enfermeiro & 0.8133 & 0,1092 \\
\hline Inovação & Técnico & 0,7679 & 0,1549 \\
\hline Inovação & Auxiliar & 0,7302 & 0,1311 \\
\hline
\end{tabular}

Observa-se que a categoria técnico de enfermagem possui a maior média da dimensão "Informação" (0,7571 - 75,7\%) e a enfermeiro a menor $(0,6666-66,6 \%)$ quando comparada às demais categorias. Já na dimensão "Conhecimento", a categoria auxiliar de enfermagem foi a que mais se sobressaiu $(0,7629-76,2 \%)$ e técnicos de enfermagem a com menor média (0,6547 - 65,4\%). Em "Inovação", o enfermeiro toma a dianteira $(0,8133-81,3 \%)$, e a categoria médico apresenta a menor média $(0,6595-65,9 \%)$.

Os Gráficos 1, 2 e 3 que se seguem representam as distribuições (das respostas) construídas com base nos valores preditos (Tabela 7) da média para cada um dos domínios separados por categoria profissional. As curvas mais achatadas representam as categorias com maior dispersão nos escores medidos. 


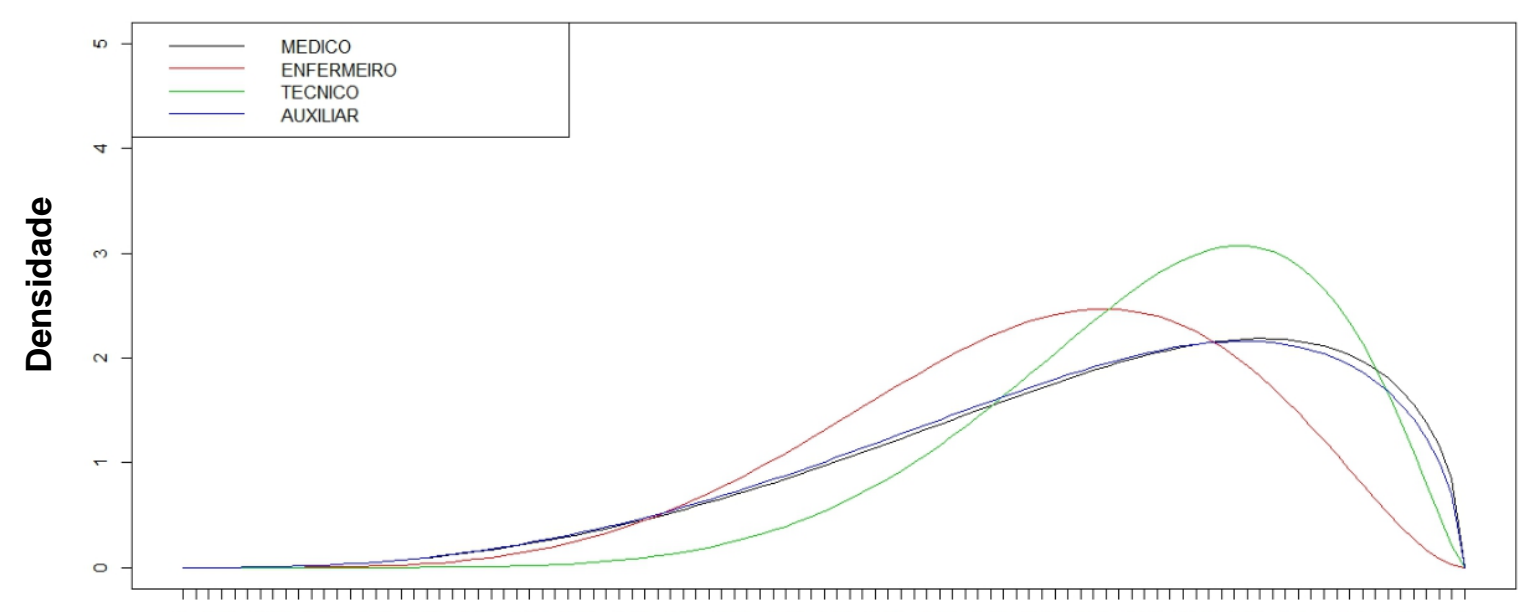

$\begin{array}{llllllllllllllllllllllllll}0 & 0.03 & 0.07 & 0.11 & 0.15 & 0.19 & 0.23 & 0.27 & 0.31 & 0.35 & 0.39 & 0.43 & 0.47 & 0.51 & 0.55 & 0.59 & 0.63 & 0.67 & 0.71 & 0.75 & 0.79 & 0.83 & 0.87 & 0.91 & 0.95 & 0.99\end{array}$

\section{Escore padronizado}

Gráfico 1 - Distribuição dos escores padronizados por categoria profissional para o domínio Informação. Porto Alegre, 2014.

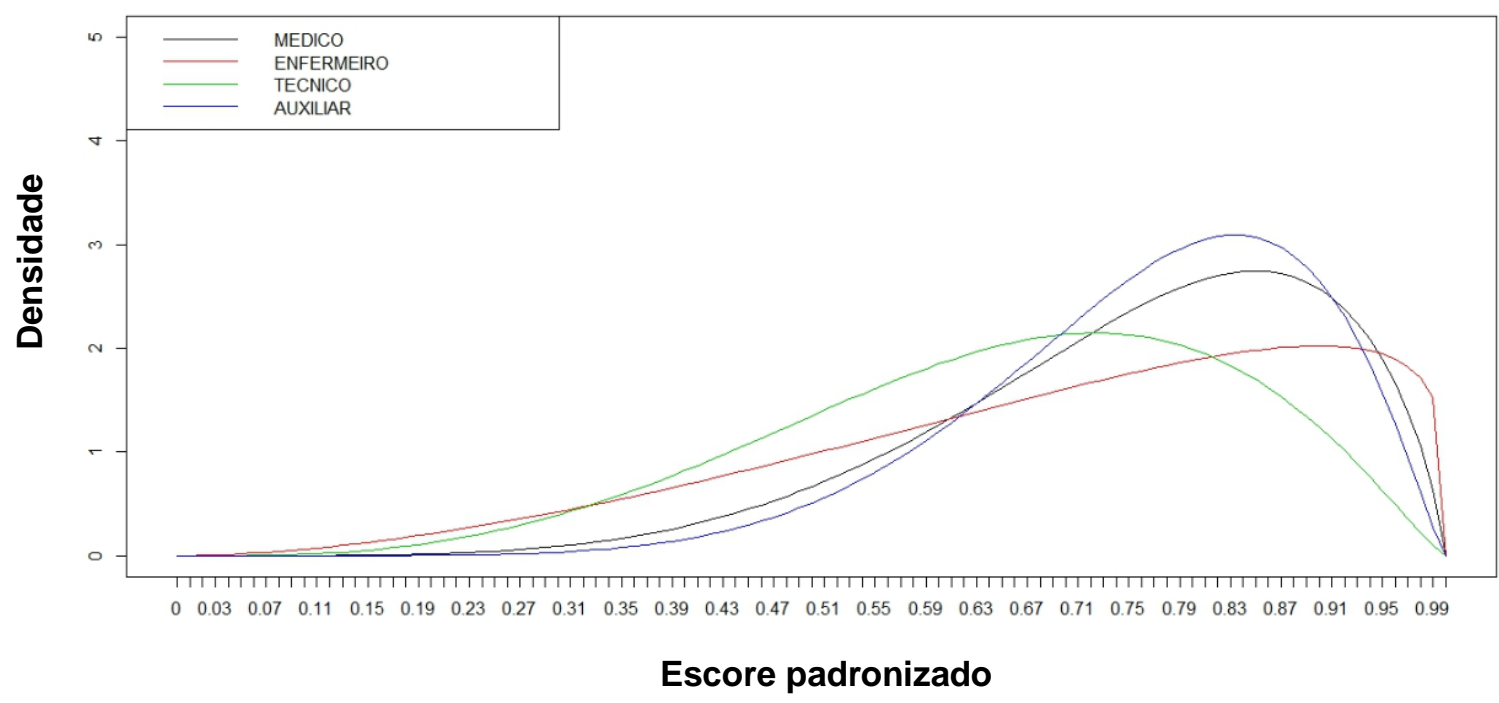

Gráfico 2 - Distribuição dos escores padronizados por categoria profissional para o domínio Conhecimento. Porto Alegre, 2014. 


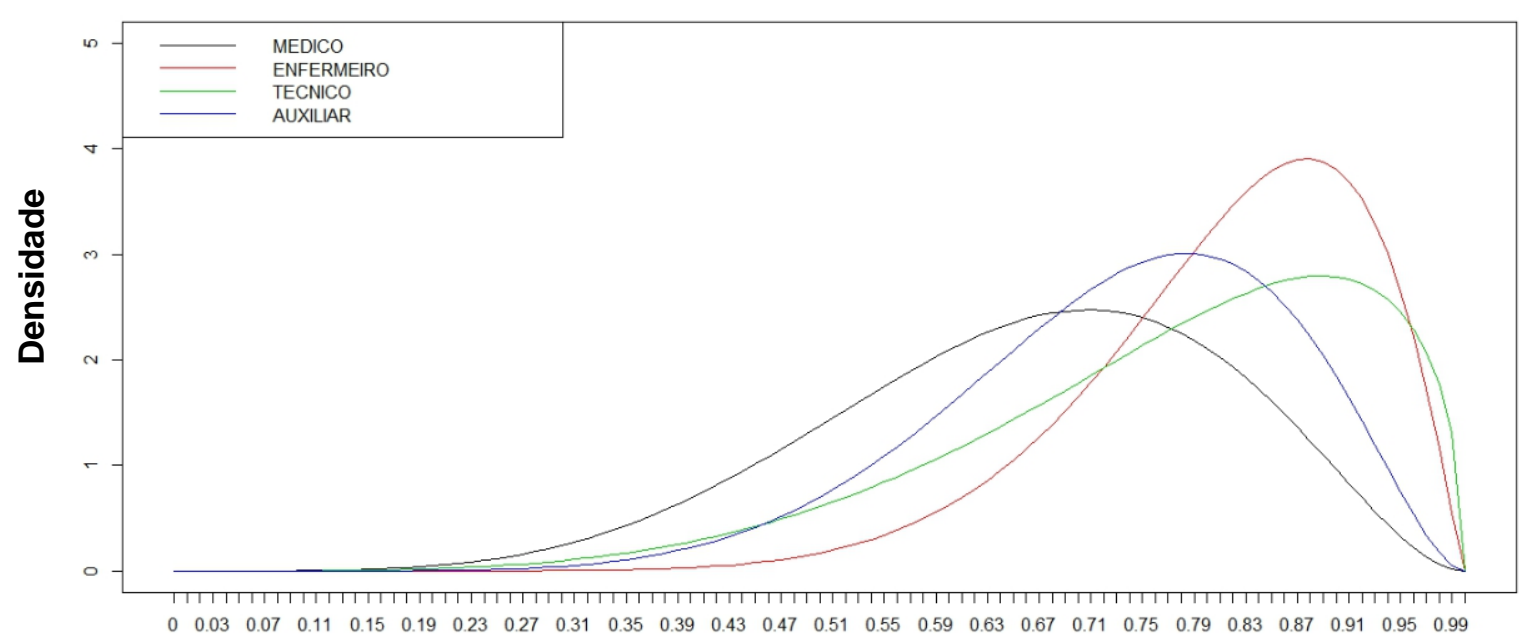

Escore padronizado

Gráfico 3 - Distribuição dos escores padronizados por categoria profissional para o domínio Inovação. Porto Alegre, 2014.

$\mathrm{Na}$ dimensão "Informação", as respostas mais dispersas (maiores desvio padrão) foram as da categoria médica e auxiliar de enfermagem $(0,1828$ [18,28\%] e 0,1824[18,24\%], respectivamente). A categoria enfermeiro apresentou o maior desvio padrão em "Conhecimento" (0.2058 [20,58\%]) e o menor em "Inovação" $(0,1092[10,92 \%])$. Já o maior desvio padrão da dimensão "inovação" pertence à categoria técnico de enfermagem, seguida de perto pela categoria médica $(0,1549$ [15,49\%] e 0,1530[15,30\%], respectivamente).

\subsection{ENTRE NÚMEROS E PALAVRAS, DADOS E FATOS: POSSÍVEIS INTERPRETAÇÕES}

A predominância de profissionais da saúde do sexo feminino no presente trabalho pode estar atrelada à vinculação histórica e naturalizada entre o ser mulher e desempenhar funções voltadas ao cuidar. Em 2007, nas regiões da América Latina e Caribe, por exemplo, foi constatado que aproximadamente sete milhões de pessoas, em sua grande maioria do sexo feminino, trabalhavam com atividades intensivas no setor saúde (PASTORE; ROSA; HOMEM, 2008). A maioria dos sujeitos que entrevistamos pertencia também ao grupo médico, apesar da 
reconhecida carência de tais profissionais nas instituições públicas. Há evidências de que para $57 \%$ da população brasileira o aumento do número de médicos é tido como fator fundamental na qualificação do serviço da rede pública (CNI - IBOPE, 2012).

Outro ponto importante refere-se às respostas dos participantes relacionadas ao questionário. Conforme visto anteriormente, os resultados em relação aos itens "3", "32", "21" e "19" nos mostram tensionamentos sobre fatos ligados à participação popular em discussões do TDO, à mobilização de recursos comunitários para incentivo à adesão do paciente, ao comprometimento da infraestrutura das unidades básicas e à necessidade de incorporação de outras instituições além das de saúde para o sucesso da política. Tais apontamentos nos levam ao encontro de achados similares na pesquisa qualitativa, em que foram observados não apenas 0 descontentamento e as queixas sobre a infraestrutura inadequada, mas também indícios de resistência, que em alguns momentos estava atrelada à visão dos profissionais de saúde do TDO enquanto sobrecarga de trabalho.

Por ser o TDO uma questão de abordagem multidisciplinar, entendemos que a participação de instituições que não da saúde torna-se igualmente importante na operacionalização de tal política, seja para o apoio ou ainda para viabilização de processos e recursos outros que independem deste setor. Talvez seja essa uma oportunidade de corresponsabilização que os profissionais de saúde conclamam também a seu favor.

O comprometimento do elemento motivacional foi outro ponto observado tanto nas entrevistas sobre a transferência do TDO com os coordenadores/gestores quanto nas respostas provenientes da aplicação do questionário aos profissionais de saúde. O item " 36 ", por exemplo, que faz referência direta ao sentir-se motivado a inovar as próprias ações no TDO, obteve média e escore padronizado de 3,79 $(69,71 \%)(T a b e l a ~ 1)$, ou seja, entre o "Indiferente" e o "Concordo parcialmente" da escala de Likert.

Assim também em relação ao planejamento. A existência de um planejamento incipiente, pouco aprofundado e sem atualização periódica pode influenciar de forma negativa o processo de transferência da política do TDO, sua compreensão e operacionalização, principalmente no que diz respeito à detecção precoce de 
problemas que precisam ser repensados e solucionados. Os sujeitos da pesquisa, por exemplo, voltaram a se posicionar entre o "Indiferente" e o "Concordo parcialmente" no que se refere à existência de treinamentos frequentes sobre o TDO para os profissionais recém-contratados ou realocados (item "37" - média/escore padronizado: 3,13 / 53,13\%, respectivamente), o que pode ser um indício de comprometimento do planejamento para manutenção do ciclo de transferência da política.

Torna-se importante fazermos ainda outra consideração pautada na análise dos resultados da Tabela 1 e a interlocução com a parte qualitativa do trabalho. Embora em determinado momento observaram-se altos escores relacionados à compreensão das diretrizes/protocolos do TDO e o reconhecimento da importância da política pela equipe de saúde (item "10" - 87,75\%; item " 11 " - 86,21\% e item "18" - 87,27\%, respectivamente), em outro o que se nota é a discrepância no que diz respeito a esse tema, já que também o item "12" obteve alto escore $(79,25 \%)$, contudo, este é empregado na contramão dos itens "10", "11" e "18”, por abordar o não seguimento das diretrizes do TDO pela falta de compreensão da importância e eficácia da política.

Nesse contexto, podemos pensar em duas possibilidades: o automatismo do sujeito ao responder o instrumento de pesquisa e a desatenção quanto aos itens colocados no formato de sentença negativa (como o item "12", por exemplo), ou ainda a contradição inerente ao sujeito de Pêcheux e as limitações ilusórias impostas pelo Universo Logicamente Estabilizado, aqui exemplificado pelo questionário, conforme dito anteriormente no presente trabalho.

Outra particularidade que merece destaque refere-se aos dados da Tabela 7. Conforme se observa, o técnico de enfermagem é a categoria com maior média e escore padronizados quanto se trata da dimensão "Informação" (0,7571 / 75,7\%); já a categoria auxiliar de enfermagem ocupa tal posição na dimensão "Conhecimento" $(0,7629$ - 76,2\%) e os enfermeiros na "Inovação" (0,8133 - 81,3\%). Contudo, conforme ressaltamos anteriormente, o instrumento ATP-IINFOC-TB não foi elaborado com o intuito de mensurar o grau de informação, conhecimento e inovação e, portanto, os resultados aqui obtidos não indicam necessariamente que os técnicos de enfermagem possuem mais informação sobre o TDO do que os 
demais profissionais de saúde, ou que os enfermeiros inovam mais na política, e assim por diante. O que se observa é que essas categorias se sobressaíram por apresentarem escores padronizados maiores e, de certa forma, mais próximos do "Concordo" da escala de Likert em relação aos respectivos grupos de itens expressos em cada dimensão do questionário.

A dimensão "Informação" (média geral de 72,7\% - entre o "Indiferente" e o "Concordo parcialmente"), por exemplo, aborda aspectos sobre a transferência de informações do TDO e a integração entre a coordenação dos serviços e os profissionais de saúde, a utilização de estratégias motivacionais nesse processo, o tipo de linguagem, estratégias e materiais educativos de sensibilização sobre a política e a participação popular em tais discussões. Na dimensão "Conhecimento" (média geral de 77,8\% - entre o "Concordo parcialmente" e o "Concordo"), são enfocados aspectos referentes à compreensão das diretrizes e protocolos do TDO, a frequência de capacitações e treinamentos, a participação dos profissionais de saúde em tais atividades, o reconhecimento da importância da política, o envolvimento de outros setores que não saúde no trato com o TDO, dentre outros. Já na dimensão "Inovação" (média geral de 67,7\% - entre o "Indiferente" e o "Concordo parcialmente"), questiona-se sobre infraestrutura adequada, a disponibilidade de recursos humanos, a elaboração de planos individuais para os pacientes e o envolvimento deles neste processo, da autonomia na escolha da modalidade de tratamento, da criação de estratégias novas para a abordagem e incentivo ao TDO, do desenvolvimento de ações intersetoriais, dos aspectos motivacionais, dentre outros.

Conforme se observa, as médias gerais dos escores padronizados por dimensões dispõem de localizações variáveis na escala de Likert, com interfaces no "Indiferente", "Concordo parcialmente" e "Concordo". Nesse sentido, torna-se importante atentar-se para o conjunto de elementos do processo de transferência relacionados às dimensões Inovação e Informação, principalmente por terem sido as que alcançaram, de forma geral, os menores e mais preocupantes escores $(67,7 \%$ e $72,7 \%$, respectivamente, ou seja, entre o "Indiferente" e o "Concordo Parcialmente") sinalizando a necessidade de reformulações e melhorias. 


\title{
5.6 IMPLICAÇÕES DA PEQUISA PARA A PRÁTICA EM ENFERMAGEM
}

Ao profissional enfermeiro são delegadas funções variadas no desempenho das suas atividades, que incluem não apenas aquelas voltadas à prática assistencialista, mas também as relacionadas ao planejamento, à coordenação, à prestação de consultorias, à organização, execução e avaliação dos serviços da assistência de enfermagem, ao desenvolvimento de atividades educativas com vistas à melhoria da saúde da população, dentre outras, conforme especificado pela Lei oㅜ 7.498 de 1986, que regulamenta o exercício da Enfermagem. Lima (1996) $)^{17}$ apud Figueredo (2013, p.65) esclarece que

\begin{abstract}
o enfermeiro enquanto agente de trabalho em saúde tem desempenhado um papel importante na educação em saúde. $O$ trabalho da enfermagem está diretamente vinculado a uma dimensão educativa desde o surgimento da enfermagem moderna no Brasil, já que os enfermeiros foram formados para preencher a falta de um profissional voltado às atividades educativas sanitárias iniciadas por médicos sanitaristas na década de 1920.
\end{abstract}

Frente a esse misto de possibilidades e desafios que perpassam há muito o âmbito da profissão, torna-se imperioso que os enfermeiros estejam preparados adequadamente e desenvolvam habilidades e potencialidades que visem 0 fortalecimento de atributos vários, como do poder de liderança, do conhecimento técnico e científico, da capacidade comunicativa, do dinamismo e da eficiência.

Fernandes et al. (2008), por exemplo, elucidaram alguns atributos desejáveis ao enfermeiro coordenador de grupo que trabalha na formação de recursos humanos (processos de treinamentos, sensibilização, educação permanente, etc.), dentre eles, a competência para estabelecer relações e ambientes baseados na confiança, em que se permite criar e construir o conhecimento a partir dos próprios recursos do grupo, a adoção de uma postura de facilitador com enfoque na educação de duplo sentido, a capacidade de observação e identificação de elementos do processo comunicativo, como bloqueios, ruídos e filtragens com vistas

\footnotetext{
${ }^{17}$ LIMA, M. A. D. S. Educação em Saúde: algumas reflexões e implicações para a prática de enfermagem. Revista Gaúcha de Enfermagem. Porto Alegre. v. 17, n. 2, p. 87-91, 1996.
} 
à qualificação das relações interpessoais e o desenvolvimento de habilidades técnicas, interacionais e de domínio das relações existentes no grupo.

Já Peres e Ciampone (2006, p.496) ressaltaram que

o envolvimento do enfermeiro no processo de educação permanente acontece com a aquisição contínua de habilidades e competências que estejam de acordo com o contexto epidemiológico e com as necessidades dos cenários de saúde, para que resultem em atitudes que gerem mudanças qualitativas no processo de trabalho da enfermagem.

Assim, considerando a responsabilidade do enfermeiro frente às atividades educativas, e compreendendo a transferência de política pública como um processo que envolve formação e qualificação de recursos humanos, acreditamos ser fundamental a observação por tais profissionais, não apenas dos atributos, habilidades e competências desejáveis neste processo, mas sobretudo da necessidade de qualificação técnico-científica e de um conhecimento holístico do contexto de trabalho.

Uma vez que se trata de assunto incipiente e ainda pouco explorado na literatura brasileira, cabe ao enfermeiro apropriar-se adequadamente do seu conteúdo com o intuito de garantir que as políticas de saúde sejam transferidas e apreendidas com eficácia pelos demais profissionais sob sua responsabilidade. Além disso, a própria complexidade do processo de transferência, a diversidade de elementos envolvidos, as várias possibilidades de abordagem de tais elementos e a necessidade de priorizá-los muitas vezes já exigem por si um preparo técnico e uma visão panorâmica do profissional envolvido em tal atividade.

Quando consideramos o processo de transferência da política do Tratamento Diretamente Observado em Porto Alegre, reconhecemos a importância da conscientização profissional não apenas do conteúdo de tal processo, mas ainda das formas apropriadas de planejar sua operacionalização. Para o enfermeiro, o planejamento é de suma importância no desempenho das suas tarefas gerenciais, bem como para a qualificação da assistência destinada aos usuários (BENETTI et al., 2011). Contudo, quando se trata de ações educativas, ele ainda nos parece frágil e insustentável, já que, conforme Roecker, Nunes e Marcon (2013), não raro o 
enfermeiro lida com empecilhos e limitações vinculadas à ausência de valorização, normatização e sistematização de tais ações.

Se os achados do presente trabalho nos levam a enfatizar a necessidade de aprimoramento técnico-científico dos profissionais de saúde (neles incluídos os enfermeiros) a respeito dos processos de planejamento e transferência de políticas públicas, eles também nos levam a ressaltar a imprescindibilidade de se atrelar tais processos ao conhecimento da situação epidemiológica da doença, o que, aliás, assume feição alarmante em se tratando da TB em Porto Alegre. Importante notar, porém, que não se trata apenas da investigação dos indicadores e taxas vinculados à doença, mas da elaboração de um diagnóstico aprofundado da influência de outros fatores causais, como, por exemplo, os determinantes sociais, econômicos, de renda, dentre outros.

Segundo Peres et al. (2013), a ausência de articulação e planejamento nos serviços de saúde acarreta um círculo vicioso baseado no atendimento das demandas espontâneas em detrimento das ações programadas, o que fortalece muito mais o enfoque curativo nas unidades de saúde. A epidemiologia por sua vez tende a favorecer um planejamento que extrapola o âmbito das práticas curativas, por justamente permitir esta visão ampliada do processo de saúde-doença. Assim, se o discurso de promoção da saúde e prevenção de doenças está cada dia mais em voga nos debates em saúde, o fato é que, para ser exitoso, ele precisa estar decididamente de mãos dadas com um bom planejamento.

Ao sugerirmos um aperfeiçoamento técnico do enfermeiro e dos demais profissionais de saúde nos domínios do planejamento e da transferência de políticas públicas, partimos da perspectiva de que ele possa ocorrer por meios diversificados, como, por exemplo, pelos processos de educação permanente no ambiente de trabalho, ou ainda pela inserção de disciplinas (nas grades curriculares da graduação) que sejam capazes de debater, fomentar e estimular o entendimento desses temas, bem como da gestão de políticas públicas, dos seus enfoques operacionais e do funcionamento da rede intra e intergovernamental. 
A tuberculose é um problema grave em Porto Alegre e exige intervenções eficazes em todos os níveis de governo. Não basta a existência de políticas públicas teoricamente perfeitas, que se tornam pouco efetivas na prática pela falta de qualificação do processo operativo, seja pelo despreparo profissional, pela falta de incentivo financeiro, pela infraestrutura inadequada ou ainda a titubeante vontade política.

O aumento contínuo das taxas da doença, contabilizados nos últimos anos nesse município, chama atenção para um desafio que extrapola os domínios patológicos de disseminação da doença, abrangendo entraves outros, como a resistência e a desmotivação gestora e dos profissionais de saúde no trato da política e do Tratamento Diretamente Observado da tuberculose. E, de fato, se o sistema falha, a população padece; não por acaso a capital rio-grandense tem ocupado há algum tempo as primeiras colocações entre os municípios brasileiros com maior incidência de TB.

Embora esforços tenham sido desprendidos com vistas à melhoria desse cenário em Porto Alegre, haja vista o processo de descentralização do atendimento da TB e da realização do TDO em todas as unidades da Atenção Primária vinculadas à SMS do município, por exemplo, o que se observa é que a luta exige maior empenho, recursos, motivação e mobilização dos seus principais atores.

Outro ponto a ser considerado é o de que, se a reestruturação dos serviços se faz necessária, que ela comece pelo enfretamento do estigma e preconceito seculares vinculados à doença, carreados no imaginário coletivo e nele incluídos o dos próprios profissionais atuantes na saúde. Nesse sentido, a informação e o conhecimento tornam-se grandes aliados.

Também se faz necessária uma reorganização das atividades vinculadas ao planejamento e à execução da transferência da política do TDO, que vá desde o entendimento e fortalecimento dos elementos envolvidos em tais processos (seja em relação às três dimensões aqui investigadas - Informação; Conhecimento e Inovação - ou ainda outros) até à padronização e sistematização das ações/instrumentos e o contínuo monitoramento, avaliação e atualização das diretrizes estratégicas que visem à divulgação da política e ao combate à doença. 
O alcance de resultados positivos passa, dentre outros, pela ação coordenada das instituições e setores diversos que não apenas a saúde, pelo envolvimento multiprofissional e da população na temática, por uma infraestrutura adequada de trabalho e pelo apoio e incentivo às práticas inovadoras, sem as quais o sistema tornar-se-ia engessado, ultrapassado e inoperante.

Como optamos por priorizar alguns elementos do arcabouço teórico proposto por Bissell, Lee e Freeman (2011) para o desenvolvimento deste trabalho, e frente às várias possibilidades de abordagem de tal modelo, sugerimos que novas pesquisas sejam feitas para abordar aspectos complementares e ainda não explorados da transferência da política do Tratamento Diretamente Observado em Porto Alegre.

Em nosso entendimento, este estudo, além de contribuir para a aquisição de evidências científicas sobre o tema, pode servir de apoio técnico para pesquisas similares a serem desenvolvidas em outros municípios do Brasil, com o diferencial de que possui flexibilidade suficiente para incorporação de outros elementos de análise. Todavia, ressaltamos a importância do uso de um modelo misto de pesquisa, com enfoque quantitativo e qualitativo, justificado pelas possibilidades de obtenção de dados mais completos e fidedignos. Este trabalho pode configurar-se ainda como subsídio teórico para a realização de diagnósticos mais aprofundados sobre a etapa de planejamento, transferência e operacionalização do TDO nas unidades de saúde estudadas, contribuindo, consequentemente, para a qualificação da política de combate à tuberculose no município.

Acreditamos que transferência de políticas públicas configura-se como importante tema de pesquisa a ser também desenvolvido nos domínios da Enfermagem, tendo em vista o papel central do profissional enfermeiro no processo de formação de recursos humanos e as funções gerenciais que comumente desempenha nos serviços de saúde. Nesse sentido, ressaltamos a importância do incentivo financeiro e do apoio institucional. Por fim, acreditamos que tal tema deva ser incluído e priorizado nas agendas dos gestores e coordenadores, como oportunidade de qualificação do processo de difusão e implementação das políticas do SUS e como passo indispensável na conquista de bons resultados. 
7. REFERÊNCIAS BIBLIOGRÁFICAS 
ACHARD, P.; DAVALLON, J.; DURAND, J-L.; PÊCHEUX, M.; ORLANDI, E. P. 0 Papel da Memória. Tradução de José Horta Nunes. $3^{\underline{a}}$ ed. Campinas, SP: Pontes Editores, 2010.

AKKARI, A. As reformas do ensino secundário: as lições das transferências NorteSul. Educação em Revista, v.44, p.257-271, 2006.

ALBAGLI, S.; MACIEL, M. L. Informação e conhecimento na inovação e no desenvolvimento local. Ciência da Informação, v.33, n.3, p.9-16, 2004.

ARTMANN, E. O planejamento estratégico situacional no nível local: um instrumento a favor da visão multissetorial. In Oficina Social no 3: desenvolvimento social. COPPE/UFRJ, 2000, 25p. Disponível em: < https://www.nescon.medicina.ufmg.br/biblioteca/registro/referencia/0000001709 >. Acesso em: 24 Fev. 2015

ASSOLINI, F. E. P. Interpretação e letramento: os pilares de sustentação da autoria. 269f. Tese (Doutorado em Ciências - Área Psicologia). Faculdade de Filosofia, Ciências e Letras de Ribeirão Preto. Departamento de Psicologia e Educação. Universidade de São Paulo. 2003.

BARCELOS, L. B. A enfermidade da saúde pública no Brasil.1 ed. Porto Alegre, RS: AGE, 2014.

BARRETO, A. A. A informação em seus momentos de passagem. DataGramaZero, Revista de Ciência da Informação, Rio de Janeiro, v.2, n.4, 2001. Disponível em: <http://www.dgz.org.br/ago01/Art_01.htm>. Acesso em: 22 Mai. 2014.

BENETTI, E. R. R.; KIRCHHOF, R. S.; GUIDO, L. de A.; PROCHNOW, A. G.; LIMA, S. B. S. de; WEILLER, T. H. Percepções acerca do planejamento em enfermagem como ferramenta de gestão. Revista Contexto \& Saúde, v.10, n.20, p.1177-1180, 2011.

BERTOLLI FILHO, C. História Social da Tuberculose e do Tuberculoso: 19001950. Rio de Janeiro: Editora FIOCRUZ, 2001. 248 p.

BISSELL, K.; LEE, K.; FREEMAN, R. Analysing policy transfer: perspectives for operational research. International Journal of Tuberculosis and Lung Disease, v.15, n.9, p.1140-1148, 2011.

BRASIL. Ministério da Saúde. Secretaria de Atenção à Saúde. Departamento de Atenção Básica. Política Nacional de Atenção Básica / Ministério da Saúde. Secretaria de Atenção à Saúde. Departamento de Atenção Básica. - Brasília: Ministério da Saúde, 2012. 110 p.: il. - (Série E. Legislação em Saúde).

BRITO, L. A. N. de. (Re)Lendo Michel Pêcheux: como a análise do discurso de linha francesa apreende a materialidade discursiva? Eutomia - Revista de Literatura e Linguística. edição 9, ano V, p.542 -562, 2012. 
BUENO, A. L.; MONROE, A. A.; GONZALES, R. I. C.; VILLA, T. C. S.; RUFFINONETO, A. A situação do controle da Tuberculose e avanços e dificuldades para a implantação da estratégia DOTS no município de Porto Alegre-RS. In: RUFFINONETO, A.; VILLA, T. C. S (Org.). Implantação do DOTS em algumas regiões do Brasil, histórico e peculiaridades regionais. REDE TB: 2006. Cap VIII, p.195-202.

BULLINGER, M.; SCHMIDT, S.; PETERSEN, C.; The DISABKIDS Group. Assessing quality of life of children with chronic health conditions and disabilities: a European approach. International Journal of Rehabilitation Research, v.25, n.3, p.197-206, 2002.

CADASTRO NACIONAL DE ESTABELECIMENTOS DE SAÚDE - CNES. Consulta - tipo de estabelecimento. Disponível em: <

http://cnes.datasus.gov.br/Mod_Ind_Unidade.asp?VEstado=43\&VMun=431490>. Acesso: 08 Fev. 2015.

CAMPOS, G. W. de S. Reflexões Temáticas sobre Equidade e Saúde: o caso do SUS. Saúde e Sociedade v.15, n.2, p.23-33, 2006.

CANADIAN INSTITUTES OF HEALTH RESEARCH. Canadian Institutes of Health Research. Innovation in Action: knowledge Translation Strategy 2004-2009. 2004. Disponível em: <http://www.cihr-irsc.gc.ca/e/documents/kt_strategy_20042009_e.pdf>. Acesso em: 22 Mai. 2014.

CARR, S. M.; CLARKE, C. L. The manager's role in mobilizing and nurturing development: entrenched and engaged approaches to change. Journal of Nursing Management, v.18, n.3, p.332-338, 2010.

CASTRO, A. L. B. de; MACHADO, C. V. A política de atenção primária à saúde no Brasil: notas sobre a regulação e o financiamento federal. Caderno de Saúde Pública, v.26, n.4, p.693-705, 2010.

CAZARIN, E. A. Gestos interpretativos na configuração metodológica de uma FD. Revista Organon: A pesquisa em Análise do Discurso no PPG-Letras/UFRGS e sua expansão institucional, v.24, n.48, 2010.

CHAROKOPOS, N.; TSIROS, G.; FOKA, A.; VOILA, P.; CHRYSANTHOPOULOS, K.; SPILIOPOULOU, I.; JELASTOPULU, E. Modified directly observed treatment for tuberculosis versus self-administered therapy: an observational study in rural Greece. The International Electronic Journal of Rural and Remote Health Research, Education, Practice and Policy. v.13, n.2, 2013.

CLANCY, L.; RIEDER, H. L.; ENARSON, D. A.; SPINACI, S. Tuberculosis elimination in the Countries of Europe and other industrialized counties. European Respiratory Journal, v.4, n.10, p.1288-1295, 1991.

CNI - IBOPE. Pesquisa CNI - IBOPE - Retratos da Sociedade Brasileira: Saúde Pública. Brasília: CNI, 2012. 67 p. 
CRIBARI-NETO, F.; ZEILEIS, A. Beta Regression in R. Journal of Statistical Software, v.34, n.2, p.1-24, 2010. Disponível em: $<$ http://www.jstatsoft.org/v34/i02/>. Acesso em: 14 Out. 2014.

CUNHA, A. L; SILVA, D. Construção e validação de um questionário de atitudes frente às relações CTS. VII Enpec, 2009. Disponível em: $<$ http://posgrad.fae.ufmg.br/posgrad/viienpec/pdfs/1195.pdf>. Acesso em: 26 Mai. 2014.

DATIKO, D. G.; LINDTJORN, B. Health Extension Workers Improve Tuberculosis Case Detection and Treatment Success in Southern Ethiopia: A Community Randomized Trial. PLoS ONE, v.4, n.5, p.1-7, 2009.

DENZIN, N. K.; LINCOLN, Y. S. Introduction: The Discipline and Practice of Qualitative Research. In. DENZIN, N.K.; LINCOLN, Y.S. (Eds.). The SAGE Handbook of Qualitative Research. Thousand Oaks: Sage Publications, 2011. Disponível em: < http://www.uk.sagepub.com/upm-data/40425_Chapter1.pdf>. Acesso em: 25 Mai 2014.

DEPARTAMENTO DE ATENÇÃO BÁSICA - DAB. Histórico de Cobertura de Saúde da Família. Disponível em: < http://dab.saude.gov.br/portaldab/ >. Acesso em: 08 Fev. 2015

DOLOWITZ, D; MARSH, D. Who learns what from whom: a review of the Policy Transfer literature. Political Studies, XLIV, p.343-357, 1996.

DOLOWITZ, D. P.; MARSH, D. Policy transfer: a framework for comparative analysis. In: MINOGUE, M; POLIDANO, C; HULME, D (Eds.). Beyond the new public management. Northhampton, MA: Edward Elgar, 1998.

DOLOWITZ, D. P. A Policy-Maker's guide to Policy Transfer. The Political Quartely Publishing Co, 2003.

EVANS, M.; DAVIES, J. Understanding policy transfer: a multi-level, multi-disciplinary perspective. Public Administration, v.77, n.2, p.361-385, 1999.

EVANS, M. New Directions in the Study of Policy Transfer. Abingdon, Oxon: Routledge, 2010.

FARAH, M. F. S. Disseminação de políticas públicas e programas governamentais no nível subnacional de governo. Revista Administração e Diálogo, v.2, n.11, p.6989, 2008a.

FARAH, M. F. S. Disseminação de inovações e políticas públicas e espaço local. Revista Organizações \& Sociedade (O\&S), v.15, n.45, p.107-126, $2008 \mathrm{~b}$.

FERNANDES, C. N. da S; MUNARI, D. B.; SOARES, S. M.; MEDEIROS, M. Habilidades e atributos do enfermeiro como coordenador de grupos. Revista da Rede de Enfermagem do Nordeste, v.9, n.1, p.146-153, 2008. 
FERRARI, S. L. P; CRIBARI-NETO, F. Beta Regression for Modelling Rates and Proportions. Journal of Applied Statistics, v.31, n.7, p.799-815, 2004.

FERREIRA, M. C. L. Linguagem, Ideologia e Psicanálise. Estudos da Lingua(gem) Michel Pêcheux e a Análise do Discurso. n.1, p.69-75, 2005a.

FERREIRA, M. C. L. Glossário de Termos do Discurso. Porto Alegre: UFRGS (Instituto de Letras), 2005b. 30 p.

FERREIRA, S. R. S.; GLASENAPP, R.; FERREIRA, R. L. T; FLORES, R. Tuberculose na Atenção Primária à Saúde. Grupo Hospitalar Conceição. Ministério da Saúde. Tuberculose na Atenção Primária à Saúde. $2^{\underline{a}}$ ed. Porto Alegre, RS: Hospital Nossa Senhora da Conceição, 2013. 220 p.

FERREIRA, S. R. S; GLASENAPP, R.; FLORES, R. Grupo Hospitalar Conceição. Ministério da Saúde. Tuberculose na Atenção Primária à Saúde. Porto Alegre, RS, 1a Ed. Ampliada. 2011 Disponível em:

<http://www2.ghc.com.br/GepNet/publicacoes/tuberculosenaatencao.pdf>. Acesso em: 16 Mai. 2014.

FIGUEIRA, M. M. C. Identificação de Outliers. Millenium, 12, p.1-16, 1998.

Disponível em:

<http://repositorio.ipv.pt/bitstream/10400.19/820/1/ldentifica\%C3\%A7\%C3\%A30\%20 de\%200utliers.pdf>. Acesso em: 11 Jan. 2015.

FIGUEREDO, R. C. de. Percepção dos educadores de uma escola pública sobre educação em saúde e atuação do enfermeiro na escola. Revista Cereus, UnirG, v.5, n.3, p.60-70, 2013.

FLANDOLI, B. X. Uma leitura crítica em psicologia sobre relações e condições de trabalho. Campo Grande, Assembleia Regional (Condições e Relações de Trabalho), 2009. Disponível em: < http://crpms.org.br/arquivos/site_noticias_1542305899.pdf> Acesso em: 24 Jun. 2014.

FREEMAN, R. Policy transfer in the health sector. European Forum Conference paper WS/35. Florence: Robert Schuman Centre for Advanced Studies, European University Institute, p.1- 25, 1999.

GARCIA, G. G. Las reformas de salud y los modelos de gestión. Revista Panamericana de Salud, v.9, n.6, p.406-412, 2001.

GAUDENZI, P.; ORTEGA, F. O estatuto da medicalização e as interpretações de Ivan Illich e Michel Foucault como ferramentas conceituais para o estudo da desmedicalização. Interface (Botucatu), v.16, n.40, p.21-34, 2012.

GIOVANELLA, L. As origens e as correntes atuais do enfoque estratégico em planejamento de saúde na América Latina. Cadernos de Saúde Pública, v.7, n.1, p. 26-44, 1991. 
GRANGEIRO, C. R. P. Discurso político: ecos de Madeira, sopros de vento. Estudos da Língua(gem), v.6, n.1, p.61-79, 2008.

GRAHAM, I. D.; LOGAN, J.; HARRISON, M. B.; STRAUS, S. E.; TETROE, J.; CASWELL, W.; ROBINSON, N. Lost in knowledge translation: time for a map? Journal of Continuing Education in the Health Professions, v.26, p.13-24, 2006.

GREENHALGH, T.; ROBERT, G.; MACFARLANE, F.; BATE, P.; KYRIAKIDOU, O. Diffusion of Innovations in Service Organizations: Systematic Review and Recommendations. The Milbank Quarterly, v.82, n.4, p.581-629, 2004.

GUIMARÃES, E. Língua e Enunciação. Caderno de Estudos Linguísticos, n.30, p.99 $-103,1996$.

HUERTAS, F. Entrevista com Carlos Matus: o método PES. Tradução de Giselda Barroso Sauveur. São Paulo: FUNDAP, 1996. 139 p.

INSTITUTO BRASILEIRO DE GEOGRAFIA E ESTATÍSTICA (IBGE). Censo 2010. Disponível em: < http://www.ibge.gov.br/home/estatistica/populacao/censo2010/tabelas_pdf/Rio_gran de_do_sul.pdf>. Acesso: 25 Mai. 2014.

JAMES, O; LODGE, M. The limitations of 'Policy Transfer' and 'Lesson Drawing' for public policy research. Political Studies Review, v.1, p.179 -193, 2003.

JASMER, R. M.; SEAMAN, C. B.; GONZALEZ, L. C.; KAWAMURA, L. M.; OSMOND, D. H.; DALEY, C. L. Tuberculosis Treatment Outcomes: Directly Observed Therapy Compared with Self-administered Therapy. American Journal of Respiratory and Critical Care Medicine, v.170, n.5, p.561-566, 2004.

JESUS, W. L. A.; ASSIS, M. M. A. (orgs.). Desafios do planejamento na construção do SUS. Salvador: EDUFBA, 2011.174 p.

JOBIM, R. D; WIEDERKEHR, P. Histórico da implantação do SINAN - Tuberculose em Porto Alegre. Boletim Epidemiológico, ano II, n.7, p.1-8, 2000.

KINOUCHI, R. R. Notas introdutórias ao pragmatismo clássico. Scientiæ Zudia, v.5, n.2, p.215-226, 2007.

KUSCHNIR, R; CHORNY, A. H. Redes de atenção à saúde: contextualizando o debate. Revista Ciência \& Saúde Coletiva, v.15, n.5, p.2307-2316, 2010.

LAGAZZI, S. O desafio de dizer não. Campinas-SP: Pontes, 1988.

LANA, F. C. F., GOMES, E. L. R. Reflexões sobre o planejamento em saúde e o processo da reforma sanitária brasileira. Revista Latino-Americana de Enfermagem, Ribeirão Preto, v.4, n.1, p.97-110, 1996. 
LEI 7.498 de 25 de Junho de 1986. Diário Oficial da União - Seção 1 - 26/6/1986, Página 9273 (Publicação Original). Disponível em: < http://www.cofen.gov.br/lei-n749886-de-25-de-junho-de-1986_4161.html>. Acesso em: 12 Jan. 2015.

LEMOS, C. Inovação na Era do Conhecimento. In: LASTRES, H. M. M.; ALBAGLI, S. (orgs.). Informação e Globalização na Era do Conhecimento. Rio de Janeiro: Campus, 1999. Capítulo 5, p.122-144.

LOTUFO, M.; MIRANDA, A. S. de. Sistemas de direção e práticas de gestão governamental em secretarias estaduais de saúde. Revista de Administração Pública, v.41, n.6, p.1143-1163, 2007.

MATUS, C. Politica, Planejamento \& Governo. vol. I e II. Brasília: IPEA, 1993.

MERHY, E. E.; CHAKKOUR, M.; STÉFANO, E.; STÉFANO, M. E.; SANTOS, C. M.; RODRIGUES, R. A.; OLIVEIRA, P. C. P de. Em busca de ferramentas analisadoras das tecnologias em saúde: a informação e o dia a dia de um serviço, interrogando e gerindo trabalhos. In: MERHY, E. E.; ONOCKO, R. Agir em Saúde um desafio para o público. São Paulo: Hucitec, 1997.

MICHELETTI, V. C. D. Programa de Controle da Tuberculose da Secretaria Municipal de Saúde de Porto Alegre - a adesão ao tratamento a partir da análise das estratégias da equipe de saúde. 2008. $53 \mathrm{f}$. Trabalho de conclusão do curso de especialização (Especialização em Gestão em Saúde) - Programa de PósGraduação em Administração da Universidade Federal do Rio Grande do Sul. Porto Alegre. 2008.

MICHELETTI, V. C. D.; MOREIRA, J. da S.; RIBEIRO, M. O.; KRITSKI, A. L.; BRAGA, J. U. Tuberculose resistente em pacientes incluídos no II Inquérito Nacional de Resistência aos Fármacos Antituberculose realizado em Porto Alegre, Brasil. Jornal Brasileiro de Pneumologia, v.40, n.2, p.155-163, 2014.

MINISTÉRIO DA SAÚDE. Tratamento Diretamente Observado (TDO) da Tuberculose na Atenção Básica: Protocolo de Enfermagem (2011). Disponível em:

$<$ http://www.suvisa.ba.gov.br/sites/default/files/vigilancia_epidemiologica/doencas_tr ansmissiveis/arquivo/2013/05/20/TDO_ultima_versao_03-08.pdf>. Acesso em: 19 Mai. 2014.

NASCIMENTO, J. C.; CHACON, L. Hesitação: um indício de autoria na conversação. In: Leda Verdiani Tfouni. (Org.). Múltiplas faces da Autoria (análise do discurso, psicanálise, literatura, modernidade, enunciação).1 ed. ljuí: Editora UNIJUÍ, 2008, v. ÚNICO, p.121-140.

NETO, H. B.; BEZZI, M. L. Regiões culturais: a construção de identidades culturais no Rio Grande do Sul e sua manifestação na paisagem gaúcha. Sociedade \& Natureza, v.20, n.2, p.135 - 155, 2008.

NEVES, J. L. Pesquisa Qualitativa - características, usos e possibilidades. Caderno de Pesquisas em Administração, v.1, n.3, p.1- 5, 1996. 
NEWMARK, A. J. An integrated approach to policy transfer and diffusion. Review of Policy Research, v.19, n.2: 153. (formerly Policy Studies Review), 2002.

NÚCLEO DAS CRÔNICAS/EVDT/CGVS/SMS/POA. Análise Epidemiológica da Tuberculose em Porto Alegre no período de 2001 a 2011, com destaque à situação epidemiológica de 2011. p. 1 - 19, 2012. Disponível em: < http://lproweb.procempa.com.br/pmpa/prefpoa/cgvs/usu_doc/analise_epidemiologica _da_tuberculose.pdf>. Acesso em: 16 Mai. 2014.

OGDEN, J.; WALT, G.; LUSH, L. The politics of 'branding' in policy transfer: the case of DOTS for tuberculosis control. Social Science \& Medicine, 57, p.179-188, 2003.

OLIVEN, R. G. A fabricação do Gaúcho. Cadernos CERU (2ª série), n.1, p.79-91, 1985.

ORLANDI, E. P. A linguagem e seu funcionamento: as formas do discurso. 4.ed. Campinas-SP: Pontes, 1996a.

ORLANDI, E. P. Exterioridade e Ideologia. Caderno Estudos da Linguagem, n.30, p. 27-33,1996b.

ORLANDI, E. P. As formas do silêncio: no movimento dos sentidos. 6a ed. Campinas - SP: Editora da Unicamp, 2007.

ORLANDI, E. P. Maio de 1968: os silêncios da memória. In: ACHARD, P. et al. O Papel da Memória. Tradução de José Horta Nunes. 3ª ed. Campinas-SP: Pontes Editores, 2010. p.58-67.

ORLANDI, E. P. Análise de discurso: princípios e procedimentos. $10^{\underline{a}} \mathrm{ed}$. Campinas - SP: Pontes, 2012.

OTT, W. P; JARCZEWSKI, C. A. Combate à tuberculose sob novo enfoque no Rio Grande do Sul. Boletim Epidemiológico, v.9, n.5, p.1-8, 2007.

PACÍFICO, S. M. R.; ROMÃO, L. M. S. Corta-dores de cana: o sujeito em migração do/no discurso. Revista Icarahy, ed.4, p.1-26, 2010.

PAGE, E. C. Future governance and the literature on policy transfer and lesson drawing. ESRC Future Governance Programme Workshop on Policy Transfer. Britannia House, London. p.1-15, 2000.

PAIM, J. S.; TEIXEIRA, C. F. Política, planejamento e gestão em saúde: balanço do estado da arte. Revista Saúde Pública, v.40, n. Esp, p.73-78, 2006.

PASQUALI, L. Instrumentos Psicológicos: Manual Prático de Elaboração. Brasília: LabPAM; IBAPP, 1999. 306 p.

PASSETI, E. Poder e Anarquia. Apontamentos literários sobre o atual conservadorismo moderado. Verve, n.12, p.11- 43, 2007. 
PASTORE, E.; ROSA, L. D.; HOMEM, I. D. Relações de gênero e poder entre trabalhadores da área da saúde. Fazendo Gênero 8 - Corpo, Violência e Poder, 2008.

PAULA, G. A. Modelos de Regressão com Apoio Computacional. Editora da USP, 2010. Disponível em:

<http://people.ufpr.br/ lucambio/CE225/2S2011/texto 2010.pdf >.

PÊCHEUX, M. A análise de discurso: três épocas (1983). In: GADET, F.; HAK, T. (orgs.).Por uma análise automática do discurso: uma introdução a obra de Michel Pêcheux. Trad.: Bethania S. Mariani et al. 3. ed. Campinas, SP: Editora da UNICAMP, 1997, p.311-319.

PÊCHEUX, M. Semântica e discurso: uma crítica à afirmação do óbvio. Trad.: Eni Puccinelli Orlandi et al. 4.ed. Campinas, SP: Editora da UNICAMP, 2009.

PÊCHEUX, M. O discurso: estrutura ou acontecimento. Trad.: Eni Puccinelli Orlandi. 6. ed. Campinas, SP: Pontes Editores, 2012.

PERES, A. M.; CIAMPONE, M. H. T. Gerência e competências gerais do enfermeiro. Texto e Contexto Enfermagem, v.15, n.3, p.492-499, 2006.

PERES, A. M.; FREITAS, L. J.; CALIXTO, R do C.; RIERA, J. R. M.; QUILES, A. S. Concepções dos enfermeiros sobre planejamento, organização e gestão de enfermagem na atenção básica: revisão integrativa. Revista de Enfermagem Referência, v.série III, n.10, p.153 -160, 2013.

PERUHYPE, R. C.; BATH-HEXTALL, F.; GALVÃO, C. M.; DARLINGTON, N.; PALHA, P. F. The effectiveness of educational interventions for health professionals in Direct Observed Therapy and the Directly Observed Therapy Short-Course strategy: a systematic review protocol. The JBI Database of Systematic Reviews and Implementation Reports, v.12, n.4, p.17-26. Disponível em: <http://joannabriggslibrary.org/index.php/jbisrir/article/view/996/1935>. Acesso em: 14 Jan. 2015.

PIZZINATO, A.; GUSTAVO, A. da S.; SANTOS, B. R. L. dos; OJEDA, B. S.; FERREIRA, E.; THIESEN, F. V.; CREUTZBERG, M.; ALTAMIRANO, M.; PANIZ, O.; CORBELLINI, V. L. A integração ensino-serviço como estratégia na formação profissional para o SUS. Revista Brasileira de Educação Médica, Rio de Janeiro, v.36, n.1, supl. 2, p.170-177, 2012.

PORTARIA 2.488 de 21 de outubro de 2011. Diário Oficial da União, 24/10/2011, Seção 1, p.48-55. Disponível em: < http://bvsms.saude.gov.br/bvs/saudelegis/gm/2011/prt2488_21_10_2011.html> Acesso em: 23 Fev. 2015.

POSSA, L. B. Mecanismos de participação e atores sociais em instituições hospitalares: o caso do Grupo Hospitalar Conceição - RS. 2007. 123 f. Dissertação de Mestrado (Mestrado em Sociologia) - Instituto de Filosofia e Ciências Humanas. Universidade Federal do Rio Grande do Sul. Porto Alegre. 2007. 
PREFEITURA MUNICIPAL DE PORTO ALEGRE. Secretaria Municipal de Saúde. Plano Municipal de Saúde 2010-2013. 2010. Disponível em: < http://lproweb.procempa.com.br/pmpa/prefpoa/sms/usu_doc/pms.pdf>. Acesso em: 09 Fev. 2015.

PROTTI, S. T.; SILVA, L. M. C. da; PALHA, P. F.; VILLA, T. C. S.; RUFFINO-NETO, A.; NOGUEIRA, J. de A.; SÁ, L. D. de. A gerência da Unidade Básica de Saúde no controle da tuberculose: um campo de desafios. Revista da Escola de Enfermagem da USP, v.44, n.3, p.665-670, 2010.

PRUSAK, L.; McGEE, J. Gerenciamento Estratégico da Informação: aumente a competitividade e a eficiência de sua empresa utilizando a informação como uma ferramenta estratégica. Tradução de Astrid Beatriz de Figueiredo. $21^{\underline{a}}$ ed. Rio de Janeiro: Elsevier, 1994. Disponível em<

http://books.google.com.br/books? id=WwHvCKH3hS0C\&printsec=frontcover\&source =gbs_ge_summary_r\&cad=0\#v=snippet $\& q=$ dados $\% 20$ coletados $\% 2 C \% 20$ organizado s\&f=false $>$ Acesso em: 09 Fev. 2015.

R Core Team. R: A language and environment for statistical computing. $R$ Foundation for Statistical Computing, Vienna, Austria, 2013. Disponível em:< http://www.R-project.org>.

RIBEIRO, D. O povo brasileiro: a formação e o sentido do Brasil. São Paulo: Companhia das Letras, 2006.

RIBEIRO, F. A. Atenção Primária (APS) e Sistema de Saúde no Brasil: uma perspectiva histórica. 2007. Dissertação de Mestrado (Mestrado em Ciências Medicina Preventiva) - Faculdade de Medicina da Universidade de São Paulo. São Paulo. 2007.

RIVERA, F. J. U. (org.). RIVERA, F. J. U.; TESTA, M.; MATUS, C. Planejamento e Programação em Saúde: um enfoque estratégico. Tradução de Elizabeth Artmann. 2.ed. São Paulo: Cortez, 1992.

RIVERA, F. J. U; ARTMANN, E. Planejamento e Gestão em Saúde: conceitos, história e propostas. Rio de Janeiro: Editora Fiocruz, 2012. 162 p.

ROCHA, N. M. F. D.; GÓIS, C. W. de L. Trajetórias de jovens no mundo do trabalho a partir da primeira inserção: o caso de Sísifo em Maracanaú - Ceará, Brasil.

Psicologia \& Sociedade, v.22, n.3, p.466-475, 2010.

ROECKER, S.; NUNES, E. de .F. P. de A.; MARCON, S. S. O trabalho educativo do enfermeiro na Estratégia Saúde da Família. Texto e Contexto Enfermagem, v.22, n.1, p.157-165, 2013.

RONZANI, T. M.; SILVA, C. de M. O Programa Saúde da Família segundo profissionais de saúde, gestores e usuários. Ciência \& Saúde coletiva, v.13, n.1, p.23 -34, 2008. 
RUFFINO-NETTO, A. Programa de Controle da Tuberculose no Brasil: situação atual e novas perspectivas. Informe Epidemiológico do SUS, v.10, n.3, p.129-138, 2001.

RUFFINO-NETTO, A. Tuberculose: a calamidade negligenciada. Revista da Sociedade Brasileira de Medicina Tropical, v.35, n.1, p.51-58, 2002.

SANTANA, R. M.; TAHARA, A. T. S. Planejamento em Enfermagem: aplicação do processo de enfermagem na prática administrativa. Ilhéus: Editus, 2008. $111 \mathrm{p}$.

SANTOS, H. S. Avaliação da rede de Unidades Básicas de Saúde com foco na integralidade. Revista Baiana de Saúde Pública, v.36, n.2, p.590-594, 2012. Disponível em: < http://inseer.ibict.br/rbsp/index.php/rbsp/article/viewFile/170/pdf_155>. Acesso em: 11 Fev. 2015.

SANTOS, S. S. B. Pêcheux. In: OLIVEIRA, L. A. (Org). Estudos do Discurso: perspectivas teóricas.1. ed. São Paulo: Parábola Editorial, 2013.

SAUAIA, A. C. A.; SYLOS, A. L. Plano Empresarial em 4 etapas. Caderno de Pesquisas em Administração, v.1, n.11, p.1-11, 2000.

SECRETARIA DE VIGILÂNCIA EM SAÚDE. MINISTÉRIO DA SAÚDE. Boletim Epidemiológico - Especial Tuberculose, v.43, p.1-12, 2012. Disponível em: < http://www.saude.rs.gov.br/upload/1337634001_Tuberculose-

Boletim\%20Epidemio.pdf>. Acesso em: 16 Mai. 2014.

SECRETARIA MUNICIPAL DE SAÚDE DE PORTO ALEGRE. Prefeitura Municipal de Porto Alegre. Relatório anual de gestão 2012. Disponível em: < http://proweb.procempa.com.br/pmpa/prefpoa/sms/usu_doc/relatorio_anual_de_gest ao_2012.pdf>. Acesso em: 17 Mai. 2014.

SILVA, S. E. D; CAMARGO, B. V.; PADILHA, M. I. A teoria das representações sociais nas pesquisas da Enfermagem Brasileira. Revista Brasileira de Enfermagem, Brasília, v.64, n.5, p.947-951, 2011.

SILVA, S.; OLIVEIRA, E. G. de; OLIVEIRA, L. C. G. de. A Expressividade Argumentativa do Adjetivo no Texto Publicitário. SIGNUM: Estudos da Linguagem, n. 16/1, p. 201-231, 2013.

SMITHSON, M.; VERKUILEN, J. A Better Lemon Squeezer? Maximum-Likelihood Regression with Beta-Distributed Dependent Variables. Psychological Methods, v.11, n.1, p.54-71, 2006.

SONTAG, S. A doença como metáfora. Rio de Janeiro - RJ: Edições Graal, 1984.

SOUZA, L. E. P. F. de. O SUS necessário e o SUS possível: estratégias de gestão. Uma reflexão a partir de uma experiência concreta. Revista Ciência \& Saúde Coletiva. v.14, n.3, p.911- 918, 2009. 
SOUZA, M. V. N. de; VASCONCELOS, T. R. A. Fármacos no combate à tuberculose: passado, presente e futuro. Química Nova, v.28, n.4, p.678-682, 2005.

STARFIELD, B. Atenção Primária: equilíbrio entre necessidades de saúde, serviços e tecnologia. Brasília: UNESCO, Ministério da Saúde, 2002. 726 p.

STONE, D. Learning Lessons and Transferring Policy across Time, Space and Disciplines. Politics - Political Studies Association, v.19, n.1, p.51-59, 1999.

STOP TB PARTNERSHIP. The Global Plan to stop TB 2011-2015: transforming the fight towards elimination of Tuberculosis. Geneva:World Health Organization (WHO), 2011-2015. Disponível em: <

http://www.stoptb.org/assets/documents/global/plan/TB_GlobalPlanToStopTB2011 2015.pdf>. Acesso em: 19 Mai. 2014.

TASCA, J. E.; ENSSLIN, L.; ENSSLIN, S. R. A avaliação de programas de capacitação: um estudo de caso na administração pública. Revista de Administração Pública, v.46, n.3, p.647-675, 2012.

TEIXEIRA, C. (org.). Planejamento em Saúde: conceitos, métodos e experiências. Salvador: EDUFBA, 2010. 161 p.

THIAM, S; LEFREVE, A. M.; HANE, F.; NDIAYE, A.; BA, F.; FIELDING, K. L.; NDIR, M.; LIENHARDT, C. Effectiveness of a Strategy to Improve Adherence to Tuberculosis Treatment in a Resource-Poor Setting: a Cluster Randomized Controlled Trial. The Journal of the American Medical Association (JAMA), v.297, n.4, p.380-386, 2007.

TURGEON, J.; GAGNON, F.; MICHAUD, M.; TREMBLAY, S. Policy Transfer and Health Impact Assessment. Groupe d'étude sur les politiques publiques et la santé. Library and Achives Canada, 2008.

UJVARI, S. C. A história da disseminação dos microrganismos. Estudos Avançados, v.22, n.64, p.171- 182, 2008.

VIEIRA, A. A.; RIBEIRO, S. A. Adesão ao tratamento da tuberculose após a instituição da estratégia de tratamento supervisionado no município de Carapicuíba, grande São Paulo. Jornal Brasileiro de Pneumologia, v.37, n.2, p.223-231, 2011.

VIEIRA, F. V.; VERÍSSIMO, M. P. Crescimento econômico em economias emergentes selecionadas: Brasil, Rússia, Índia, China (BRIC) e África do Sul. Economia e Sociedade, Campinas, v.18, n.3 (37), p.513-546, 2009.

WORLD HEALTH ORGANIZATION. Global Tuberculosis Report, 2013. Disponível em: <http://apps.who.int/iris/bitstream/10665/91355/1/9789241564656_eng.pdf>. Acesso em: 16 Mai. 2014.

WORLD HEALTH ORGANIZATION. The Stop TB strategy: Building on and enhancing DOTS to meet the TB-Millennium Development Goals. Gevena: WHO/HTM/TB, 2006. Disponível em: < 
http://whqlibdoc.who.int/hq/2006/WHO_HTM_STB_2006.368_eng.pdf?ua=1 >. Acesso em: 19 Mai. 2014.

ZANDWAIS, A. Perspectivas da análise do discurso fundada por Michel

Pêcheux na França: uma retomada de percurso. Série Cogitare, v.8. Santa Maria: UFSM, Programa de Pós-Graduação em Letras, 2009. 50 p. 


\title{
ANEXO A
}

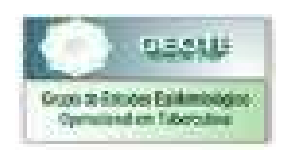

\author{
Grupo de Estudos Epidemiológico-Operacionais em \\ Tuberculose \\ Grupo de Estudos Qualitativos em Saúde
}

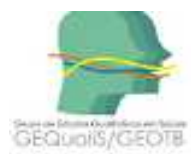

ATP-IINFOC-TB

Avaliação da Transferência de Políticas - Inovação, Informação e Conhecimento em tuberculose

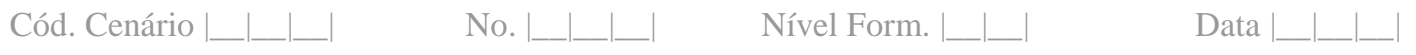

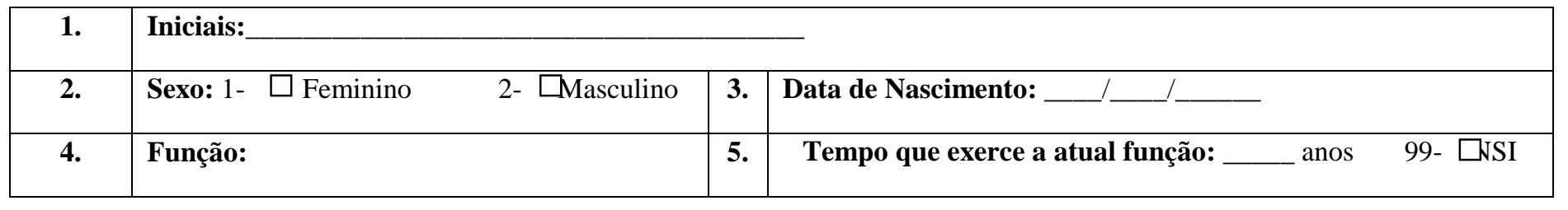

\begin{tabular}{|c|c|c|c|c|c|c|c|c|}
\hline \multicolumn{9}{|c|}{ Dimensão Informação } \\
\hline & Questão & $\begin{array}{c}1 \\
\text { Discordo }\end{array}$ & $\begin{array}{c}2 \\
\text { Discordo }\end{array}$ & $\begin{array}{c}3 \\
\text { Indiferente }\end{array}$ & $\begin{array}{c}4 \\
\text { Concordo }\end{array}$ & $\begin{array}{c}5 \\
\text { Concordo }\end{array}$ & $\begin{array}{l}\text { Não } \\
\text { se }\end{array}$ & $\begin{array}{l}\text { Resp. } \\
\text { (Dig.) }\end{array}$ \\
\hline 1 & $\begin{array}{l}\text { A coordenação do Programa de Controle } \\
\text { da Tuberculose (PCT municipal/estadual) } \\
\text { tem discutido o Tratamento Diretamente } \\
\text { Observado (TDO) com a equipe da } \\
\text { unidade de saúde em que trabalho. }\end{array}$ & & & & & & & \\
\hline 2 & $\begin{array}{l}\text { O TDO tem sido discutido entre } \\
\text { profissionais/equipe que atuam com a TB } \\
\text { na unidade de saúde em que trabalho. }\end{array}$ & & & & & & & \\
\hline 3 & $\begin{array}{l}\text { A população participa de discussões } \\
\text { sobre o TDO na unidade de saúde em que } \\
\text { trabalho. }\end{array}$ & & & & & & & \\
\hline 4 & $\begin{array}{l}\text { Não existe integração/interação entre a } \\
\text { coordenação do PCT } \\
\text { (municipal/estadual) e a equipe a unidade } \\
\text { de saúde em que trabalho. }\end{array}$ & & & & & & & \\
\hline 5 & $\begin{array}{l}\text { A coordenação do PCT } \\
\text { (municipal/estadual) utiliza de estratégias } \\
\text { para motivar e envolver a equipe da } \\
\text { unidade de saúde em que trabalho com } \\
\text { relação ao TDO. }\end{array}$ & & & & & & & \\
\hline 6 & $\begin{array}{l}\text { Ao discutir sobre o TDO, a coordenação } \\
\text { do PCT (municipal/estadual) se utiliza de } \\
\text { linguagem clara, concisa e de fácil } \\
\text { entendimento. }\end{array}$ & & & & & & & \\
\hline 7 & $\begin{array}{l}\text { Para viabilizar o TDO, são utilizadas } \\
\text { estratégias educativas e de sensibilização } \\
\text { da equipe (palestras, seminários, grupos } \\
\text { operativos, manual, encontros, entre outros). }\end{array}$ & & & & & & & \\
\hline 8 & $\begin{array}{l}\text { As estratégias de sensibilização da equipe } \\
\text { produzem impactos positivos nas ações } \\
\text { relacionadas ao TDO. }\end{array}$ & & & & & & & \\
\hline
\end{tabular}




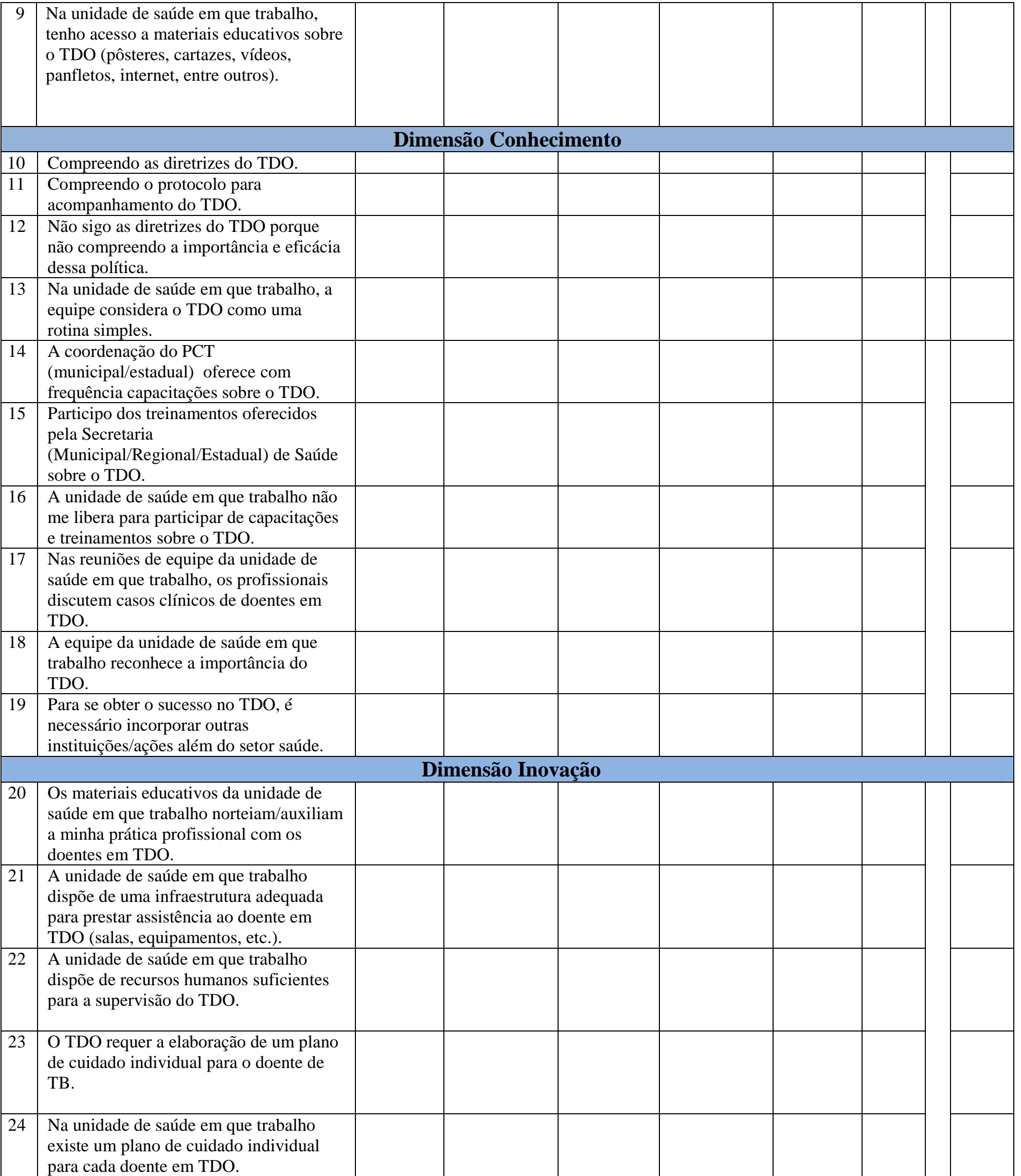




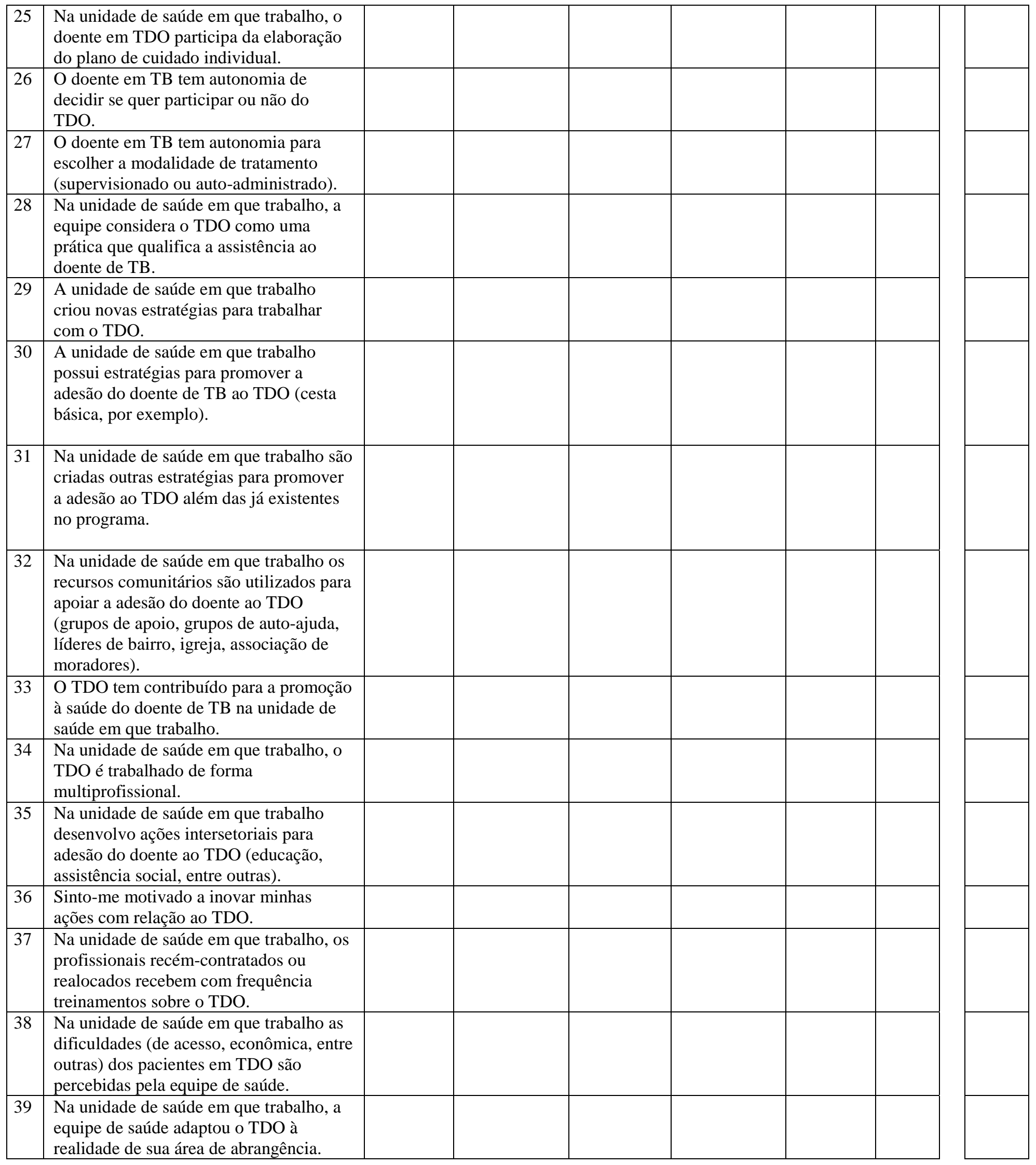




\begin{abstract}
ANEXO B
TERMO DE CONSENTIMENTO LIVRE E ESCLARECIDO - GRUPO HOSPITALAR CONCEIÇÃO
\end{abstract}

Prezado (a) senhor (a),

Gostaria de convidá-lo (a) a participar de uma pesquisa sobre "Avaliação do planejamento e execução da transferência da política do Tratamento Diretamente Observado (TDO) no município de Porto Alegre, RS". Esta pesquisa está sendo realizada pela Doutoranda, em Enfermagem em Saúde Pública, Rarianne Carvalho Peruhype sob supervisão e orientação do professor Dr. Pedro Fredemir Palha da Escola de Enfermagem de Ribeirão Preto - Universidade de São Paulo/EERP/USP. Ela tem como objetivo avaliar o planejamento e a operacionalização da transferência da política do TDO para o controle da Tuberculose na capital do Rio Grande do Sul.

Esta pequisa não apresenta qualquer tipo de risco à integridade física e/ou mental dos sujeitos participantes e espera-se obter os seguintes benefícios:

1. Aprofundar conhecimentos e compreensão sobre o processo de planejamento e transferência da política do TDO;

2. Identificar, como está sendo operacionalizadas as modalidades de transferência de políticas coerciva ou voluntária;

3. Promover intercâmbio de informações, conhecimentos e inovações em linguagem adequada aos diferentes públicos, por meio de divulgação e publicações específicas, com vistas a subsidiar a tomada de decisão no TDO no município no que concerne ao controle da TB;

4. Publicizar informações com a finalidade de subsidiar o planejamento e execução de ações de controle da TB por meio do TDO junto ao SUS;

5. Difundir e publicizar a produção científica e tecnológica sobre a avaliação de transferência de política por meio do TDO para o controle da TB no SUS;

6. Colaborar com os gestores municipais na adoção/manutenção/implementação do TDO como política para o controle da TB.

Sua participação consistirá em responder a um questionário e/ou uma entrevista que será audiogravada, podendo durar em média 40 minutos e ser realizada no local de sua preferência (serviço de saúde ou domicílio). As informações fornecidas contribuirão com a melhoria dos serviços de saúde.

$\mathrm{Eu}$, tendo recebido as informações acima e ciente de meus direitos abaixo relacionados, concordo em participar.

A garantia de receber todos os esclarecimentos sobre as perguntas do questionário antes e durante a entrevista, podendo afastar-me em qualquer momento se assim o desejar, bem como está me assegurado o segredo das informações por mim reveladas;

A segurança de que não serei identificado, assim como está assegurado que a pesquisa não trará prejuízo a mim e a outras pessoas; pesquisa,

A segurança de que não terei nenhuma despesa financeira durante o desenvolvimento da

A garantia de que todas as informações por mim fornecidas serão utilizadas apenas na construção da pesquisa e ficará sob a guarda dos pesquisadores, podendo ser requisitada por mim a todo o momento. 
Em caso de dúvida quanto às questões éticas, o Sr. (a) poderá entrar em contato com Daniel Demétrio Faustino da Silva, Coordenador-geral do Comitê de Ética em Pesquisa do GHC pelo telefone 3357 -2407, endereço Av. Francisco Trein 596, 3ำ andar, Bloco H, sala 11.

Uma cópia desta declaração deve ficar com o (a) Sr. (a).

Porto Alegre, de de 2012.

Telefone:

Informações adicionais favor contactar: Pedro Fredemir Palha. Email: palha@eerp.usp.br Escola de Enfermagem de Ribeirão Preto da Universidade de São Paulo. Tel: (16) 36023949. Porto Alegre: Rarianne C. Peruhype. Email: rarianne@usp.br ; Cel: (51) 81483724. 


\section{ANEXO C}

\section{TERMO DE CONSENTIMENTO LIVRE E ESCLARECIDO}

Prezado (a) senhor (a),

Gostaria de convidá-lo (a) a participar de uma pesquisa sobre " Avaliação do planejamento - execuçäo da transferência da política do Tratamento Diretamente Observado (TDO) no municipio de Porto Alegre, RS". Esta pesquisa está sendo realizada pela Doutoranda. em Enfermagem em Saúde Pública, Rarianne Carvalho Peruhype sob supervisảo e orientação do professor Dr. Pedro Fredemir Palha da Escola de Enfermagem de Ribeirão Preto - Universidade de Săo Paulo/EERP/USP. Ela tem como objetivo avaliar o planejamento e a operacionalizaçăo da transferência da política do TDO para o controle da Tuberculose na capital do Rio Grande do Sul.

Sua participação consistirá em responder a um questionário e/ou uma entrevista que será audiogravada, podendo durar em média 40 minutos a ser realizada no local de sua preferência (serviço de saúde ou domicílio). As informaçōes fornecidas contribuirăo com a melhoria dos serviços de saúde.

Você será esclarecido(a) sobre a pesquisa em qualquer aspecto que desejar. Você é livre para recusar-se a participar, retirar seu consentimento ou interromper a participaçăo a qualquer momento. A sua participaçăo é voluntária e a recusa em participar năo irá acarretar qualquer penalidade ou perda de benefícios. Os pesquisadores irăo tratar a sua identidade com padrōes profissionais de sigilo. Assim, seu nome ou o material que indique sua participaçăo năo será divulgado. Você năo será identificado em nenhuma publicaçăo que possa resultar deste estudo. A participaçăo no estudo năo acarretará custos para você e não será disponivel nenhuma compensaçấo financeira adicional.

Em caso de dúvidas entrar em contato com o professor orientador Prof. Pedro Fredemir Palha. Escola de Enfermagem de Ribeirâo Preto da Universidade de Săo Paulo. Endereço: Avenida Bandeirantes, 3900 Campus Universitário - Ribeirăo Preto - SP. CEP 14040-902.Telefone: (16) 36023949e com o Comite de Ética em Pesquisa da Secretaria Municipal de Saúde de Porto Alegre pelo telefone (51) 32895517 ou 91441379.

Porto Alegre, de de 2012 .

Assinatura do sujeito de pesquisa

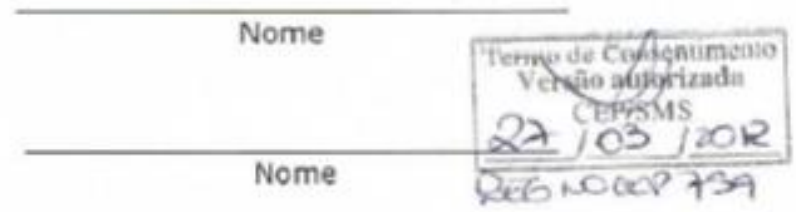

Assinatura do Pesquisador

Observaçì): o presente documento, baseado no item IV das Diretrizes e Normas Regulamkatasoras para a Pesquisa en Sab́de, do Conselho Nacional de Saide (Resoluchio $196(96)$, será assinado en duas vias, de igaal toos, ficando una via em poder do participante e a outra com o (a) pesquisador (a) responsável. 


\title{
ANEXO D \\ ROTEIRO PARA GERAÇÃO DOS DADOS DO SECRETÁRIO MUNICIPAL/ESTADUAL DE SAÚDE
}

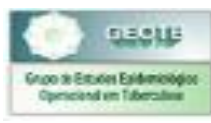

\author{
Grupo de Estudos Epidemiológico- \\ Operacionais em Tuberculose \\ Grupo de Estudos Qualitativos em Saúde
}

ORIENTAÇÕES INICIAIS

Roteiro de Entrevista - Projeto: Avaliação da Transferência de Políticas de Saúde do Tratamento Diretamente Observado em alguns municípios da região Sul, Sudeste, Nordeste e Norte.

\section{Secretário Municipal/Estadual de Saúde}

Primeiro momento: Expor o projeto, bem como do que se trata a "Transferência de Políticas".

O presente projeto de pesquisa tem por objetivo conhecer como ocorre a transferência da política do Tratamento Diretamente Observado (TDO - antigo Tratamento Supervisionado) para a Tuberculose em seu nível de coordenação. A Transferência de Políticas se trata de um conceito ainda novo em estudos brasileiros e consiste em compreender como ocorre o processo de transferência de uma determinada política (ou prática de cuidado, por exemplo, o TDO), de um determinado nível governamental, até os serviços de saúde que realizam o TDO. Dessa forma, é de grande importância ouvir as contribuições de vocês para compreender o como a transferência do TDO passa da esfera nacional para a estadual, a regional e, por fim, a municipal. Isso nos auxiliará a compreender as potencialidades e também as fragilidades que podem estar presentes nesse processo, além de contribuir para identificar as alternativas que podem ser empreendidas na melhoria da atenção aos doentes de TB de nosso país.

Segundo momento: Fazer a leitura do Termo de Consentimento Livre e Esclarecido junto ao entrevistado, pedir para que, em caso de concordância, o mesmo assine as duas vias, sendo que uma ficará com o entrevistador, e outra com o entrevistado.

Ao iniciar a entrevista, se atentar ao preenchimento de todas as informações no formulário abaixo, pois as mesmas serão importantes para a organização das informações obtidas pelo grupo de pesquisa. 


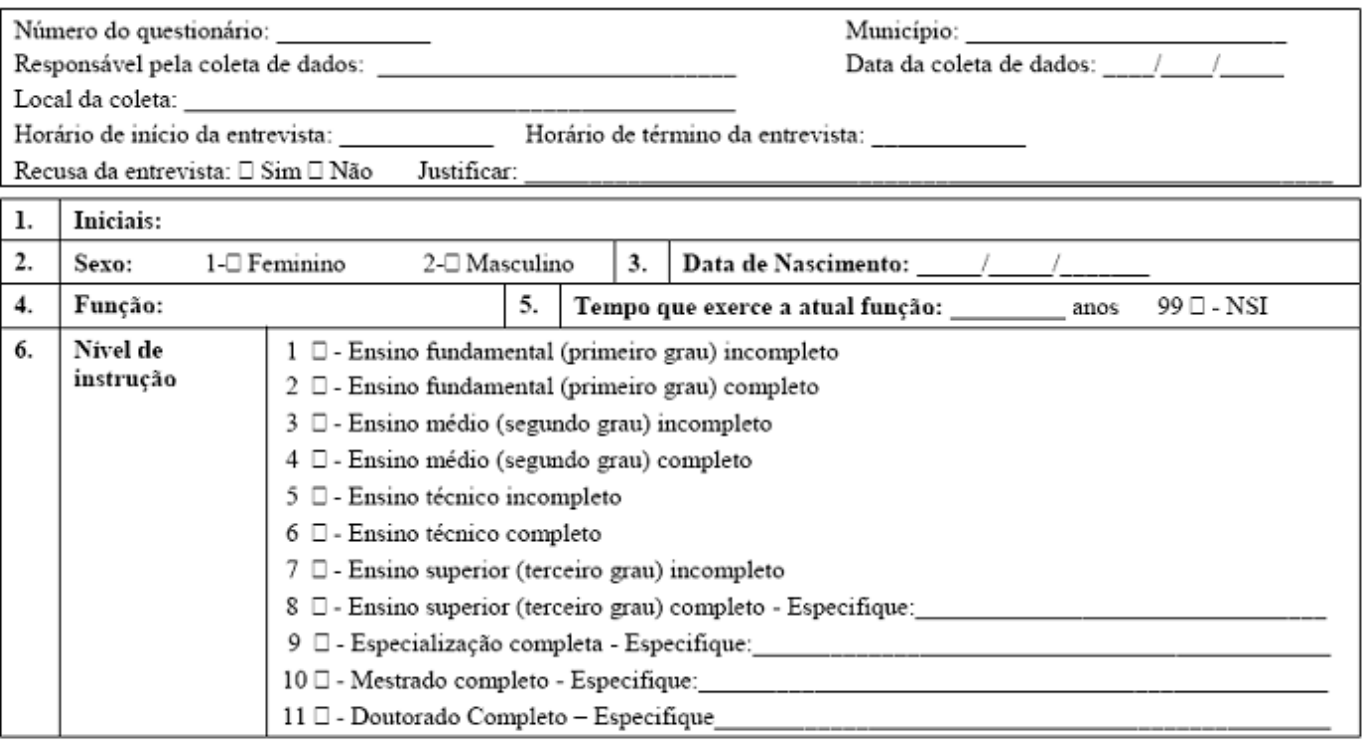

Observação: para cada questão, será considerado o nível de coordenação em que o sujeito do estudo se encontra (nacional, estadual, regional municipal e SMS)

1. Fale sobre a experiência da implantação/descentralização do TDO para o(s) seu(s) município(s).

2. Comente sobre a experiência na implantação/descentralização do TDO junto aos profissionais da Atenção Básica/Unidades de Referência.

3. Comente sobre o fluxo de comunicação das informações sobre o TDO entre os diferentes níveis de coordenação.

4. Fale sobre as informações sobre o TDO com os profissionais da Atenção Básica/Unidades de Referência.

5. Como o município tem envolvido/motivado os profissionais da Atenção Básica/Unidades de Referência junto ao TDO?

6. Você observa alguns aspectos favoráveis à implantação/descentralização do TDO? Quais?

7. Você identifica barreiras no processo de implantação/descentralização do TDO? Quais?

8. Tem sido feitas adequações para efetivar a política do TDO em seu(s) município(s)? Quais? 


\begin{abstract}
ANEXO E
ROTEIRO PARA GERAÇÃO DOS DADOS DOS COORDENADORES DA ATENÇÃO À TUBERCULOSE (Nível Federal, Estadual, Regional e Municipal)
\end{abstract}

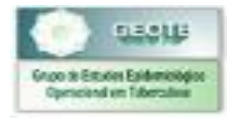

\author{
Grupo de Estudos Epidemiológico- \\ Operacionais em Tuberculose
}

Grupo de Estudos Qualitativos em Saúde

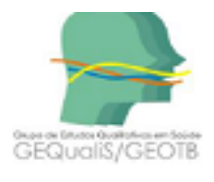

\title{
ORIENT AÇÕES INICIAIS
}

\begin{abstract}
Roteiro de Entrevista - Projeto: Avaliação da Transferência de Políticas de Saúde do Tratamento Diretamente Observado em alguns municípios da região Sul, Sudeste, Nordeste e Norte.
\end{abstract}

\section{Coordenadores da Atenção à Tuberculose (Nível Federal, Estadual, Regional e Municipal)}

Primeiro momento: Expor o projeto, bem como do que se trata a "Transferência de Políticas".

O presente projeto de pesquisa tem por objetivo conhecer como ocorre a transferência da política do Tratamento Diretamente Observado (TDO - antigo Tratamento Supervisionado) para a Tuberculose em seu nível de coordenação. A Transferência de Políticas se trata de um conceito ainda novo em estudos brasileiros e consiste em compreender como ocorre o processo de transferência de uma determinada política (ou prática de cuidado, por exemplo, o TDO), de um determinado nível governamental, até os serviços de saúde que realizam o TDO. Dessa forma, é de grande importância ouvir as contribuições de vocês para compreender o como a transferência do TDO passa da esfera nacional para a estadual, a regional e, por fim, a municipal. Isso nos auxiliará a compreender as potencialidades e também as fragilidades que podem estar presentes nesse processo, além de contribuir para identificar as alternativas que podem ser empreendidas na melhoria da atenção aos doentes de TB de nosso país.

Segundo momento: Fazer a leitura do Termo de Consentimento Livre e Esclarecido junto ao entrevistado, pedir para que, em caso de concordância, o mesmo assine as duas vias, sendo que uma ficará com o entrevistador, e outra com o entrevistado. 
Ao iniciar a entrevista, se atentar ao preenchimento de todas as informações no formulário abaixo, pois as mesmas serão importantes para a organização das informações obtidas pelo grupo de pesquisa.

\begin{tabular}{|c|c|c|c|c|c|c|}
\hline \multirow{3}{*}{\multicolumn{3}{|c|}{$\begin{array}{l}\text { Número do questionário: } \\
\text { Responsável pela coleta de dados: } \\
\text { Local da coleta: }\end{array}$}} & \multicolumn{4}{|c|}{ Municipio: } \\
\hline & & & & & \multirow{2}{*}{\multicolumn{2}{|c|}{ Data da coleta de dados: }} \\
\hline & & & & & & \\
\hline \multirow{2}{*}{\multicolumn{3}{|c|}{$\begin{array}{l}\text { Horário de início da entrevista: } \\
\text { Recusa da entrevista: } \square \text { Sim } \square \text { Não }\end{array}$}} & Ho & \multirow{2}{*}{\multicolumn{2}{|c|}{ Horário de término da entrevista: }} & \\
\hline & & & Justificar: & & & \\
\hline 1. & \multicolumn{6}{|l|}{ Iniciais: } \\
\hline 2. & \multirow{2}{*}{\multicolumn{2}{|c|}{$\begin{array}{l}\text { Sexo: } \\
\text { Função: }\end{array}$}} & 2- $\square$ Masculin & 3. & Data de Nascimento: & \\
\hline 4. & & & 5. & Tempo & ne exerce a atual função: __ anos & $99 \square-N S I$ \\
\hline \multirow{11}{*}{6.} & \multirow{11}{*}{$\begin{array}{l}\text { Nivel de } \\
\text { instrução }\end{array}$} & \multicolumn{5}{|c|}{$1 \square$ - Ensino fundamental (primeiro grau) incompleto } \\
\hline & & \multicolumn{5}{|c|}{$2 \square$ - Ensino fundamental (primeiro grau) completo } \\
\hline & & \multicolumn{5}{|c|}{$3 \square$ - Ensino médio (segundo grau) incompleto } \\
\hline & & \multicolumn{5}{|c|}{$4 \square$ - Ensino médio (segundo grau) completo } \\
\hline & & \multicolumn{5}{|c|}{$5 \square$ - Ensino técnico incompleto } \\
\hline & & \multicolumn{5}{|c|}{$6 \square$ - Ensino técnico completo } \\
\hline & & \multicolumn{5}{|c|}{$7 \square$ - Ensino superior (terceiro grau) incompleto } \\
\hline & & \multirow{2}{*}{\multicolumn{5}{|c|}{$\begin{array}{l}8 \square \text { - Ensino superior (terceiro grau) completo - Especifique: } \\
9 \square \text { - Especialização completa - Especifique: }\end{array}$}} \\
\hline & & $9 \square-$ Esp & & & & \\
\hline & & \multicolumn{5}{|c|}{$10 \square$ - Mestrado completo - Especifique: } \\
\hline & & \multicolumn{5}{|c|}{$11 \square$ - Doutorado Completo - Especifique_ } \\
\hline
\end{tabular}

Observação: para cada questão, será considerado o nivel de coordenação em que o sujeito do estudo se encontra (nacional, estadual, regional municipal e SMS)

1. Comente a implantação/descentralização do TDO?

2. Fale (a partir do seu nível de coordenação) sobre o processo de implantação/descentralização do TDO.

3. Fale sobre a sua experiência na discussão da transferência da política do TDO com outros coordenadores do PCT.

4. Você já pensou em como os níveis de coordenação têm se articulado para a efetivação da transferência de política do TDO? Como isso vem acontecendo?

5. A transferência de política relacionada ao TDO trouxe inovações nas ações de controle da TB? Se sim, descreva algumas experiências exitosas.

6. Foram utilizadas estratégias na transferência de política do TDO? Quais?

7. A partir dessas estratégias, quais as lições que foram apreendidas na melhoria das ações de controle da TB?

8. Você identifica aspectos favoráveis à implantação/descentralização do TDO? Quais?

9. Você observa barreira(s) no processo de implantação/descentralização do TDO? Quais?

10. Tem sido feitas adequações para efetivar a transferência da política do TDO entre os demais níveis de coordenação? Quais? 


\title{
ANEXO F

\begin{abstract}
ROTEIRO DE ENTREVISTA (PLANEJAMENTO DA TRANSFERÊNCIA DO TDO) DOS
\end{abstract} GESTORES/COORDENADORES DO PCT E SECRETÁRIO MUNICIPAL DE SAÚDE
}

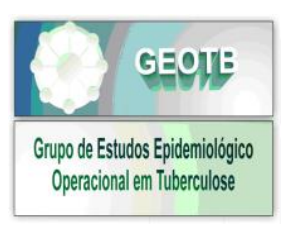

\author{
Grupo de Estudos Epidemiológico - Operacionais em \\ Tuberculose - GEOTB \\ Grupo de Estudos Qualitativos em Saúde - GEQualis
}

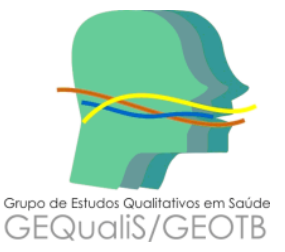

\begin{tabular}{|c|c|c|c|c|}
\hline \multirow{2}{*}{\multicolumn{5}{|c|}{ Local da coleta: }} \\
\hline & & & & \\
\hline \multicolumn{3}{|c|}{$\begin{array}{l}\text { Horário de início da entrevista: } \\
\text { Recusa da entrevista: } \square \text { Sim } \square \text { Não }\end{array}$} & \multicolumn{2}{|c|}{$\begin{array}{l}\text { Horário de término da entrevista: } \\
\text { Justificar: }\end{array}$} \\
\hline 1. & \multicolumn{4}{|c|}{ Iniciais: } \\
\hline 2. & \multicolumn{2}{|c|}{ Sexo: $1-\square$ Feminino 2 - $\square$ Masculino } & 3. & Data de Nascimento / \\
\hline 4. & \multicolumn{2}{|c|}{ Função: } & 5. & $\begin{array}{l}\text { Tempo que exerce a atual função: } \\
\text { anos. }\end{array}$ \\
\hline 6. & $\begin{array}{l}\text { Nível de } \\
\text { Instrução }\end{array}$ & \multicolumn{3}{|c|}{$\begin{array}{l}1 \\
1 \\
2 \\
3 \\
3 \\
4 \text { - Ensino técnico incompleto } \\
4 \square \text { - Ensino superino superior (terceiro grau) incompleto grau) completo - Especifique: } \\
5 \square \text { - Especialização Completa - Especifique: } \\
6 \square \text { - Mestrado Completo - Especifique: } \\
7 \square \text { - Doutorado Completo - Especifique: }\end{array}$} \\
\hline
\end{tabular}

Observação: para cada questão, será considerado o nível de coordenação em que o sujeito do estudo se encontra (regional, estadual, municipal e SMS)

\section{Coordenadores / Gestores / Secretário Municipal de Saúde}

1) O que significa planejamento para você?

2) Na sua concepção, qual a importância atribuída pelos gestores à atividade de planejamento na área da saúde?

3) Com relação à execução da transferência de uma política pública de saúde (entre os diferentes níveis do governo e seus profissionais), opine sobre a necessidade ou não da elaboração de um plano operacional.

4) Relate como foi realizado o planejamento para a transferência da política do Tratamento Diretamente Observado (TDO) da Tuberculose da sua coordenação.

5) Identifique quais atores estiveram envolvidos no processo de planejamento da transferência da política do TDO e seus respectivos papéis.

6) Mencione quais foram as estratégias e/ou recursos utilizados para formular e executar o plano, em cada um dos itens:
a) Financeiros
b) Humanos
c) Físicos
d) Organizacionais e outros.

7) Aponte as Potencialidades, Fraquezas, Oportunidades e Ameaças (Análise SWOT) identificadas, por você ou sua equipe de trabalho, no planejamento do processo de transferência do TDO.

8) O plano é revisitado? Com qual periodicidade? De que maneira?

9) Comente sobre os resultados obtidos com a transferência da política do TDO e a relação destes com os objetivos estabelecidos no plano.

10) Em sua opinião, qual tem sido a maior dificuldade para a elaboração e/ou implementação do plano referente à transferência da política do TDO em seu contexto de trabalho? 


\section{ANEXO G}

\section{Prefeitura Municipal de Porto Alegre Secretaria Municipal de Saúde Comitê de Ética em Pesquisa \\ PARECER CONSUBSTANCIADO}

Pesquisador (a) Responsável: Pedro Fredemir Palha Registro no CEP: 759 Processo $N^{0}$. 001.008442.12.6

Instituição onde será desenvolvido: Secretaria Municipal de Saúde - USF Sta Cecilia ;USF Modelo; CS Modelo; USF Sem Domicilio; CS Navegantes ; CS Bom Jesus; CSVC; USF Nossa Sra das Graças; US Restinga; US Sanatório

Utilização: TCLE

Situação: APROVADO

O Comitê de Ética em Pesquisa da Secretaria Municipal de Saúde de Porto Alegre analisou o processo $\mathrm{N}$ 001.008442.12.6, referente ao projeto de pesquisa: "Avaliaçâo do planejamento e execução da transferência da política do tratamento diretamente observado no município de Porto Alegre, RS", tendo como pesquisador responsável Pedro Fredemir Palhacujo objetivo é "Avaliar o processo de planejamento e transferência de política do Tratamento Diretamente Observado (TDO) para o controle da Tuberculose em Porto Alegre, Rio Grande do Sul. Objetivos Específicos: 1. Analisar as estratégias empregadas na transferência da política do TDO; 2. Identificar os recursos (materiais, humanos, físicos, outros) engendrados e utilizados na transferência da política do TDO; 3 . Avaliar o envolvimento dos gestores, coordenadores e profissionais de saúde para trabalhar com a transferência da política do TDO; 4 . Identificar a forma (coerciva/voluntária) em que a política foi transferida entre os gestores, coordenadores e profissionais da saúde".

Assim, o projeto preenche os requisitos fundamentais das resoluçóes. O Comitê de Ếtica em Pesquis: segue os preceitos das resoluç一es CNS 196/96, 251/97 a 292/99, sobre as Diretrizes e Normas Regulamentadoras de Pesquisa Envolvendo Seres Humanos, do Conselho Nacional de Saúde / Conselho Nacional de Ética em Pesquisa / Agência nacional de Vigilância Sanitária. Em conformidade com os requisitos éticos, classificamos o presente protocolo como APROVADO.

O Comitê de Ética em Pesquisa, solicita o atendimento aos itens abaixo:

1. Enviar primeiro relatório parcial em seis meses a contar desta data e a apresentaçăo do trabalho $\mathrm{em} \mathrm{CD}$ no final;

2. Informar imediatamente qualquer evento adverso ocorrido;

3. Comunicar qualquer alteração no projeto c no TCLE;

4. Entregar junto com o relatório, todos os TCLEs assinados pelos sujeitos de pesquisas $\mathrm{c}$ a apresentaçâo do trabalho, $\mathrm{e}$ o formulário de relatório que esta no site.

5. Após o término desta pesquisa, o pesquisador responsável deverá apresentar os resultados junto à equipe da unidade a qual fez a coleta de dados e/ou entrevista, inclusive para o Conselho Local da Unidade de Saúde.

Porto Alegre, 27/03/2012.

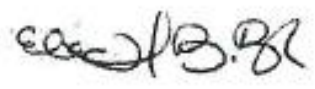

Elen Maria Borba

Coordenadora do CEP 


\title{
ANEXO H
}

Plataforma Brasil - Ministério da Saúde

Grupo Hospitalar Conceição/Hospital Nossa Senhora da Conceição S.A.

\section{PROJETO DE PESQUISA}

Área Temática:

Título:Avaliação do Planejamento e Execução da Transferência da política do Tratamento Diretamente Observado no município de Porto Alegre, RS.

\author{
Pesquisador: Pedro Fredemir Palha \\ Instituição: Grupo Hospitalar Conceição/Hospital Nossa \\ Senhora da Conceição S.A.
}

Versão: 3

CAAE: 01649012.9 .0000 .5530

\section{PARECER CONSUBSTANCIADO DO CEP}

Número do Parecer: 55576

Data da Relatoria: $\quad$ 21/06/2012

\section{Apresentação do Projeto:}

Tese de Doutorado da Escola de Enfermagem da Universidade de São Paulo (Ribeirão Preto).

A proposta do projeto visa compreender o processo de planejamento e a transferência da política do Tratamento Diretamente Observado (TDO) utilizado para o controle da Tuberculose (TB), tendo como cenário o município de Porto Alegre.

Conta com um modelo misto de abordagens (quantitativo e qualitativo).

O componente quantitativo refere-se à aplicação de um questionário auto-dirigido (previamente validado) à uma população de referência constituida por profissionais de saúde (estimativa de 380 , aproximadamente 284 sujeitos do GHC e 96 da Secretaria Municipal de Saúde) sendo eles médicos, enfermeiros, técnicos/auxiliares de enfermagem, agentes comunitários de saúde e odontólogos envolvidos com o Tratamento Diretamente Observado na capital riograndense. Os sujeitos de pesquisa são trabalhadores de 10 Unidades da Secretaria Municipal de Saúde e 12 do Grupo Hospitalar Conceição (US Vila Floresta; US Santíssima Trindade; UBS Jardim Itu; US Conceição; US Parque dos Maias; US Nossa Senhora Aparecida; US Jardim Leopoldina; US Costa e Silva; US Barấo de Bagé; US Coinma; US Divina Providência e US SESC).

As entrevistas ocorrerão por meio da aplicação de um questionário fechado auto-aplicável aos participantes selecionados. Dados de fontes secundárias de informação como Sistemas de Informação (SINAN, SIAB, DATASUS, SIM, CNES), documentos, relatórios e outros materiais impressos e digitais serão também investigados e considerados na análise.

$\mathrm{Na}$ abordagem qualitativa serão entrevistados os gestores/coordenadores regionais, estaduais e municipais do Programa de Tuberculose bem como o secretário municipal de saúde por meio da aplicação de um questionário semi-dirigido.

Análise dos dados: no plano qualitativo da pesquisa, os dados coletados por meio das entrevistas semidirigidas serão organizados e codificados por um sistema digital de apoio, o software Atlas. Ti 6.0 e posteriormente serão analisados com base na fundamentação teórico-metodológica da Análise de Discurso (AD) de matriz francesa, que versa sobre três regiões do conhecimento: o Materialismo histórico, a Linguística e a Psicanálise (ORLANDI, 2009).

Para a análise dos dados quantitativos coletados, serão utilizados métodos estatísticos, com a descrição das frequências das variáveis e a distribuição (média, mediana e desvio-padrão, caso necessário).

\section{Objetivo da Pesquisa:}

Objetivo Geral

Avaliar o processo de planejamento e transferência de política do Tratamento Diretamente Observado (TDO) para o controle da Tuberculose em Porto Alegre, Rio Grande do Sul.

Objetivos Específicos

1. Analisar as estratégias empregadas na transferência da política do TDO;

2. Identificar os recursos (materiais, humanos, físicos, outros) engendrados e utilizados na transferência da política do TDO; 
3. Avaliar o envolvimento dos gestores, coordenadores e profissionais de saúde para trabalhar com a transferência da política do TDO;

4. Identificar a forma (coerciva/voluntária) em que a política foi transferida entre os gestores, coordenadores e profissionais da saúde.

\section{Avaliação dos Riscos e Benefícios:}

Os documentos solicitados no parecer anterior foram apresentados. A Pesquisa não apresenta riscos aos sujeitos que dela participarão.

Comentários e Considerações sobre a Pesquisa:

sem comentários.

Considerações sobre os Termos de apresentação obrigatória:

TCLE apresentado (único para todos os sujeitos). De acordo com a Resolução 196/96.

Recomendações:

Nada a recomendar.

Conclusões ou Pendências e Lista de Inadequações:

Pendências atendidas na terceira versão do projeto.

Situação do Parecer:

Aprovado

Necessita Apreciação da CONEP:

Não

Considerações Finais a critério do CEP:

Projeto aprovado. Será enviado por email a carta de aprovação e TCLEs carimbados e assinador pelo coordenador. Lembramos aos pesquisadores que essa versão do TCLE assinada e carimbada é que deve ser usada no estudo.

PORTO ALEGRE, 12 de Julho de 2012

Assinado por

Daniel Demétrio Faustino da Silva 


\section{ANEXO I}

\section{ESCOLA DE ENFERMAGEM DE Platoforma RIBEIRÃO PRETO - USP}

\section{PARECER CONSUBSTANCIADO DO CEP}

\section{DADOS DO PROJETO DE PESQUISA}

Título da Pesquisa: Avaliação da transferência de políticas de saúde do Tratamento Diretamente Observado em alguns municípios da região Sul, Sudeste, Nordeste e Norte.

Pesquisador: Pedro Fredemir Palha

Área Temática:

Versäo: 4

CAAE: 01197312.3 .0000 .5393

Instituição Proponente: Escola de Enfermagem de Ribeirão Preto - USP

Patrocinador Principal: Financiamento Próprio

\section{DADOS DO PARECER}

Número do Parecer: 413.471

Data da Relatoria: 25/09/2013

\section{Apresentaçäo do Projeto:}

Trata-se de análise de emenda,solicitando a inclusão de um roteiro de entrevista (Apêndice A) a ser aplicado na região Sul (cidade de Porto Alegre), cujo objetivo consiste na avaliação da etapa de planejamento (pelos gestores e coordenadores do Programa de Controle da Tuberculose - PCT) do processo de transferência da política do Tratamento Diretamente Observado da Tuberculose (TDO). Pretende-se investigar, por meio deste roteiro, quais os métodos, recursos e estratégias têm subsidiado o processo de planejamento da transferência da política do TDO e os mecanismos utilizados pelos gestores/coordenadores para organização e operacionalização da transferência desta política.

\section{Objetivo da Pesquisa:}

Dessa forma, ao acrescentar o roteiro de entrevista do planejamento para aplicação na região Sul (Porto Alegre), incluiu-se um novo objetivo de pesquisa neste cenário, neste caso, relativo à investigação da metodologia, das técnicas e recursos (materiais, humanos, físicos, outros) engendrados e utilizados para o planejamento da transferência da política do TDO pelos gestores e coordenadores do PCT de Porto Alegre e do estado do Rio Grande do Sul.

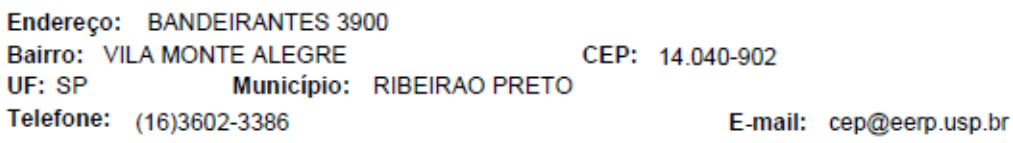




\section{ESCOLA DE ENFERMAGEM DE Plotoforma RIBEIRÃO PRETO - USP}

Continuação do Parecer: 413.471

Avaliação dos Riscos e Benefícios:

Sem alterações.

Comentários e Considerações sobre a Pesquisa:

Por meio deste Adendo, o pesquisador responsável comunica e justifica as razões pelas quais pretende-se fazer uso do modelo de TCLE requisitados e aprovados pelas instituições de saúde de Porto Alegre (da Secretaria Municipal de Saúde - SMS e do Grupo Hospitalar Conceição- GHC), que reiteraram a imprescindibilidade da utilização de TCLE aprovados pelos seus CEPs quando da realização da pesquisa nas unidades sob suas responsabilidades.

Ressalta-se que o projeto de pesquisa referente a este cenário foi submetido ao Comitê de Ética, tanto da Secretaria Municipal quanto do Grupo Hospitalar Conceição, sendo aprovados em ambos os CEPs no ano de 2012.

Consideraçóes sobre os Termos de apresentação obrigatória:

Sem alterações.

Recomendações:

Não há.

Conclusōes ou Pendências e Lista de Inadequaçōes:

Solicitações acatadas.

Situação do Parecer:

Aprovado

Necessita Apreciação da CONEP:

Não

Consideraçóes Finais a critério do CEP:

Parecer apreciado na 168 reunião ordinária.

Endereço: BANDEIRANTES 3900

Bairro: VILA MONTE ALEGRE

UF: SP Município: RIBEIRAO PRETO

Telefone: (16)3602-3386

CEP: $14.040-902$

E-mail: cep@eerp.usp.br 


\section{ESCOLA DE ENFERMAGEM DE} RIBEIRÃO PRETO - USP

RIBEIRAO PRETO, 02 de Outubro de 2013

Assinador por:

Claudia Benedita dos Santos

(Coordenador) 


\section{ANEXO J}

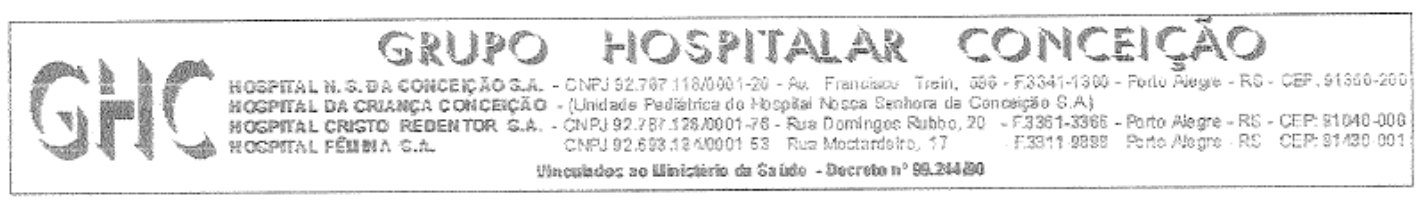

TERMO DE CIENCIA DO COORDENADOR DE CRS ONDE SERA REALIZADA A PESQUISA

EU, SIMONE FAORO BERTONI Coordenadora do Serviço/Responsável pela Área de Serviço de Saúde Comunitária, conheço o protocolo de pesquisa intitulado: AVALIACĂO DO PLANEJAMENTO E EXECUÇÄO DA. TRANSFERENCIA DA POLITICA DO TRATAMENTO DIRETAMENTE OBSERVADO NO MUNICIPIO DE PORTO ALEGRE - RS, desenvolvido por RARIANNE CARVALHO PERUHYPE, conheço seus objetivos e a metodologia que será desenvolvida, estando ciente de que o pesquisador não irá interferir no fluxo normal deste Serviço.

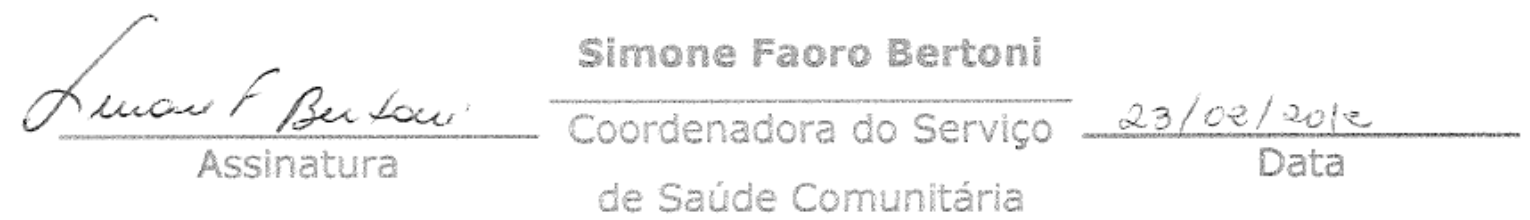




\section{ANEXO K}

$$
000442-1216 \text { Rarlannes }
$$

\section{Prefeitura Municipal de Porto Alegre Secretaria Municipal de Saúde Comitê de Ética em Pesquisa}

\section{TERMO DE CIÊNCIA DO RESPONSÁVEL PELO LOCAL ONDE SERÁ REALIZADA A} PESQUISA

EU CHRISTIANE NUNES DE FREITAS matrícula 42183.5 responsável pelo Serviço

DE COORDENACAOO DO CAPSES
conheço
○
Protocolo
de
Pesquisa
intitulado

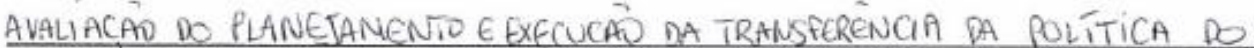
TRATAMENTO DIRETAMENIE OBSERVADO NO MUNCFFIO DE PORTO ALEGRE, RS. tendo como Pesquisador Responsável PEDRO FREDEMIR PALHA

declaro que sua realização não irá interferir no fluxo normal deste Serviço.

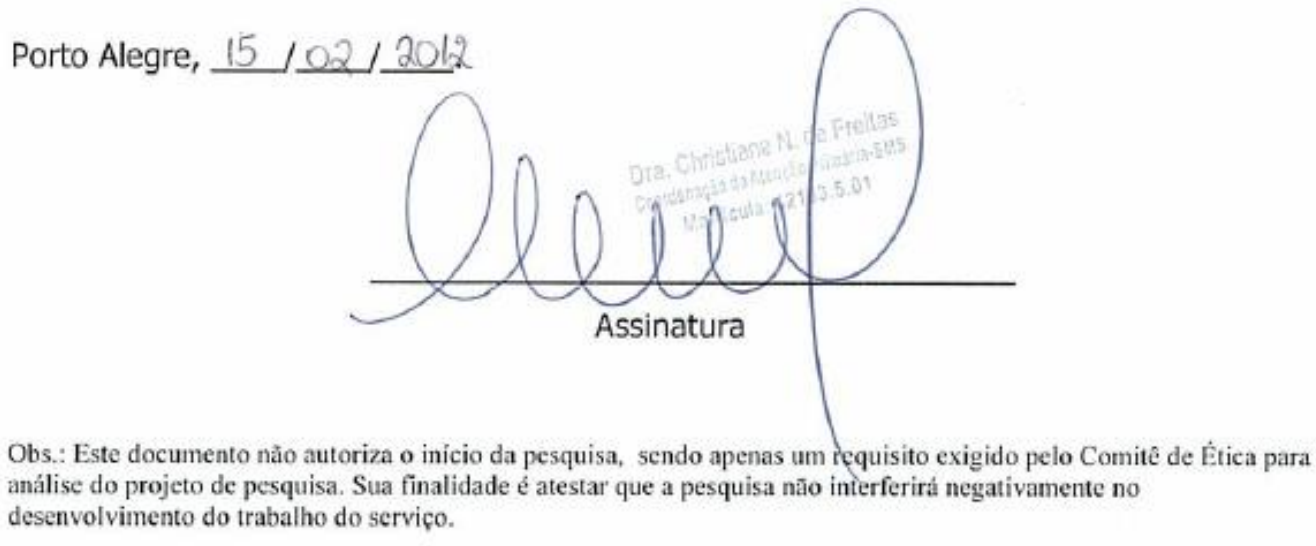




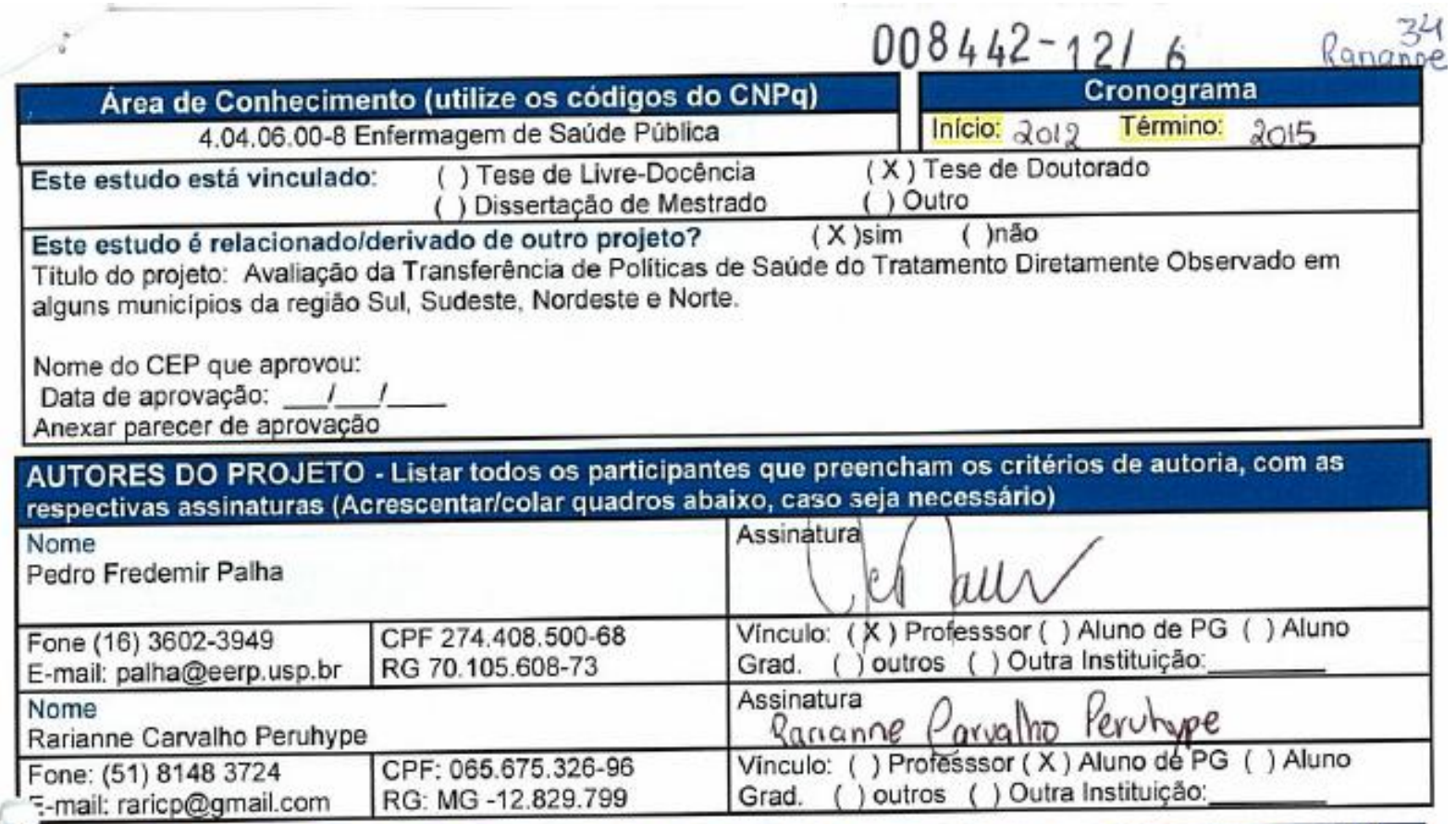

LOCAL DE ORIGEM (Serviço, Departamento ou Curso de Pós-Graduaçāo que chancela o projeto)

\begin{tabular}{c|c} 
Escola de Enfermagem de Ribeirăo Preto da & $\begin{array}{c}\text { Assinatura e Carimbo do Responsável } \\
\text { Universidade de Săo Paulo (EERP-USP) }\end{array}$ \\
$\begin{array}{c}\text { Profa. Dra. Ana Maria de Almeida } \\
\text { Coordanadora do Fograme de Pón. } \\
\text { Grodueço Enformagem em Saúde Pública }\end{array}$ \\
\hline
\end{tabular}

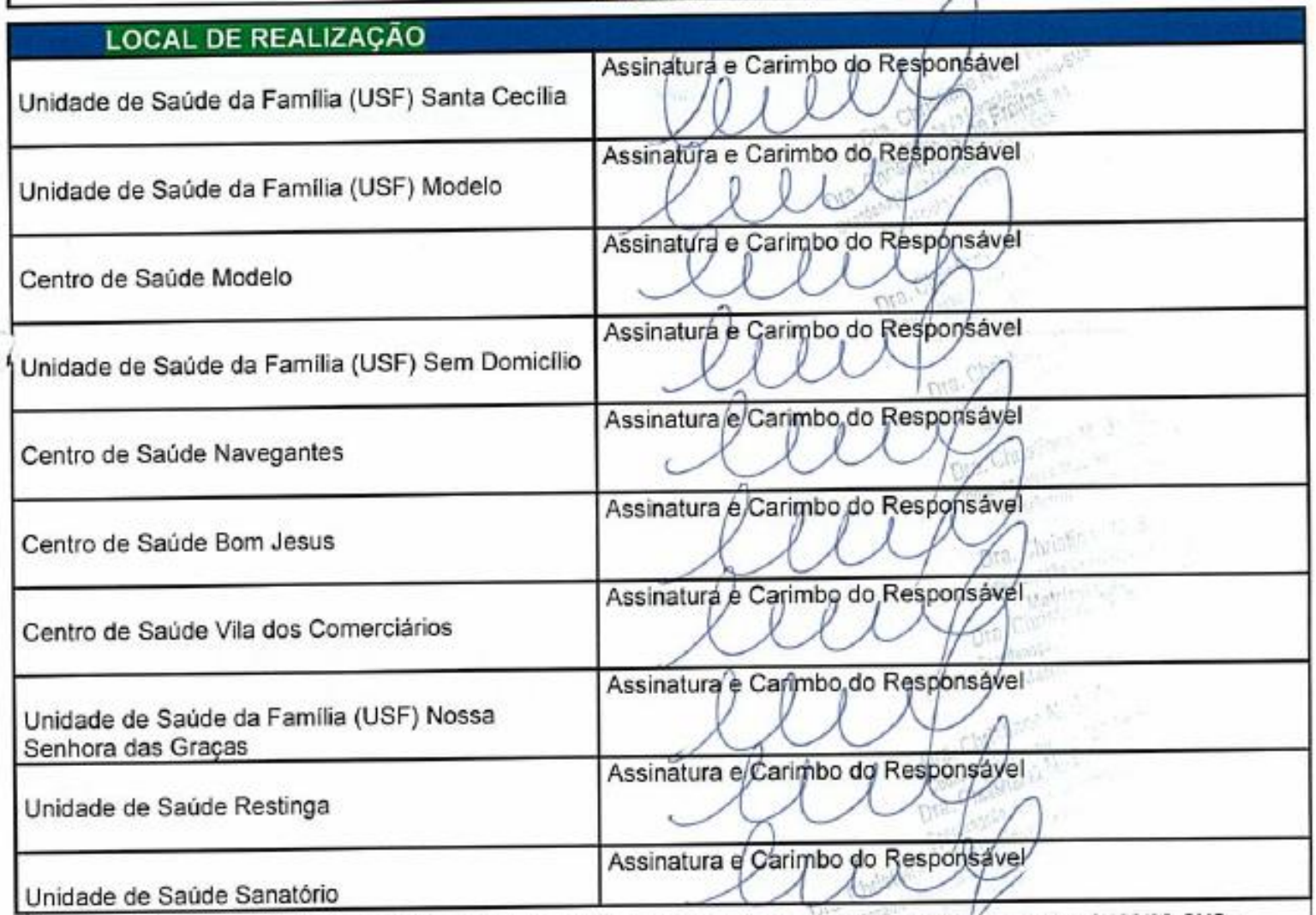

Ao encaminhar o seu projeto de pesquisa, certifique-se de que contenha os itens exigidos pela Resolução $n^{\circ} 196 / 96$-CNS e complementares. 
ANEXO L

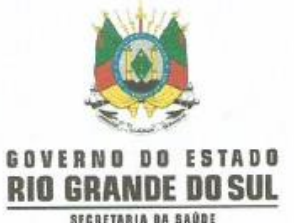

seteremanin an saudet

\section{CENTRO ESTADUAL DE VIGILÂNCIA EM SAÚDE \\ DIVISÃO DE VIGILÂNCIA EPIDEMIOLÓGICA}

PROGRAMA ESTADUAL DE CONTROLE DA TUBERCULOSE

OFICIO N009/2013 - CEVS/DVE/PECT/RS

Porto Alegre, 21 de fevereiro de 2013.

Assunto: Autorização para realização de pesquisa

De: Coordenação Estadual do PCT Rio Grande do Sul

Para: Escola de Enfermagem de Ribeirão Preto (EERP/USP)

Prezada Pesquisadora,

Rarianne Carvalho Peruhype

Prezado Pesquisador e Orientador,

Pedro Fredemir Palha

Eu, Carla Adriane Jarczewski, responsável pela Coordenação Estadual do Programa Estadual de Controle da Tuberculose do Estado do Rio Grande do Sul-PECT/RS manifesto concordância e autorização para a coleta de dados do projeto de pesquisa "Avaliação do Planejamento e Execução da Transferência da política do Tratamento Diretamente Observado no município de Porto Alegre, RS" (Projeto aprovado no ano de 2012 pelo Comitê de Ética do Grupo Hospitalar Conceição e da Secretaria Municipal de Saúde de Porto Alegre, RS), a ser realizada sob a forma de entrevista com o Coordenador Estadual e suplentes do PECT/RS deste nível de organização dos serviços.

Atenciosamente,

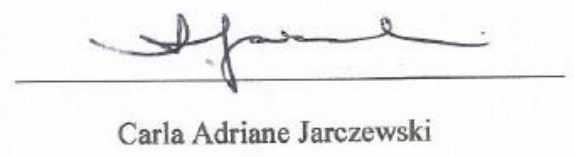

Coordenadora do PECT/RS

Rua Domingos Crescêncio, 132 - Bairro Santana - Porto Alegre-RS - CEP 90650-090 Fone: (51) 3901 -1163 - Fone/Fax: 3901-1084 - E-mail: via-tbrs@saude.rs.aov.br 